\title{
Comfort with uncertainty in medical professionals
}

Citation for published version (APA):

Ilgen, J. S. (2021). Comfort with uncertainty in medical professionals: an exploration of how clinicians experience and manage dynamic problems in practice. [Doctoral Thesis, Maastricht University]. Maastricht University. https://doi.org/10.26481/dis.20211215ji

Document status and date:

Published: 01/01/2021

DOI:

10.26481/dis.20211215ji

Document Version:

Publisher's PDF, also known as Version of record

\section{Please check the document version of this publication:}

- A submitted manuscript is the version of the article upon submission and before peer-review. There can be important differences between the submitted version and the official published version of record.

People interested in the research are advised to contact the author for the final version of the publication, or visit the DOI to the publisher's website.

- The final author version and the galley proof are versions of the publication after peer review.

- The final published version features the final layout of the paper including the volume, issue and page numbers.

Link to publication

\footnotetext{
General rights rights.

- You may freely distribute the URL identifying the publication in the public portal. please follow below link for the End User Agreement:

www.umlib.nl/taverne-license

Take down policy

If you believe that this document breaches copyright please contact us at:

repository@maastrichtuniversity.nl

providing details and we will investigate your claim.
}

Copyright and moral rights for the publications made accessible in the public portal are retained by the authors and/or other copyright owners and it is a condition of accessing publications that users recognise and abide by the legal requirements associated with these

- Users may download and print one copy of any publication from the public portal for the purpose of private study or research.

- You may not further distribute the material or use it for any profit-making activity or commercial gain

If the publication is distributed under the terms of Article $25 \mathrm{fa}$ of the Dutch Copyright Act, indicated by the "Taverne" license above, 


\title{
Comfort with uncertainty in medical professionals
}

\author{
An exploration of how clinicians experience \\ and manage dynamic problems in practice
}


The research reported here was carried out at

\section{Maastricht University (4) Maastricht UMC+}

in the School of Health Professions Education

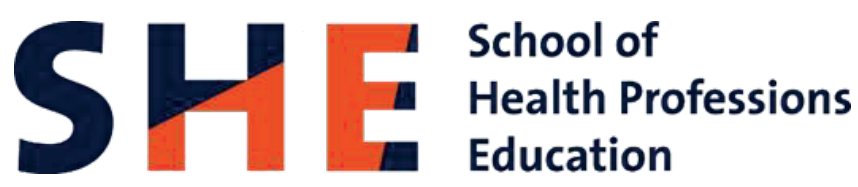

Cover design \& layout: Glideprint, Enschede

Cover photograph courtesy of Erin Moon, BSN, CEN

(C) copyright J.S. Ilgen, Maastricht 2021

Printing: Glideprint, Enschede

ISBN: 978-94-6419-358-9 


\section{Comfort with uncertainty in medical professionals An exploration of how clinicians experience and manage dynamic problems in practice}

ter verkrijging van de graad van doctor aan de Universiteit Maastricht, op gezag van de Rector Magnificus, Prof. dr. Rianne M. Letschert, volgens het besluit van het College van Decanen,

in het openbaar te verdedigen, op woensdag 15 december 2021 , om 16.00 uur door

Jonathan Seth Ilgen 


\section{Promotors}

Prof. dr. A.B.H. de Bruin

Prof. dr. G. Regehr, University of British Columbia

Prof. dr. P.W. Teunissen

\section{Assessment Committee}

Prof. dr. J.J.G. van Merriënboer (Chair)

Dr. S. Cristancho, Schulich School of Medicine and Dentistry, The University of Western

Ontario

Prof. dr. E.W. Driessen

Prof. dr. W.N.K.A. Van Mook

Dr. L. Zwaan, Erasmus University Rotterdam 


\section{Table of Contents}

$\begin{array}{lll}\text { Chapter } 1 & \text { Introduction } & 7\end{array}$

Chapter 2 Comfort with uncertainty: Reframing our conceptions of how clinicians 25 navigate complex clinical situations

Published as: Ilgen JS, Eva KW, de Bruin A, Cook DA, Regehr G. Comfort with uncertainty: Reframing our conceptions of how clinicians navigate complex clinical situations. Advances in Health Sciences Education. 2019 October; 24(4):797-809.

Chapter 3 "I was worried about the patient, but I wasn't feeling worried": How physicians judge their comfort in settings of uncertainty Published as: Ilgen JS, Bowen JL, de Bruin ABH, Regehr G, Teunissen PW. "I was worried about the patient, but I wasn't feeling worried": How physicians judge their comfort in settings of uncertainty. Academic Medicine. 2020 November; 95(11S): S67-S72.

Chapter 4 Warning bells: How clinicians leverage their discomfort to manage moments of uncertainty

Published as: Ilgen JS, Teunissen PW, de Bruin ABH, Bowen JL, Regehr G. Warning bells: How clinicians leverage their discomfort to manage moments of uncertainty. Medical Education. 2021 February; 55(2): 233-241.

Chapter 5 Skeptical self-regulation: Resident experiences of uncertainty about uncertainty

Published as: Ilgen JS, Regehr G, Teunissen PW, Sherbino J, de Bruin ABH. Skeptical self-regulation: Resident experiences of uncertainty about uncertainty. Medical Education. 2021 June; 55(6): 749-757.

Chapter 6 Supported independence: The role of supervision in helping trainees manage uncertainty

Published as: Ilgen JS, de Bruin ABH, Teunissen PW, Sherbino J, Regehr G. Supported independence: The role of supervision in helping trainees manage uncertainty. Academic Medicine. 2021 November; 96(11): S81-S86.

Chapter 7 Discussion

Summary 
Acknowledgments

SHE Dissertation Series 
CHAPTER 1

Introduction 


\section{CHAPTER 1}

To be willing and able to take safe and effective action despite uncertainty is a paradox of expert clinical practice. Yet a common concern expressed by medical educators is that clinician trainees are often "uncomfortable" with uncertainty or lack sufficient training and skill to "manage" or "tolerate" these complex moments in their daily work. ${ }^{1-3}$ These deficiencies have been hypothesized to result in a range of downstream consequences, from an overreliance on diagnostic tests, ${ }^{4}$ to a tendency to assign solutions to problems that are insufficiently differentiated (e.g., premature closure). ${ }^{5}$ Thus there have been continued calls for programs to more purposefully reinforce these skills in undergraduate and post-graduate training programs. $^{6-8}$

But what does it mean when we say that we want clinicians to be comfortable with uncertainty? To be comfortable implies a willingness to continue to work with a problem rather than seek an inappropriately early resolution. ${ }^{4,9}$ Yet it could also suggest an inappropriate absence of caution or vigilance that could lead to patient harm, such as when educators lament that trainees seem over-confident, taking actions without attending to emergent risks or missing signals that harm has occurred. ${ }^{10}$ It seems that what educators are looking for is for trainees to be appropriately comfortable with uncertainty, though defining this state and effectively targeting instructional approaches to help learners achieve this balance has proved elusive. So how might we help clinicians to find this sweet spot of the "right" amount of comfort with uncertainty and to identify the signals they can use to get a sense of whether they are working safely and effectively?

In this thesis, I explore how comfort manifests in clinicians' minds as they work through experiences of uncertainty in practice. Experienced clinicians speak of this state as if it is knowable and germane to their work, ${ }^{1}$ yet how they work safely and effectively when they are uncertain has remained poorly defined. Thus, I examine the signals that clinicians attend to during these challenging moments of uncertainty in practice, as well as how they use appraisals of comfort to continue managing patient problems despite an ongoing sense of uncertainty. I further explore how novices' experiences with uncertainty are both resonant with, and 


\section{CHAPTER 1}

importantly distinct from, the experiences of practicing clinicians. In doing so, I aim to highlight how their appraisals of comfort are importantly different and explore ways that trainees and their supervisors might form more effective partnerships to support the growth of these vital skills.

In this chapter, I set the larger context for the program of research. I first describe my efforts to reframe how uncertainty has been conceptualized in the health professions literature, emphasizing how this program of research shifts the paradigm towards experiences embedded in clinicians' authentic practice settings. Next, I introduce the notion of ill-defined problems, using this as the conceptual scaffolding for understanding the idiosyncratic and negotiated ways that clinicians work through experiences of uncertainty in practice. I then propose the idea of comfort as a means of understanding the state that clinicians dwell in when managing ill-defined problems in practice, drawing contrast to past notions such as 'tolerance' that have treated clinicians' approaches as context-independent and experience-independent traits. I conclude the chapter by highlighting the central questions of this program of research, providing reflexivity around my approach to these questions and a summary of the chapters thereafter.

\section{Reframing uncertainty in clinical reasoning}

Medical practice occupies the intersection between the basic sciences and humanities, and past efforts to characterize uncertainty have thus drawn from vastly different conceptual and research traditions. ${ }^{11}$ Some of this work has attempted to categorize different sources of uncertainty as a means for developing unifying taxonomies that could reduce uncertainty through more effective information gathering. ${ }^{12-14}$ Others have conceptualized uncertainty as a spectrum of "completeness" or "incompleteness" of one's knowledge, ${ }^{11}$ and have used frequencies (e.g., the proportion of patients with an aortic dissection who present with back pain), or probabilities (e.g., a post-test probability in Bayesian approaches) to represent how much of a situation might be known. And yet others have highlighted the risks of biases in settings of uncertainty, drawing from psychology literature demonstrating that humans 


\section{CHAPTER 1}

frequently tackle problems using non-probabilistic rules of thumb (heuristics). ${ }^{5,15-17}$ The lessons from most of these constructions align with the notion that uncertainty is a "metacognitive awareness of ignorance"13(pg.1) and efforts to manage these experiences are principally focused on ways to reduce uncertainty through more effective data gathering and analysis. ${ }^{13}$

The vast majority of clinical reasoning literature in health professions education reinforces these reductionistic approaches to uncertainty. Case-based studies typically present clinical information as a series of facts about a patient's history, exam, and diagnostic tests, and performance is then measured by clinicians' abilities to identify solutions to problems in the form of a correct diagnosis or management decision. This approach has its advantages: by defining problems in a reasonably clear way and measuring outcomes in a dichotomous (right/wrong) fashion, one can manipulate various influences on participants' cognitive processes-such as the speed at which they should work through problems, or the influences of deliberate processes of reflection-and see how clinicians' diagnostic performance changes. This type of work has advanced our understanding of how physicians use their existing knowledge for problem-solving, ${ }^{18}$ and how knowledge structures might be changed through reflection. ${ }^{19}$ Assessment methods such as script concordance testing ${ }^{20}$ and key features problems ${ }^{21}$ layer additional nuance to these case-based paradigms, attempting to approximate how experts consider sequential pieces of data as they move through a clinical case, or reinforce the ways in which clinicians prioritize or privilege some pieces of data over others. These methods highlight important ways that clinicians make sense of evolving situations and wade through the variety of datapoints that are impacting a clinical situation.

It is important to note, however, that these conceptual, probabilistic, assessment, and research paradigms treat uncertainty as analogous to "something that is unknown." ${ }^{11}$ This implies that diagnoses or management decisions, could be known-or known with a greater degree of certainty-if clinicians used a variety of theoretical, ${ }^{12,14}$ statistical, ${ }^{22}$ or cognitive ${ }^{16-18,23}$ approaches to reduce uncertainty. They further imply that clinical reasoning is a relatively solitary exercise, divorced from the human, technological, and material resources that clinicians 


\section{CHAPTER 1}

draw upon when working through complex cases in authentic medical settings. ${ }^{24}$ And finally, these approaches-particularly the assessment methods highlighted above-build from the assumption that expert clinical reasoning is normative, a set of skills that reliably converge in solutions that are agreed-upon by expert clinicians in practice (e.g., that two expert clinicians would agree about the "right" diagnosis for a given clinical scenario or initiate the same "correct" treatment decision). These abstractions of uncertainty centering around efforts to reduce what is unknown towards reliable solutions may thus be importantly distinct from what it means to be uncertain in practice.

Workplace-based experiences of uncertainty are complex and idiosyncratic. One could liken clinicians' skills at managing experiences of uncertainty to those of an expert jazz musician, ${ }^{25}$ engaging with a situation intentionally to understand what is going on around them (e.g., playing in the right key), embarking on approaches that align with the implicit and explicit structures of a system (e.g., playing the right chords, finding the right tempo), and planning ahead-or stepping in - to ensure patient safety (e.g., improvising at the right moments of a song, coordinating their actions with other musicians). The non-normative ways that clinicians learn to feel their way through these kinds of experiences highlight that being uncertain and managing uncertainty in the moment encompasses more than just activities to reduce what is not known. Instead, these lived experiences highlight the active, negotiated, and variable ways that clinicians make sense of complex situations in practice, and the ways that they work strategically to leverage the resources of their unique work settings. Elaborating these types of experiences is the focus of this program of research.

\section{Shifting the Focus Towards III-defined Problems}

Renee Fox's work "Training for Uncertainty" laid the foundation for understanding how clinicians' experiences with uncertainty might be importantly different than the abstractions described above. In interviewing medical students at Cornell Medical College in the 1950s, she found that their uncertainty could be attributed to three sources: 1) the "incomplete or imperfect mastery of available knowledge; 2 ) "limitations in current medical knowledge;" and 


\section{CHAPTER 1}

3) "difficulty in distinguishing between personal ignorance or ineptitude and the limitations of present medical knowledge."26(pg. 208) While the first two themes feel similar to normative, knowledge-based frameworks of uncertainty described above-e.g., both imply that limitations in their own or the field's knowledge could at some point be reduced-the third theme underscored individuals' hesitancy or skepticism distinguishing their own limitations from the limitations inherent in a situation. Subsequent work elaborated similar idiosyncrasies around how students understood uncertainties around diagnosis, treatment plans, patient responses to treatment, and expectations of instructors. ${ }^{27}$ This early work also elaborated how students noticed that their instructors seemed to approach uncertainty in variable ways.

Practice variation has typically been conceptualized as something that should be minimized through interventions such as improved education, practice guidelines, and interventions that guide consistent treatment within healthcare systems. ${ }^{28}$ But what if we instead viewed these idiosyncrasies of diagnosis, treatment, and management as a signal of how expertise with managing uncertainty manifests in clinical practice? If we conceptualized clinical problems as inherently different than the types of scenarios tackled in literatures such as economics, psychology, or mathematics, we could acknowledge that not all clinical problems can be worked towards discrete and agreed-upon solutions. Instead, variance reflects the idiosyncratic ways that expert clinicians understand complex clinical situations and work to align their own abilities and the resources around them to address to the needs of the situation.

The notion of "ill-defined problems" is a particularly useful way to conceptualize these individualized, idiosyncratic, and negotiated clinical experiences. Kitchener advanced the idea that ill-defined problems are characterized by "conflicting assumptions, evidence, and opinion which may lead to different solutions," ${ }^{29(p g . ~ 223) ~ h i g h l i g h t i n g ~ t h e ~ w a y s ~ t h a t ~ e x p e r t i s e ~ m i g h t ~}$ manifest when clinicians were making sense of imperfect or negotiated stimuli in their environment. This distinction between well-defined problems-such as those typically represented in the case-based studies above-and ill-defined problems offers an important gap 


\section{CHAPTER 1}

in the uncertainty literature that could be probed by learning more about the real-time experiences that clinicians have in practice.

Additionally, focusing on problems that are ill-defined also acknowledges the influence of ambiguity, a term that has frequently been used synonymously with uncertainty, ${ }^{8,30-32}$ but typically refers to perceptual characteristics that leads to differences in interpretation between individuals, or within the same individual at different points in time. ${ }^{33-36}$ In these ways, the inherent ambiguity of different cues may contribute to an individual's uncertainty when tackling ill-defined problems.

\section{In-the-moment experiences of comfort}

How can we conceptualize what clinicians experience when managing ill-defined problems in practice? And how do they harness these processes to take action despite an ongoing sense of uncertainty? The health professions education literature would seem to imply that experienced clinicians need to find a sweet spot between over- and under-confidence to successfully manage uncertainty. ${ }^{1}$ And greater granularity of what clinicians notice and act upon during these experiences could potentially help clarify the behaviors educators feel that more novice clinicians should be working towards when they lament that students should be more comfortable with uncertainty.

Much of the health professions literature conceptualizes clinicians' experiences with, and responses to, uncertainty as "tolerance."1,2,31,32,37 In a recent conceptual review of clinicians' "tolerance of uncertainty," ${ }^{\dagger}$ Hillen and colleagues highlighted the spectrum of cognitive, behavioral, and emotional aspects of tolerance that have been implicitly or explicitly represented in past measurement instruments. ${ }^{2}$ For example, some work has treated tolerance as a cognitive appraisal, encompassing individuals' perceptions of a situation ${ }^{38,39}$ or their

\footnotetext{
' Authors have used the phrases 'tolerance of uncertainty' and 'tolerance of ambiguity' interchangeably, and I have focused on the former here. The psychology literature typically uses the term ambiguity to reflect perceptual variations in stimuli that could lead to differences in interpretation, either between individuals or in the same individual at different points in time. I was interested in broader experiences of uncertainty and thus use this term throughout, recognizing that ambiguity may be a contributor to individuals' experiences.
} 


\section{CHAPTER 1}

general views about whether uncertainty was desirable or threatening. ${ }^{40,41}$ Tolerance has also been represented as a range of cognitive responses, such as acknowledgment, aversion, confusion, or denial. ${ }^{42,43}$ Other work has explored tolerance of uncertainty in the form of emotions such as anger or enjoyment, or behaviors such as avoidance or paralysis that were generated from uncertainty. ${ }^{44}$ Across these various domains, to be tolerant was generally understood to represent a form of "preventing, avoiding, or mitigating uncertainty's adverse effects, ${ }^{\prime 2(p g .66)}$ though Hillen and colleagues generally concluded that the variance in how this term has been used and conceptualized has limited reliable interpretation.

It should be noted that most of this literature on "tolerance of uncertainty" is founded on questionnaires that ask participants to gauge how they would react to a variety of hypothetical scenarios. For example, the "Revised Physicians Reactions to Uncertainty Scale" asks physicians to consider questions such as "I usually feel anxious when I am not sure of a diagnosis," and "I am quite comfortable with the uncertainty in patient care," and to rate their reactions on a 6point Likert scale. ${ }^{45(\mathrm{pg} .181)}$ Drawing conclusions from questions such as these treats tolerance as a trait, a stable predisposition for how individuals react and respond to uncertainty. And some have gone as far as to suggest that medical schools should even select for this trait as part of their admission processes. ${ }^{30}$

Yet treating tolerance as a stable trait would seem to be in contradiction to the 'state' that clinicians describe when they say that they are comfortable managing a particular problem. Measuring tolerance using abstracted statements such as the examples in the instruments above is akin to capturing individuals' 'self-concept beliefs,' which are "context free, generalized judgments of self-worth that involve cognitive self-appraisals independent of a specific task or goal." ${ }^{46(p g . ~ 548)}$ Treating tolerance as a trait neglects the dynamic and negotiated ways that uncertainty is experienced in authentic clinical settings, where context and case attributes interact with clinicians' own past experiences to iteratively shape how they appraise and react in these moments. ${ }^{47,48}$ These types of situation-specific reactions are more aligned with the notion of 'self-efficacy,' which reflects the interaction between individuals' self- 


\section{CHAPTER 1}

concept beliefs and the specific demands of knowledge and skill that are needed to address a particular situation. ${ }^{46}$ For these reasons, it felt important to draw a distinction between past constructions of tolerance and this research program's explorations of comfort, which I have conceptualized as an idiosyncratic, iterative, and contextually embedded state that enables clinicians to effectively work through experiences of uncertainty.

\section{Research Questions and Approach}

The research presented in this thesis aims to elaborate how comfort manifests during experiences of uncertainty and how clinicians use appraisals of comfort to manage these challenging moments in practice. Specific research questions include:

1. What types of circumstances in practicing clinicians' daily work generate the sense that they have an incomplete or insufficient understanding of a situation, and how is this sense of uncertainty experienced in these moments?

2. How do practicing clinicians use judgments of comfort to appraise the extent to which their knowledge and skills are sufficiently aligned with a situation to deliver safe and effective care, and how do these appraisals shift their approaches to these situations?

3. How do novice clinicians' appraisals of comfort differ from more experienced practicing clinicians, and how do novices think about potential responses given their sense of the challenges and affordances in the situation?

4. How does supervision impact trainees' experiences with uncertainty, and how do they perceive and balance the competing tensions of clinical independence, supervisory support, and patient safety?

All the studies in this thesis were informed by a constructivist epistemology, which enabled me to probe the idiosyncratic and negotiated ways that individual clinicians make their way 


\section{CHAPTER 1}

through ill-defined problems in practice. I used a constructivist grounded theory (CGT) approach for each of these studies, with inductive analyses that were well suited to explore the complex cognitive and social processes that shaped these clinicians' experiences with uncertainty.

\section{Reflexivity}

My interest in these questions grew from my dueling roles as a practicing emergency physician, a clinical educator for medical students and resident trainees, and a researcher interested in the underpinnings of clinical reasoning. I have been fortunate to work with several collaborative teams over the past decade exploring how clinicians' cognitive processes impacted diagnostic performance, how these processes might be assessed, and the potential influences of cognitive biases. Yet as I engaged in this research, I grew increasingly concerned about the ecological validity of how the clinical problems used for such studies were represented in the health professions literature, and felt that the clinical experiences represented in this body of research-including work of my own-were distilled in ways that were importantly disconnected from my experiences as a clinician and an educator. The ways that I and my students iteratively worked our way through messy, in-the-moment experiences of uncertainty in clinical practice seemed underrepresented in the health professions literature and an important gap to fill.

I began this program of research with a general goal of exploring how experiences of comfort might manifest in in the minds of clinicians when they experienced uncertainty in their authentic clinical practice settings. ${ }^{49}$ This clearly cognitivist epistemological lens with which my research team and I approached these questions undoubtedly impacted the literatures I drew upon as I thought through how appraisals of comfort arise during experiences of uncertainty, how clinicians experience these appraisals in the moment, and how they acted upon these appraisals in service of working towards safe and effective care. 


\section{CHAPTER 1}

I began my first round of data collection with the assumption that clinicians could identify moments of uncertainty in their practice. I assumed-based upon my conceptual review, ${ }^{49}$ and past work by others in operative settings ${ }^{10,50-54}$ - that clinicians would be able to identify and describe cues from their patients, their environment, and themselves that were influencing these experiences. I also started with the end in mind: thinking deliberately about the ways that more effective role modeling and supervision could help learners reach the state of appropriate comfort with uncertainty in practice. I decided that to accomplish this, I first needed to explore the experiences of expert clinicians (in my case board-certified emergency physicians) on the assumption that these experts could elaborate what comfort looked like in their practice, describe factors that shaped their appraisals of comfort, and animate the actions they took based upon these appraisals. By doing so, I could get a clear sense of our goal for clinical learners. Only then could I turn my attention towards the experiences of novices during my second round of data collection, signposting the ways that their approaches differed from more experienced clinicians. In doing so, I could begin to identify the gaps between novices' current management of uncertainty and the expert version of uncertainty management that we should be guiding them toward.

All of the participants in these studies were emergency physicians, and many of them either faculty colleagues of mine or trainees that I supervise. This was an intentional choice in two respects. First, I expected that these physicians would regularly care for patients with complex, dynamic, and undifferentiated problems, thus offering many opportunities to collect rich descriptions of stories that were exemplary for ways that ill-defined problems are experienced in practice. Second, as an emergency physician myself, this was the clinical and training context with which I was most familiar. As a result, I was able to probe my participants' stories in ways that were more nuanced than what would have been possible had I chosen a different practice or educational context. Further, because the constructivist grounded theory orientation places emphasis on subjectivity over objectivity as the preferred path to making knowledge, ${ }^{55}$ this enrollment choice enabled me to derive deeper meaning about these phenomena of interest 


\section{CHAPTER 1}

through my interactions with participants whose work experiences were resonant with my own.

\section{Thesis Outline}

Chapter 2 provides a critical review of the literature to explore what it means to be comfortable when ill-defined problems generate uncertainty in the minds of clinicians. This chapter draws from a variety of theories and frameworks to better understand what is meant by 'comfort with uncertainty.' It provides several examples of how comfort might manifest in practice and offers several hypotheses for how clinicians might generate and maintain comfort in the face of uncertainty.

Chapter $\mathbf{3}$ explores practicing emergency physicians' experiences of uncertainty and comfort in their clinical work. This qualitative study aimed to elaborate the types of circumstances that give these clinicians the sense that they have an incomplete or insufficient understanding of a situation, and how this sense of uncertainty was experienced. It further sought to describe the processes that these clinicians used to maintain comfort despite these feelings of uncertainty.

Chapter 4 continues the line of inquiry into the experiences of practicing emergency physicians by exploring how they notice and respond to discomfort arising from uncertainty. This work elaborated the ways that discomfort was manifest cognitively, emotionally, and behaviorally, and the ways that clinicians leveraged their discomfort to act in ways that were intended to maintain safety during experiences of uncertainty.

Chapter 5 shifts the focus of inquiry towards novice emergency medicine trainees' experiences with uncertainty. This study probed how junior residents noticed cues from within themselves, their patients, and their environment to better understand how their experiences with uncertainty were both similar and importantly distinct from those of more experienced clinicians. 


\section{CHAPTER 1}

Chapter 6 further explores the experiences of novice trainees in supervised practice, elaborating the ways in which they strategically engaged with their supervisors to maintain comfort when experiencing uncertainty. By highlighting the ways that trainees were agentic in both protecting their own independence (for the purposes of learning) and garnering support from their supervisors (for the purposes of maintaining safety), this study suggests several ways that supervisors can better support trainees' growth of effective self-regulation during experiences of uncertainty.

Chapter 7 summarizes the findings from this program of research and elaborates how fluid appraisals of comfort manifest during experiences of uncertainty. These findings are then contextualized within the broader literature, in particular how appraisal theories of emotion help to explain why different individuals in the same environment are likely to appraise and act upon situations differently. The synthesis then considers the implications of the findings that clinicians titrate their appraisals of comfort through interactions with others, drawing connections to the self-regulation literature and the ways that Vygotsky's zone of proximal development might manifest differently in the context of ill-defined problems. The chapter concludes with implications for teaching and learning and suggests several directions for future research. 


\section{CHAPTER 1}

\section{References}

1. Simpkin AL, Schwartzstein RM. Tolerating Uncertainty - The Next Medical Revolution? N Engl J Med. 2016;375:1713-1715.

2. Hillen MA, Gutheil CM, Strout TD, Smets EMA, Han PKJ. Tolerance of uncertainty: Conceptual analysis, integrative model, and implications for healthcare. Soc Sci Med. 2017;180:62-75.

3. Gheihman G, Johnson M, Simpkin AL. Twelve tips for thriving in the face of clinical uncertainty. Med Teach. 2020;42:493-499.

4. Kassirer JP. Our stubborn quest for diagnostic certainty. A cause of excessive testing. N Engl J Med. 1989;320:1489-1491.

5. Croskerry $P$. The importance of cognitive errors in diagnosis and strategies to minimize them. Acad Med. 2003;78:775-780.

6. Fargason CAJ, Evans HH, Ashworth CS, Capper SA. The importance of preparing medical students to manage different types of uncertainty. Acad Med. 1997;72:688-692.

7. Luther VP, Crandall SJ. Commentary: Ambiguity and Uncertainty: Neglected Elements of Medical Education Curricula? Acad Med. 2011;86:799-800.

8. White G, Williams S. The certainty of uncertainty: can we teach a constructive response? Med Educ. 2017;51:1200-1202.

9. Ilgen JS, Eva KW, Regehr G. What's in a Label? Is Diagnosis the Start or the End of Clinical Reasoning? J Gen Intern Med. 2016;31:435-437.

10. Moulton CA, Regehr G, Lingard L, Merritt C, Macrae H. Operating from the other side of the table: control dynamics and the surgeon educator. J Am Coll Surg. 2010;210:79-86.

11. Djulbegovic B, Hozo I, Greenland S. Uncertainty in Clinical Medicine. In: Gifford F, Gabbay D, Thagard P, Woods J. Handbook of Philosophy of Science. Vol 16. Amsterdam, NL: North Holland Publishing Co.; 2011, 299-356.

12. Han PKJ, Klein WMP, Arora NK. Varieties of Uncertainty in Health Care: A Conceptual Taxonomy. Med Decis Making. 2011;31:828-838.

13. Han PKJ, Strout TD, Gutheil C, et al. How Physicians Manage Medical Uncertainty: A Qualitative Study and Conceptual Taxonomy. Med Decis Making. 2021;41:275-291. 


\section{CHAPTER 1}

14. Pomare C, Churruca K, Ellis LA, Long JC, Braithwaite J. A revised model of uncertainty in complex healthcare settings: A scoping review. J Eval Clin Pract. 2019;25:176-182.

15. Croskerry P. More on the Causes of Errors in Clinical Reasoning. Acad Med. 2017;92:1064.

16. Croskerry P. From mindless to mindful practice--cognitive bias and clinical decision making. N Engl J Med. 2013;368:2445-2448.

17. Croskerry P. Cognitive forcing strategies in clinical decisionmaking. Ann Emerg Med. 2003;41:110-120.

18. Norman GR, Monteiro SD, Sherbino J, Ilgen JS, Schmidt HG, Mamede S. The Causes of Errors in Clinical Reasoning: Cognitive Biases, Knowledge Deficits, and Dual Process Thinking. Acad Med. 2017;92:23-30.

19. Mamede S, Schmidt HG, Rikers RM, Penaforte JC, Coelho-Filho JM. Breaking down automaticity: case ambiguity and the shift to reflective approaches in clinical reasoning. Med Educ. 2007;41:1185-1192.

20. Lubarsky S, Dory V, Duggan P, Gagnon R, Charlin B. Script concordance testing: from theory to practice: AMEE guide no. 75. Med Teach. 2013;35:184-193.

21. Farmer EA, Page G. A practical guide to assessing clinical decision-making skills using the key features approach. Med Educ. 2005;39:1188-1194.

22. Edwards W, Miles RF, Von Winterfeldt D. Advances in decision analysis. Cambridge, New York. 2007.

23. Eva KW. What every teacher needs to know about clinical reasoning. Med Educ. 2005;39:98-106.

24. Durning $S$, Artino Jr AR, Pangaro L, van der Vleuten CP, Schuwirth L. Context and clinical reasoning: understanding the perspective of the expert's voice. Med Educ. 2011;45:927938.

25. Miller WL, McDaniel RR, Jr., Crabtree BF, Stange KC. Practice jazz: understanding variation in family practices using complexity science. J Fam Pract. 2001;50:872-878.

26. Fox R. Training for uncertainty. In: Merton RK, Reader G, Kendall PL (Eds.). The student physician. Cambridge: Harvard University Press; 1957, 207-241. 


\section{CHAPTER 1}

27. Light D. Uncertainty and Control in Professional Training. J Health Soc Behav. 1979;20:310-322.

28. Wennberg JE. Time to tackle unwarranted variations in practice. BMJ. 2011;342:d1513.

29. Kitchener KS. Cognition, metacognition, and epistemic cognition: a three-level model of cognitive processing. Hum Dev. 1983;4:222-232.

30. Geller G. Tolerance for ambiguity: an ethics-based criterion for medical student selection. Acad Med. 2013;88:581-584.

31. Geller G, Faden RR, Levine DM. Tolerance for ambiguity among medical students: implications for their selection, training and practice. Soc Sci Med. 1990;31:619-624.

32. Geller G, Tambor ES, Chase GA, Holtzman NA. Measuring physicians' tolerance for ambiguity and its relationship to their reported practices regarding genetic testing. Med Care. 1993;31:989-1001.

33. Dogra N, Giordano J, France N. Cultural diversity teaching and issues of uncertainty: the findings of a qualitative study. BMC Med Educ. 2007;7:1-13.

34. Levine DN. The flight from ambiguity: Essays in social and cultural theory. Chicago: University of Chicago Press; 1985.

35. Rensink RA, O'Regan JK, Clark JJ. To See or not to see: The need for attention to perceive changes in scenes. Psychol Sci. 1997;8:368-373.

36. Simons DJ, Chabris CF. Gorillas in our midst: sustained inattentional blindness for dynamic events. Perception. 1999;28:1059-1074.

37. Hancock J, Mattick K. Tolerance of ambiguity and psychological well-being in medical training: A systematic review. Med Educ. 2020;54:125-137.

38. Furnham A, Ribchester T. Tolerance of ambiguity: A review of the concept, its measurement and applications. Curr Psychol. 1995;14:179-199.

39. Ladouceur R, Blais F, Freeston MH, Dugas MJ. Problem solving and problem orientation in generalized anxiety disorder. J Anxiety Disord. 1998;12:139-152.

40. Budner S. Intolerance of ambiguity as a personality variable. J Pers. 1962;30:29-50.

41. Buhr K, Dugas MJ. The intolerance of uncertainty scale: Psychometric properties of the English version. Behav Res Ther. 2002;40:931-945. 


\section{CHAPTER 1}

42. Gerrity MS, Devellis RF, Earp JA. Physicians Reactions to Uncertainty in Patient Care. A new measure and new insights. Med Care. 1990;28:724-736.

43. Norton RW. Measurement of ambiguity tolerance. J Pers Assess. 1975;39:607-619.

44. Carleton RN, Norton MPJ, Asmundson GJ. Fearing the unknown: A short version of the Intolerance of Uncertainty Scale. J Anxiety Disord. 2007;21:105-117.

45. Gerrity MS, White KP, DeVellis RF, Dittus RS. Physicians' reactions to uncertainty: Refining the constructs and scales. Motiv Emot. 1995;19:175-191.

46. Eva KW, Regehr G. Self-assessment in the health professions: a reformulation and research agenda. Acad Med. 2005;80:S46-54.

47. Norman G, Bordage G, Page G, Keane D. How specific is case specificity? Med Educ. 2006;40:618-623.

48. Eva KW. On the generality of specificity. Med Educ. 2003;37:587-588.

49. Ilgen JS, Eva KW, de Bruin A, Cook DA, Regehr G. Comfort with uncertainty: reframing our conceptions of how clinicians navigate complex clinical situations. Adv Health Sci Educ Theory Pract. 2019;24:797-809.

50. Cristancho SM, Apramian T, Vanstone M, Lingard L, Ott M, Novick RJ. Understanding clinical uncertainty: what is going on when experienced surgeons are not sure what to do? Acad Med. 2013;88:1516-1521.

51. Moulton CA, Regehr G, Lingard L, Merritt C, Macrae H. 'Slowing down when you should': initiators and influences of the transition from the routine to the effortful. J Gastrointest Surg. 2010;14:1019-1026.

52. Moulton CA, Regehr G, Lingard L, Merritt C, MacRae H. Slowing down to stay out of trouble in the operating room: remaining attentive in automaticity. Acad Med. 2010;85:1571-1577.

53. Cristancho SM, Apramian $\mathrm{T}$, Vanstone $\mathrm{M}$, et al. Thinking like an expert: surgical decision making as a cyclical process of being aware. Am J Surg. 2016;211:64-69.

54. Cristancho SM, Vanstone $M$, Lingard L, LeBel ME, Ott M. When surgeons face intraoperative challenges: a naturalistic model of surgical decision making. Am J Surg. 2013;205:156-162. 
55. Albert M, Mylopoulos M, Laberge S. Examining grounded theory through the lens of rationalist epistemology. Adv Health Sci Educ Theory Pract. 2018;24:827-837. 


\section{CHAPTER 2}

\section{Comfort with uncertainty: Reframing our conceptions of how clinicians navigate complex clinical situations}

Published as:

Ilgen JS, Eva KW, de Bruin A, Cook DA, Regehr G. Comfort with uncertainty: Reframing our conceptions of how clinicians navigate complex clinical situations. Advances in Health Sciences Education. 2019 October; 24(4):797-809.

(C) 2019 Springer Nature Switzerland AG 


\title{
CHAPTER 2
}

\begin{abstract}
Learning to take safe and effective action in complex settings rife with uncertainty is essential for patient safety and quality care. Doing so is not easy for trainees, as they often consider certainty to be a necessary precursor for action and subsequently struggle in these settings. Understanding how skillful clinicians work comfortably when uncertain, therefore, offers an important opportunity to facilitate trainees' clinical reasoning development. This critical review aims to define and elaborate the concept of 'comfort with uncertainty' in clinical settings by juxtaposing a variety of frameworks and theories in ways that generate more deliberate ways of thinking about, and researching, this phenomenon. We used Google Scholar to identify theoretical concepts and findings relevant to the topics of 'uncertainty,' 'ambiguity,, 'comfort,' and 'confidence,' and then used preliminary findings to pursue parallel searches within the social cognition, cognition, sociology, sociocultural, philosophy of medicine, and medical education literatures. We treat uncertainty as representing the lived experience of individuals, reflecting the lack of confidence one feels that he/she has an incomplete mental representation of a particular problem. Comfort, in contrast, references confidence in one's capabilities to act (or not act) in a safe and effective manner given the situation. Clinicians' 'comfort with uncertainty' is informed by a variety of perceptual, emotional, and situational cues, and is enabled through a combination of self-monitoring and forward planning. Potential implications of using 'comfort with uncertainty' as a framework for educational and research programs are explored.
\end{abstract}




\section{CHAPTER 2}

Authentic clinical reasoning requires practitioners to collect and interpret imperfect data in real time. Learning how to take safe and effective action in these complex and ambiguous settings is essential for patient safety and high-quality care. ${ }^{1-4}$ Thus, health professions educators often express concerns that students struggle with ambiguity and uncertainty, ${ }^{2,4,5}$ and instead strive to impose certainty on inherently ambiguous situations. ${ }^{1,6,7}$ As a result, there are ongoing calls to help learners develop "positive" responses to uncertainty and ambiguity. ${ }^{5}$

To act with confidence while simultaneously remaining uncertain is a paradox that epitomizes expert practice. Thus, understanding how skillful clinicians are able to enact this paradox could offer an important first step toward providing educators with the guidance they need to support trainees' development of clinical reasoning. In particular, there is little in the medical education literature regarding how physicians manage uncertainty arising from complex, illdefined problems where "there are conflicting assumptions, evidence, and opinion which may lead to different solutions." ${ }^{1(\mathrm{pg} .}{ }^{223)}$ Cristancho has argued that these ill-defined problems are characterized by the need for clinicians to continuously reconstruct and redefine their understanding of the problem, even as they are trying to solve it. ${ }^{9}$ Yet the processes and mechanisms that enable clinicians to maintain a sense of comfort (or not) when continuing along in these moments of uncertainty in ill-defined problems remains largely unexplored. Thus the question is: how do clinicians become sufficiently comfortable dwelling in these "swampy lowlands of indeterminate practice,"10(pg. 42) remaining confident that their continued efforts will result in greater diagnostic clarity or resolve their patients' problems altogether?

The purpose of this critical review, therefore, is to explore what it means to be 'comfortable' when working in ill-defined clinical situations while feeling 'uncertain.' We will elaborate the concept of 'comfort with uncertainty' using a variety of frameworks and theories, examining what is meant by 'uncertainty' and 'ambiguity,' and what it means to feel 'comfortable' in these situations. We will then illustrate how the concept of 'comfort with uncertainty' manifests in clinical medicine, provide an analysis of potential mechanisms that might facilitate a feeling of 


\section{CHAPTER 2}

comfort in the face of uncertainty, and conclude with implications of this analysis for medical education practice and future research.

\section{Method}

To explore this problem space, we conducted a critical synthesis of relevant literature and theoretical frameworks. Although comprehensiveness is not the goal in critical synthesis, ${ }^{11}$ we nonetheless sought empiric and theoretical work beyond our a priori knowledge by methodologically searching published literature. We first used Google Scholar to identify theoretical concepts and findings relevant to the topics of 'uncertainty, 'ambiguity, ' comfort,' and 'confidence.' We then used the search terms identified through this process to pursue parallel searches within the fields of social cognition, cognition, sociology, sociocultural, philosophy of medicine, and medical education, utilizing the following databases: Academic Search Premier, Biomedical Reference Collection: Comprehensive, CINAHL, Dissertation abstracts, ERIC, MEDLINE, PsycINFO, SocINDEX and Web of Science.

\section{Results}

\section{Defining comfort with uncertainty}

In exploring the phrase 'comfort with uncertainty', we found a lack of specificity in how the terms 'uncertainty' and 'comfort' are used in published literature. Thus, in this section we will discuss and clarify each of these terms individually, and then propose an operational definition of what clinicians mean when they say 'comfort with uncertainty.'

The term 'uncertainty,' as applied to ill-defined problems in medicine, is frequently used in ways that do not sufficiently distinguish between the properties of the situation and the 'lived experience $^{\prime \ddagger}$ of the individual. ${ }^{1,12-24}$ In fact, the term 'uncertainty' is often used interchangeably

\footnotetext{
‡ The word "experience" is used in the English language to represent the process of personally observing, encountering, or undergoing something as well as the knowledge or practical wisdom gained from what one has observed, encountered, or undergone. For the purposes of clarifying these two meanings, we will use 'lived experience' to describe experiences in the moment, and 'accrued experience' to represent the historical accumulation of such moments.
} 


\section{CHAPTER 2}

with the term 'ambiguity. ${ }^{5,7}$ To draw this important distinction between the situation and the lived experience more explicitly, we propose using 'ambiguity' to represent the properties of the situation and 'uncertainty' to represent the lived experience of an individual. Thus, we will consider some thing, be it an image, a sound, or a constellation of clinical findings, to be inherently ambiguous if it can be interpreted in two or more distinct ways by different individuals, or by the same individual at different moments in time. ${ }^{25-28}$ For example, a heart sound that might or might not indicate a murmur is 'ambiguous.' In contrast, we will preserve the term 'certainty' to reference the lived experience of the individual, describing the extent to which one feels confident in one's representation of the underlying cause of a particular problem or situation (e.g., the pathology causing a patient's illness). Certainty is expressed whenever a clinician says things like "this patient's symptoms are from granulomatosis with polyangiitis" or "this patient's otitis media will get better without antibiotics." In contrast, 'uncertainty' represents a state of tentativeness with regard to one's conception of the underlying causes of a patient's symptoms. This can arise from recognizing that a situation is ambiguous, ${ }^{13,21}$ from perceived limitations in one's own knowledge, ${ }^{15}$ or from recognition that one has incomplete information. ${ }^{12}$

If 'certainty' represents one's confidence in interpreting a clinical situation, 'comfort' references the confidence one feels in being capable of acting (or deciding to wait and watch) safely and effectively in a given situation. ${ }^{29,30}$ Thus, for example, comfort is expressed when a clinician confidently chooses to write a prescription, enact a particular procedure, or withhold action while observing a patient. In each case, the individual is exhibiting a willingness to 'manage a problem,' at least through its most imminent stages. By contrast, 'discomfort' is likely to arise because one is concerned that the demands of the situation outstrip one's capacity to deal with it. ${ }^{31,32}$ This can occur, for example, because a clinician has not dealt with a particular problem before (or for a long period of time), or because a clinician feels that something needs to be done while simultaneously believing the appropriateness of a particular management plan is dependent on knowing the yet unknown root cause of the issue. ${ }^{12}$ 


\section{CHAPTER 2}

In short, for the purposes of this analysis, we will define 'certainty' as the confidence in one's interpretation of a clinical situation and we will define 'comfort' as the confidence in one's ability to act (or choose to continue monitoring the situation without direct action). Accordingly, 'comfort with uncertainty,' can be operationally defined as the phenomenological lived experience of having the confidence to act on a problem (or wait and observe) in the absence of full confidence in one's understanding of the underlying cause of the issue. Parenthetically, we note that this also would allow us to acknowledge the state of being 'certain but uncomfortable' in which one perceives a clear understanding of the problem and realizes that one is not capable of managing it.

\section{Circumstances that embody comfort with uncertainty}

Having developed a definition of 'comfort with uncertainty' in the context of ill-defined problems, we next sought to use the literature to explore various manifestations of this construct in clinical practice. We identified two broad categories that could be considered manifestations of 'comfort with uncertainty' that are framed around the source of uncertainty: uncertainty regarding the diagnosis and uncertainty regarding the treatment plan. Each is elaborated below, although we note that the current literature does not allow us to make claims regarding the prevalence, variety of manifestations, or degree of risk associated with either.

\section{Letting go of the need to know}

The first form of 'comfort with uncertainty' organizes around comfort with a management plan in the face of uncertainty regarding the diagnosis. In some cases, this involves accepting the ongoing possibility of a less common or rare diagnosis that could only be excluded through expensive or risky diagnostic tests. Although these less likely diagnoses are theoretically possible, seriously considering them would likely take clinicians down paths that are neither feasible nor in patients' best interests. ${ }^{33}$ Skillful clinicians thus comfortably adopt the position of conscious inaction toward these rare diagnoses. ${ }^{33,34}$ They hone their management plans towards a more probable and limited subset of diagnoses while remaining alert to changes (or 


\section{CHAPTER 2}

lack thereof) in patients' clinical status that would suggest the need to more seriously consider improbable diagnoses.

In other cases that involve 'comfort with uncertainty' regarding diagnosis, it is not necessary to tease apart confusable diseases that manifest with similar symptoms because one can comfortably use symptom-focused management strategies that focus on 'what will work' without the need for diagnostic precision. ${ }^{35,36}$ That is, clinicians can comfortably adopt a pragmatic treatment-oriented categorization of illness, grouping a subset of possible diagnoses in ways that allow them to confidently initiate empiric therapies that have a high probability of success while remaining uncertain about the actual diagnosis. In these situations, perfect certainty regarding diagnosis is not a goal because it is not necessary for action. Instead, clinicians monitor their patients' progress to ensure they are indeed achieving the anticipated outcomes, and pivot towards further evaluation or a change in management if the illness progression deviates from the anticipated path.

\section{Feeling your way through a problem}

A second form of 'comfort with uncertainty' takes place under circumstances of greater ambiguity, complexity, and acuity where definitive management strategies are less clear. In these situations where multiple conceptualizations of an illness remain possible, ${ }^{9}$ multiple management approaches also remain reasonable. Clinicians' 'comfort' in these settings reflects feeling able to take a reasonable next step in managing the situation at hand despite not being certain that it will lead to the desired outcome. Indeed, clinicians might consciously remain uncertain, recognizing that their initial steps in management will likely provide additional data that will enhance their understanding of a situation.

When clinicians act in this way they are engaging in an exercise of "pragmatic empiricism,"14(pg. ${ }^{954)}$ using symptom evolution and treatment responses as additional data to frame and reframe problems, and shifting management strategies based upon how a patient's illness evolves under their care. ${ }^{37,38}$ For example, an emergency physician may preliminarily classify a patient 


\section{CHAPTER 2}

as having "acute respiratory distress," lacking certainty whether these symptoms are secondary to a diagnosis of congestive heart failure, pneumonia, or a number of other pulmonary pathologies. Classifying the situation as an ill-defined problem rather than a specific diagnosis provides an initial roadmap for immediate actions (e.g., pulse oximetry, cardiac monitoring) and helps to plan for future potentially necessary actions (e.g., bringing intubation equipment to the bedside). ${ }^{39}$ It also provides a framework for tentative treatments, the response to which clinicians use to better understand a situation. For example, an effective dose of a diuretic may affirm a clinician's hypothesis that her patient's shortness of breath is from congestive heart failure. In contrast, a therapeutically ineffective dose of this medication is unlikely to cause long-lasting harm and may help her to consider alternative diagnoses.

Engaging with this form of uncertainty is thus akin to walking down a familiar dark path: it involves the recognition that even if a problem definition remains elusive, it is a problem within one's realm of expertise. ${ }^{40}$ Skillful clinicians therefore assume the risks of engaging with these ill-defined problems, feeling comfortable that even if a multitude of potential problems, risks, and management paths remain possible, their skillset will enable them to manage these complexities safely and effectively in the absence of certainty.

\section{Conditions and processes that facilitate comfort with uncertainty}

Having identified several circumstances that embody comfort with uncertainty in the context of ill-defined problems in clinical practice, we turn to the processes that might facilitate such comfort. To frame this discussion, Koriat's dual-basis view of metacognitive judgments proved particularly generative. This model, developed to explain individuals' judgments of their own learning, ${ }^{41}$ suggests that people use cues drawn from both their lived experience in the moment (e.g., their current subjective feelings that manifest when engaging in a task) and their theories about the situation (e.g., their beliefs about how memory works based on assumptions built from the accrual of previous experiences) to make a judgment about whether or not they 


\section{CHAPTER 2}

have learned a set of materials. For Koriat, an "experience-based cue"§ might be the ease with which the material is read, with individuals interpreting their reading fluency in the moment of reading as mastery of the material. ${ }^{41,42} \mathrm{~A}$ "theory-based cue" might be drawn from the belief that reading the material multiple times enables one to remember it, such that if one has read the material several times, one feels increased confidence that one must know it. ${ }^{42}$ Our review of the literature around 'comfort with uncertainty,' suggests that such experience-based and theory-based cues are likely to be similarly influential when making judgments about one's comfort when facing uncertainty. We elaborate on these connections below.

\section{Experience-based cues that influence feelings of comfort with uncertainty}

Experience-based cues come directly from an individual's internal lived experience when engaging in a clinical reasoning situation in the moment. For example, as alluded to above, the cognitive psychology literature suggests that perceived fluency (i.e., how easily one is able to read and understand a text) is used as a cue for the extent to which one has mastered new material that one is trying to learn. ${ }^{43,44}$ In a similar way, clinicians likely use the ease with which they are able to listen to and think about patients' problems as cues for the extent to which they have mastery of the situation, drawing on perceptions that 'this is going well' and 'this is what I expected to happen, ${ }^{9,45}$ even if they are as yet uncertain of the end game. A broad set of accrued experiences, the development of automaticity, and processes of encapsulation are likely important factors in determining this perception of fluency. ${ }^{46}$ With accrued experience, a range of plausible explanatory models, possible actions, and implications of these various possibilities are more likely to arise, in part explaining why seasoned clinicians are likely to feel more comfortable than novices in the face of uncertainty.

The identification of these experience-based cues is represented in the medical education literature under the construct of monitoring. Moulton and colleagues, for example, have described a process of remaining "attentive in automaticity," ${ }^{47}$ combining situational awareness

\footnotetext{
$\S$ For Koriat, the term "experience-based cue" describes what we have been labeling as 'lived experiences' in the moment.
} 


\section{CHAPTER 2}

with meta-cognition as a means to "remain aware of the whole situation, to monitor events as they occur, [and] to reflect on alternative possibilities should a decision need to be made." $48(\mathrm{pg}$ 108) Similarly, Eva and Regehr have described a moment-by-moment self-monitoring process regarding one's factual knowledge as a mechanism for "knowing when to look it up." ${ }^{49}$ This idea of monitoring and staying attentive in automaticity suggests that comfort does not imply a 'lack of vigilance' or a 'relaxed state.' Rather, comfort without vigilance is akin to automaticity without attention, and might be considered the management equivalent of premature diagnostic closure..$^{50}$

\section{Theory-based cues that influence feelings of comfort with uncertainty}

Theory-based cues are those that come from the deliberate application of metacognitive beliefs. ${ }^{41}$ If, for example, clinicians feel comfortable acting in a state of uncertainty because they "have seen it all before," or encourage a trainee to carry forward because "there is nothing you can get into here that I cannot get you out of," they are expressing a view that their accrued experience will enable them to derive an appropriate solution. Studies of experts in other fields suggest that they draw from accrued experiences to quickly surmise a situation ${ }^{51}$ and then attempt to make reasonable predictions for how a situation is likely to evolve. ${ }^{41,45,52,53}$ These predictions then contribute to experts feeling comfortable that they can manage whatever arises in a given situation. In short, the theory-based cue for 'comfort' is a belief that one has sufficient accrued experience with all of the reasonably probable scenarios, and the ability to control the situation in ways that will avoid instances where evolving situational needs will likely outstrip the resources available.

Clinicians engage in these forms of forward planning in moments of uncertainty by considering a range of management plans and potential outcomes that might result. ${ }^{54}$ In contrast to decision-making analyses, where 'getting the diagnosis right' is tantamount to high performance, ${ }^{55}$ forward planning in moments of uncertainty arising from an ill-defined problem instead employs knowledge from accrued experiences with similar problems to predict various potential events that are sufficiently probable. The ability to anticipate, which tends to arise 


\section{CHAPTER 2}

with expertise, ${ }^{53}$ allows one to preemptively put resources such as technology or personnel in place. ${ }^{56}$ These resources minimize the risk of reasonably probable events that would lead to situations that exceed a clinician's abilities given their particular treatment context ${ }^{32,39,40}$. Putting these resources in place, therefore, allows clinicians to move forward with comfort. Discomfort occurs, in contrast, when clinicians can imagine likely scenarios that they perceive to be outside of their knowledge or skills, or if the anticipated problems outstrip the available resources. ${ }^{32}$ This sentiment may ultimately prompt clinicians to consider whether they ask for help, ${ }^{56,57}$ look for ways to further disambiguate a problem, ${ }^{49}$ or triage the problem to colleagues with different skillsets or resources. ${ }^{40}$

\section{Social complexities around 'comfort with uncertainty'}

While we have prioritized consideration of cognitive factors that are likely to influence skillful practitioners' feelings of 'comfort with uncertainty,' it is likely that social and social-emotional cues will also play a role. Local and discipline-specific cultures around risk tolerance, reactions to adverse events, and vulnerability to peers are all likely to impact clinicians' comfort with managing problems independently, ${ }^{56-59}$ particularly when considering how patients or colleagues retrospectively judge each other's actions or inactions. ${ }^{56,60}$ Similarly, the design of the health system in which one works will determine the external resources that clinicians have available-such as when backup from another clinician is easily accessible ${ }^{61}$ or when tests are more readily available ${ }^{62}$-as well as the external pressures they are managing. ${ }^{63}$ These socialcultural influences on 'comfort' warrant attention in future work; however, the focus of this paper is on the cognitive aspects of this phenomenon, so we will leave it to others to elaborate these aspects of 'comfort.'

\section{Discussion}

This review has explored the premise that 'comfort with uncertainty' can be deconstructed in ways that provide new insights into how clinicians navigate the interconnected complexities of diagnosis and management in practice. Exploring how comfort is established and used within this framework illustrates the iterative and cyclical nature of clinical reasoning in complex 


\section{CHAPTER 2}

settings ${ }^{38}$ whereby comfort enables action and the ease with which one is able to act provides comfort. When working within settings where patients' problems are ill-defined or incompletely conceptualized (i.e., where the cause of the problem is uncertain), clinicians harness actionoriented categorizations of problems and "pragmatic empiricism"14(pg. 954) to get started with their management approaches, then couple these approaches with ongoing forward planning and intensive monitoring to clarify and re-conceptualize the situation at hand. Becoming comfortable in maintaining uncertainty in these settings is important because uncertainty serves as a catalyst for ongoing skepticism about working hypotheses, thereby setting an expectation that these tentative hypotheses will be continually revised. Remaining uncertain additionally triggers clinicians to put resources in place to minimize risk around problems that remain sufficiently possible.

\section{Implications for Educators}

How might this model of 'comfort with uncertainty' inform how educators support the development of clinical reasoning in trainees? We offer three preliminary educational implications that follow from this exploration of 'comfort with uncertainty.' First, to exist in this conceptual space of 'informed speculation' clinicians must adopt a deliberatively iterative and flexible construction of how patients' problems are defined, approached, and managed. To get students into a mindset where 'comfort with uncertainty' is possible thus requires educators to first disabuse their trainees of the notion that clinical knowledge exists in a binary format of 'knowing' and 'not knowing. ${ }^{64}$ We believe that widely-used formulations for teaching clinical reasoning that are centered around diagnosis may contribute to learners' challenges. ${ }^{35,36}$ These models implicitly suggest that 'not knowing' precludes taking action, while 'knowing' provides license for unwavering certitude when moving forward. Shifting our instructional models towards an emphasis on 'comfort with uncertainty' would instead teach students that skillful clinicians use problem-definition and problem-solving in parallel, ${ }^{9}$ treating possible diagnoses as merely provisional conceptual frameworks that facilitate action, and using responses to these actions as a means to further clarify their understanding of their patients' problems. 


\section{CHAPTER 2}

Second, we believe our treatment of the terms 'comfort' and 'discomfort' can help trainees better identify the limits of what is safe to do, ${ }^{56,59,65,66}$ and better understand that safety will facilitated by forward planning and monitoring. Educators can reinforce forward planning skills by prompting trainees to preemptively consider the resources they may need if any of a number of anticipated high-risk events were to take place (e.g. "what will we do if $X$ happens?"). ${ }^{67}$ Further, consistent with Koriat's work, ${ }^{41,42}$ educators can encourage trainees to monitor for cues that might signal that they are 'on track' or that they are veering into dangerous territory where conditions are beyond their abilities to control or manage. ${ }^{47}$

Lastly, we would encourage clinical preceptors to reflect upon the underpinnings of their own 'comfort' in uncertain situations. As Koriat argues, 'comfort' is enabled by the rich accrual of experiences and beliefs about how these experiences prepare clinicians to take action. ${ }^{41,42}$ So, just because this impulse is triggered in a preceptor does not mean that a trainee should feel the same way. Trainees' abilities to imagine the multitude of possible downstream scenarios are limited given their lack of prior exposure to similar problems (thus restricting forward planning) and novices' lack of automaticity and limited attentional reserves are likely to impair their abilities to self-monitor. ${ }^{47}$ Taken together, it is not at all surprising that supervisors frequently feel 'out of sync' with their trainees ${ }^{67}$ as learners' 'discomfort with uncertainty'manifested as behaviors such as hesitation ${ }^{68}$-is a developmentally appropriate response for their stage of training. Educational programs that encourage students to generically 'tolerate' uncertainty ${ }^{69}$ deemphasize the importance of self-monitoring, encourage a lack of vigilance, or prompt trainees to fall back into models where diagnostic certainty is necessary for action. ${ }^{64}$ These pitfalls risk premature closure around problems that are still ill-defined and risk overtesting in ways that are not patient centered. Instead, we would encourage supervisors to use these 'out of sync' instances as critical opportunities for learning. Working within a framework of 'comfort with uncertainty' allows supervisors and trainees to instead speculate together about the possible downstream events that pose risk to their patients (thereby enriching skills in forward planning), while concurrently considering the specific actions that allow them to move forward safely while continually monitoring their progress in these settings. 


\section{Implications for Research}

Further development of this framework and the proposed educational innovations requires a more robust understanding of how skillful clinicians recognize the boundaries between comfort and discomfort in moments of uncertainty. Doing so would help to better define instances where problems can be managed within the confines of clinicians' existing cognitive, emotional, and environmental resources, and when help is needed. Existing research examines how established clinicians preemptively steer clear of problems that are likely to misalign with their skillset, ${ }^{39,40}$ but there has been less work directed toward understanding how clinicians' moment-to-moment appraisals of comfort are both enacted and acted upon, as well as when they reach the limits of their comfort. Koriat's dual-basis view of metacognitive judgments may provide helpful scaffolding to categorize the types of cues that clinicians use in the moment, ${ }^{41,42}$ and these can ultimately be linked to downstream event as a means to illustrate whether or not these cues are predictive for desired outcomes. ${ }^{45}$

Further, as a supplement to research exploring how clinicians manage uncertainty effectively, there is need for an exploration of how this framework is conceptualized by novices, and how it aligns with their lived experiences. How do learners define the edges of their zones of practice while still learning the practice itself? How are the edges of a novice's comfort zone experienced in the context of working with different supervisors and in different settings? Are lived experiences of discomfort viewed as limitations of practice or opportunities for learning? Are such perceptions derived from the implicit messages they receive from their training programs and clinical preceptors? How novices respond in moments of uncertainty or moments of discomfort will determine the extent to which they engage in entrustable practice and learning ${ }^{70}$ or hide their feelings in a manner that could compromise patient safety. ${ }^{67}$ Research in this respect could thus probe learners to determine how they manage problems in the context of ongoing uncertainty while simultaneously navigating the tensions between learning, risk, and emerging independence. 


\section{CHAPTER 2}

Finally, if comfort and discomfort reflect holistic cognitive frameworks that guide the management of uncertainty, what does it mean for learners to be 'overconfident', and how do supervisors identify these attributes in trainees? In past work, definitions of over- and underconfidence were based upon retrospective alignment or misalignment with measures of diagnostic accuracy as determined by expert consensus, ${ }^{55,71}$ pathology results, ${ }^{72}$ or autopsy findings. ${ }^{73}$ Our definition of confidence is likely to change if we move away from a goal of 'getting a diagnosis right' towards 'taking a reasonable next step while attending to and anticipating varied responses to management plans.' Thus, unearthing the roots of trainees' 'comfort' might help to further elaborate what faculty members mean when they say trainees are 'over-confident' in uncertain settings. This will help us understand the behaviors that give supervisors the perception that trainees are acting as "cowboys" (taking undue risk) or being overly "timid" (risk-intolerant) in settings of uncertainty. ${ }^{40,74}$

\section{Conclusion}

'Comfort with uncertainty' describes instances where clinicians have the confidence to act on a problem (or wait and observe) while lacking full confidence in their understanding of the underlying cause of the issue. This framework provides a new model for exploring and conceptualizing the critical cognitive and environmental cues that impact moment-to-moment decision-making. By focusing on the influences that shape individuals' comfort, the management of uncertainty can focus on planning and enacting defensible clinical actions even when downstream outcomes remain unknown. 


\section{References}

1. Simpkin AL, Schwartzstein RM. Tolerating Uncertainty - The Next Medical Revolution? N Engl J Med. 2016;375:1713-1715.

2. Fargason CAJ, Evans HH, Ashworth CS, Capper SA. The importance of preparing medical students to manage different types of uncertainty. Acad Med. 1997;72:688-692.

3. Hartmann WH. Preparing medical students to "manage uncertainty". Acad Med. 1998;73:116-117.

4. Luther VP, Crandall SJ. Commentary: Ambiguity and Uncertainty: Neglected Elements of Medical Education Curricula? Acad Med. 2011;86:799-800.

5. White $\mathrm{G}$, Williams $\mathrm{S}$. The certainty of uncertainty: can we teach a constructive response? Med Educ. 2017;51:1200-1202.

6. Lingard L, Garwood K, Schryer CF, Spafford MM. A certain art of uncertainty: case presentation and the development of professional identity. Soc Sci Med. 2003;56:603616.

7. Geller G. Tolerance for ambiguity: an ethics-based criterion for medical student selection. Acad Med. 2013;88:581-584.

8. Kitchener KS. Cognition, metacognition, and epistemic cognition: a three-level model of cognitive processing. Hum Dev. 1983;4:222-232.

9. Cristancho S, Lingard L, Forbes T, Ott M, Novick R. Putting the puzzle together: the role of 'problem definition' in complex clinical judgement. Med Educ. 2017;51:207-214.

10. Schön DA. The reflective practitioner: How professionals think in action. New York: Basic Books; 1983.

11. Grant MJ, Booth A. A typology of reviews: an analysis of 14 review types and associated methodologies. Health Info Libr J. 2009;26:91-108.

12. Light D. Uncertainty and Control in Professional Training. J Health Soc Behav. 1979;20:310-322.

13. Babrow AS, Kasch CR, Ford LA. The many meanings of uncertainty in illness: toward a systematic accounting. Health Commun. 1998;10:1-23.

14. Atkinson P. Training for certainty. Soc Sci Med. 1984;19:949-956. 


\section{CHAPTER 2}

15. Fox R. Training for uncertainty. In: Merton RK, Reader G, Kendall PL (Eds.). The student physician. Cambridge: Harvard University Press; 1957, 207-241.

16. Simpson DE, Dalgaard KA, O'Brien DK. Student and faculty assumptions about the nature of uncertainty in medicine. The Journal of family practice. 1986;23:468-472.

17. Lazarus RS. Emotion and adaptation. New York: Oxford University Press; 1991.

18. Mishel MH. Uncertainty in Illness. Image J Nurs Sch. 1988;20:225-232.

19. Mishel MH. Reconceptualization of the uncertainty in illness theory. Image J Nurs Sch. 1990;22:256-262.

20. Schwartz S, Griffin T. Medical thinking: The psychology of medical judgment and decision making. New York: Springer-Verlag; 1986.

21. Lazarus RS, Folkman S. Stress, appraisal, and coping. New York: Springer; 1984.

22. Lipshitz R, Strauss O. Coping with Uncertainty: A Naturalistic Decision-Making Analysis. Organ Behav Hum Perform. 1997;69:149-163.

23. Djulbegovic B, Hozo I, Greenland S. Uncertainty in Clinical Medicine. In: Gabbay D, Thagard P, Woods J. Handbook of Philosophy of Science. Vol 16. Amsterdam, NL: North Holland Publishing Co.; 2011, 299-356.

24. Schraw G, Dunkle ME, Bendixen LD. Cognitive processes in well-defined and ill-defined problem solving. Appl Cogn Psychol. 1995;9:523-538.

25. Dogra N, Giordano J, France N. Cultural diversity teaching and issues of uncertainty: the findings of a qualitative study. BMC Med Educ. 2007;7:1-13.

26. Simons DJ, Chabris CF. Gorillas in our midst: sustained inattentional blindness for dynamic events. Perception. 1999;28:1059-1074.

27. Rensink RA, O'Regan JK, Clark JJ. To See or not to See: The Need for Attention to Perceive Changes in Scenes. Psychol Sci. 1997;8:368-373.

28. Levine DN. The flight from ambiguity: Essays in social and cultural theory. Chicago: University of Chicago Press; 1985.

29. Eva KW, Regehr G. Self-assessment in the health professions: a reformulation and research agenda. Acad Med. 2005;80:S46-54. 


\section{CHAPTER 2}

30. Barbalet JM. Confidence: time and emotion in the sociology of action. J Theory Soc Behav. 1993;23:229-246.

31. LeBlanc VR. The effects of acute stress on performance: implications for health professions education. Acad Med. 2009;84:S25-33.

32. LeBlanc VR, McConnell MM, Monteiro SD. Predictable chaos: a review of the effects of emotions on attention, memory and decision making. Adv Health Sci Educ Theory Pract. 2015;20:265-282.

33. Jha S. Stop hunting for zebras in Texas: end the diagnostic culture of "rule-out". BMJ. 2014;348:g2625.

34. Smith CS, Paauw DS. When you hear hoof beats: four principles for separating zebras from horses. J Am Board Fam Pract. 2000;13:424-429.

35. Bordage G, Lemieux M. Semantic structures and diagnostic thinking of experts and novices. Acad Med. 1991;66:S70-72.

36. Bowen JL. Educational strategies to promote clinical diagnostic reasoning. N Engl J Med. 2006;355:2217-2225.

37. Cristancho $S M$, Vanstone $M$, Lingard $L$, LeBel ME, Ott $M$. When surgeons face intraoperative challenges: a naturalistic model of surgical decision making. Am J Surg. 2013;205:156-162.

38. Cristancho SM, Apramian T, Vanstone M, et al. Thinking like an expert: surgical decision making as a cyclical process of being aware. Am J Surg. 2016;211:64-69.

39. Zilbert NR, St-Martin L, Regehr G, Gallinger S, Moulton CA. Planning to Avoid Trouble in the Operating Room: Experts' Formulation of the Preoperative Plan. J Surg Educ. 2015;72:271-277.

40. Zilbert NR, Murnaghan ML, Gallinger S, Regehr G, Moulton CA. Taking a Chance or Playing It Safe: Reframing Risk Assessment Within the Surgeon's Comfort Zone. Ann Surg. 2015;262:253-259.

41. Koriat A. Monitoring one's own knowledge during study: A cue-utilization approach to judgments of learning. J Exp Psychol Gen. 1997;126:349-370. 
42. Koriat A, Bjork RA, Sheffer L, Bar SK. Predicting one's own forgetting: the role of experience-based and theory-based processes. J Exp Psychol Gen. 2005;133:643-656.

43. Begg I, Duft S, Lalonde P, Melnick R, Sanvito J. Memory predictions are based on ease of processing. J Mem Lang. 1989;28:610-632.

44. Rawson KA, Dunlosky J. Are performance predictions for text based on ease of processing? J Exp Psychol Learn Mem Cogn. 2002;28:69-80.

45. de Bruin A, Dunlosky J, Cavalcanti R. Monitoring and Regulation of Learning in Medical Education: The Need for Predictive Cues. Med Educ. 2017;51:575-584.

46. Reber R, Greifeneder R. Processing Fluency in Education: How Metacognitive Feelings Shape Learning, Belief Formation, and Affect. Educ Psychol. 2017;52:84-103.

47. Moulton CA, Regehr G, Lingard L, Merritt C, MacRae H. Slowing down to stay out of trouble in the operating room: remaining attentive in automaticity. Acad Med. 2010;85:1571-1577.

48. Dunphy BC, Williamson SL. In pursuit of expertise. Toward an educational model for expertise development. Adv Health Sci Educ Theory Pract. 2004;9:107-127.

49. Eva KW, Regehr G. Knowing when to look it up: a new conception of self-assessment ability. Acad Med. 2007;82:S81-84.

50. Croskerry P. The importance of cognitive errors in diagnosis and strategies to minimize them. Acad Med. 2003;78:775-780.

51. Chase WG, Simon HA. The mind's eye in chess. In: Chase WG. Visual Information Processing. New York: Academic Press; 1973.

52. Ilgen JS, Brydges R. Cues for self-regulation: it's difficult to make predictions, especially about the future. Med Educ. 2017; 51:566-568.

53. Ericsson KA, Patel V, Kintsch W. How experts' adaptations to representative task demands account for the expertise effect in memory recall: Comment on Vicente and Wang (1998). Psychol Rev. 2000;107:578-592.

54. Moulton CA, Regehr G, Lingard L, Merritt C, Macrae H. 'Slowing down when you should': initiators and influences of the transition from the routine to the effortful. J Gastrointest Surg. 2010;14:1019-1026. 
55. Friedman CP, Gatti GG, Franz TM, et al. Do physicians know when their diagnoses are correct? Implications for decision support and error reduction. J Gen Intern Med. 2005;20:334-339.

56. Novick RJ, Lingard L, Cristancho SM. The call, the save, and the threat: understanding expert help-seeking behavior during nonroutine operative scenarios. J Surg Educ. 2015;72:302-309.

57. Jin CJ, Martimianakis MA, Kitto S, Moulton CA. Pressures to "measure up" in surgery: managing your image and managing your patient. Ann Surg. 2012;256:989-993.

58. Luu S, Patel P, St-Martin L, et al. Waking up the next morning: surgeons' emotional reactions to adverse events. Med Educ. 2012;46:1179-1188.

59. Kennedy TJ, Regehr G, Baker GR, Lingard LA. 'It's a cultural expectation...' The pressure on medical trainees to work independently in clinical practice. Med Educ. 2009;43:645653.

60. Leung A, Luu S, Regehr G, Murnaghan ML, Gallinger S, Moulton CA. "First, do no harm": balancing competing priorities in surgical practice. Acad Med. 2012;87:1368-1374.

61. Williams RG, Silverman R, Schwind C, et al. Surgeon Information Transfer and Communication: Factors Affecting Quality and Efficiency of Inpatient Care. Ann Surg. 2007;245:159-169.

62. Plebani M. The clinical importance of laboratory reasoning. Clinica Chimica Acta. 1999;280:35-45.

63. Cristancho SM, Apramian T, Vanstone M, Lingard L, Ott M, Novick RJ. Understanding clinical uncertainty: what is going on when experienced surgeons are not sure what to do? Acad Med. 2013;88:1516-1521.

64. Ilgen JS, Eva KW, Regehr G. What's in a Label? Is Diagnosis the Start or the End of Clinical Reasoning? J Gen Intern Med. 2016;31:435-437.

65. Kennedy TJ, Regehr G, Baker GR, Lingard L. Preserving professional credibility: grounded theory study of medical trainees' requests for clinical support. BMJ. 2009;338:b128.

66. Stewart J. To call or not to call: a judgement of risk by pre-registration house officers. Med Educ. 2008;42:938-944. 


\section{CHAPTER 2}

67. Moulton CA, Regehr G, Lingard L, Merritt C, Macrae H. Operating from the other side of the table: control dynamics and the surgeon educator. J Am Coll Surg. 2010;210:79-86.

68. Ott M, Schwartz A, Goldszmidt M, Bordage G, Lingard L. Resident hesitation in the operating room: does uncertainty equal incompetence? Med Educ. 2018;52:851-860.

69. Cooke G, Tapley A, Holliday E, et al. Responses to clinical uncertainty in Australian general practice trainees: a cross-sectional analysis. Med Educ. 2017;51:1277-1288.

70. Ten Cate O, Hart D, Ankel F, et al. Entrustment Decision Making in Clinical Training. Acad Med. 2016;91:191-198.

71. Potchen EJ. Measuring observer performance in chest radiology: some experiences. J Am Coll Radiol. 2006;3:423-432.

72. Dreiseitl S, Binder M. Do physicians value decision support? A look at the effect of decision support systems on physician opinion. Artif Intell Med. 2005;33:25-30.

73. Landefeld CS, Chren MM, Myers A, Geller R, Robbins S, Goldman L. Diagnostic yield of the autopsy in a university hospital and a community hospital. N Engl J Med. 1988;318:1249-1254.

74. Cassell J. Expected Miracles: Surgeons at Work. Philadelphia: Temple University Press; 1991. 


\section{CHAPTER 3}

\section{"I was worried about the patient, but I wasn't feeling worried": How physicians judge their comfort in settings of uncertainty}

Published as:

Ilgen JS, Bowen JL, de Bruin ABH, Regehr G, Teunissen PW. "I was worried about the patient, but I wasn't feeling worried": How physicians judge their comfort in settings of uncertainty. Academic Medicine. 2020 November; 95(11S): S67-S72.

(C) 2020 the Association of American Medical Colleges 


\title{
CHAPTER 3
}

\begin{abstract}
Purpose. Clinical educators often raise concerns that learners are not comfortable with uncertainty in clinical work, yet existing literature provides little insight into practicing clinicians' experiences of comfort when navigating the complex, ill-defined problems pervasive in practice. Exploring clinicians' comfort as they identify and manage uncertainty in practice could help us better support learners through their discomfort.
\end{abstract}

Method. We employed a constructivist grounded theory approach to explore experiences of uncertainty in emergency medicine faculty. We used a critical incident technique to elicit narratives about decision-making immediately following participants' clinical shifts, exploring how they experienced uncertainty and made real-time judgments regarding their comfort to manage a given problem. Two investigators analyzed the transcripts, coding data line-by-line using constant comparative analysis to organize narratives into focused codes. These codes informed the development of conceptual categories that formed a framework for understanding comfort with uncertainty.

Results. Participants identified multiple forms of uncertainty, organized around their understanding of the problems they were facing and the potential actions they could take. When discussing their comfort in these situations, they described a fluid, actively negotiated state. This state was informed by their efforts to project forward and imagine how a problem might evolve, with boundary conditions signaling the borders of their expertise. It was also informed by ongoing monitoring activities pertaining to patients, their own metacognitions, and their environment.

Conclusions. Our findings offer nuances to current notions of comfort with uncertainty. Uncertainty involved clinical, environmental and social aspects, and comfort dynamically evolved through iterative cycles of forward planning and monitoring. 


\section{CHAPTER 3}

Clinical work is filled with uncertainty. ${ }^{1-7}$ Working effectively in clinical settings requires expert practitioners to tackle problems for which multiple interpretations of the situation and multiple management approaches may be reasonable as they work towards patient-centered solutions. ${ }^{8-10}$ Thus, there have been continued calls for clinicians to "tolerate" ${ }^{7}$ or respond more constructively to the uncertainty they face in authentic clinical settings, ${ }^{11-13}$ aiming to avoid maladaptive behaviors such as 'fitting' discrepant data into a diagnosis prematurely, ${ }^{14,15}$ pursuing unnecessary tests in pursuit of diagnostic certainty, ${ }^{16}$ or "ploughing through" situations while neglecting threats to patient safety. ${ }^{17}$ Yet most studies attempting to develop theoretical models of clinical reasoning and decision-making have tended to utilize problems that are deterministic (one right diagnosis) ${ }^{18-21}$ or at best probabilistic (each diagnosis having a determinable probability of being correct). ${ }^{22-24}$ Drawing lessons from these models may work for well-defined problems with "absolutely correct and knowable solutions." ${ }^{25(p g . ~ 223)}$ yet when applied in the ill-defined problem spaces commonly encountered in clinical practice they may implicitly promote the maladaptive behaviors they were intended to correct. This highlights a potential conceptual gap in our current literature: Do existing models of clinical reasoning based upon well-defined problems sufficiently capture and elaborate what clinicians do when wrestling with the ill-defined problems that they experience in authentic practice?

One approach to address this gap between theory and practice is to first better understand how clinicians experience and attend to uncertainty in their daily work. A more nuanced explication of the ways in which experienced clinicians proceed through the ill-defined problem spaces that are pervasive in practice has the potential to reconcile the disconnect between theoretical models of expert reasoning and authentic reasoning in clinical practice. Thus, the purpose of this study is to explore physicians' experiences with uncertainty in their clinical work, elaborating what they notice and consider in these moments as they make judgments about whether they can capably handle uncertain situations safely and effectively. In particular, we were interested in exploring questions such as: 
- What types of circumstances in clinicians' daily work generate the sense that they have an incomplete or insufficient understanding of a situation, and how is this sense of uncertainty experienced?

- What types of activities or processes help clinicians to paradoxically remain 'comfortable' handling a problem despite these feelings of uncertainty?

- How do experienced clinicians identify these moments and make real-time judgments about whether their knowledge and skills are sufficiently aligned with a situation to deliver safe and effective care?

In exploring these questions, we aim to provide linkages between theory and practice as a first step towards more purposefully understanding, studying, and promoting effective behaviors in practicing clinicians and trainees.

\section{Method}

We employed a constructivist grounded theory (CGT) approach, ${ }^{26}$ using data from semistructured interviews to build understanding of cognitive and social processes that are not well explained by established theoretical constructs. CGT employs inductive reasoning to generate interpretive theory, placing emphasis on subjectivity over objectivity as the preferred path to making knowledge. ${ }^{27}$ This approach acknowledges that meaning is created through the interaction between the investigators and participants, an important feature of our methodological orientation because the principal investigator (J.I.) is a practicing emergency medicine (EM) clinician-educator. Two study team members are clinicians (P.T., J.B.), three have backgrounds in qualitative research (P.T., J.B., G.R.) and two have training in cognitive psychology (A.dB., G.R.).

Setting, Population, and Sampling Strategy. This study took place at two large, urban, University-affiliated teaching hospitals between December 2018 and April 2019. We enrolled a cohort of practicing EM faculty, hypothesizing that because these clinicians regularly tackle clinical problems that are complex, dynamic, and undifferentiated, this study population would provide rich descriptions that are exemplary for the range of ways that physicians experience 


\section{CHAPTER 3}

ill-defined problems in everyday practice. Importantly, the principal investigator (J.I.) also works in these environments and is well-acquainted with the clinical problems that participants' encounter and the unique factors that impact care in these environments. Because we expected that 'uncertainty' and 'comfort' would be shaped by past experiences, we purposefully sampled participants with a spectrum of time in clinical practice. The University's institutional review board reviewed the study protocol and determined that it met exempt status.

Procedures. The principal investigator (J.I.) conducted hour-long semi-structured interviews with participants using a critical incident technique ${ }^{28}$ to elicit narratives immediately after the conclusion of participants' clinical shifts. Following a brief introduction, interviews began by prompting participants to think about cases from their shift when they needed the help from others (or not), and instances when they made decisions to discharge or admit patients with a lingering sense of uncertainty. They were given were given 10 minutes to hand-draw visual representations of 2 such cases that were then used as prompts to elicit participants' reflections and-with the aid of a case log listing all of the patients they had seen during the preceding shift-served as a starting point to discuss additional cases. We used probing questions that explored the origins of their uncertainty (or uncertainties) and how they approached and experienced these moments (including both emotional and somatic manifestations). As the interviews progressed, we adapted our interview guide iteratively to gather data based on evolving categories and themes. ${ }^{29}$ Audio-recordings of the interviews were transcribed for analysis.

Analysis. We analyzed participants' narratives iteratively alongside data collection. Two investigators (J.I., J.B.) coded data line-by-line using constant comparison to organize data into focused codes, key conceptual categories, and then major themes. We coded transcripts using Dedoose (SocioCultural Research Consultants, Manhattan Beach, CA), which facilitated analytic memoing and network displays that enabled the entire team to discuss the evolving codes, their meaning in light of our research question, and connections between them. We identified 


\section{CHAPTER 3}

relationships between codes and categories, and developed a conceptual framework reflecting the possible relationships between themes. After 10 interviews, the final 2 interviews offered no additional insights or counterexamples, and we deemed our sample theoretically sufficient to address the study purpose. ${ }^{30}$

\section{Results}

Twelve EM faculty physicians (4 female) participated in this study. These clinicians had a broad range of years in practice (2-32 years) and had practiced at their respective clinical sites for an average of 7.5 years (range 0.5 to 13 years). Participants discussed a total of 55 unique patient cases, with a range of 3-7 cases per interview. Regardless of their years in practice, participants consistently described multiple forms of uncertainty that were manifest in their experiences, and multiple considerations they used to judge their comfort in these situations.

\section{Perceptions of Uncertainty}

Participants' experiences of uncertainty organized into the two broad categories that could be captured in the questions, "What is going on?" and "What should I do?". These categories of uncertainty frequently coexisted in the same clinical case, and the relative contributions of each form of uncertainty evolved as clinicians engaged in the care of a given patient over time.

What is going on? This form of uncertainty generally centered around participants' incomplete understanding of a problem's root cause or uneasiness in predicting how a problem might progress. Efforts to understand the origins and evolution of the problem ranged from identifying a limited set of possibilities to acknowledging a vague and broader set of complete unknowns. A relatively extreme case of uncertainty with regard to both etiology and course was described by Participant 5 while caring for a patient after a skiing accident:

"It's truly just a complete unknown why the kid is down... He had no physical signs of trauma anywhere except that he's got a bloody nose... Could [he have] fainted? Could he have seized? Did he get that bloody nose after he got combative with medics? We just didn't know...This is one where like I still kind of think like "what's my initial gut 


\section{CHAPTER 3}

sense?" but I have very low valence attached to it. This is probably what's going to happen, but I don't really know." (Participant 5)

What should I do? Participants also told stories of uncertainty regarding management, which took three forms: a) clinical uncertainty, generated when they were unsure which actions would be safe and effective; b) skill-based uncertainty, when they perceived a possible mismatch between their skills and the problem at hand; and c) moral uncertainty, when they expressed uneasiness about whether their actions aligned with patients' goals of care, or with institutional expectations within their system of care .

First, participants wrestled with the competing risks and benefits of particular treatment decisions and described how time impacted case-specific hypothetical pros and cons. For example, Participant 4, when caring for a patient whose clinical presentation suggested that she might be having a stroke (e.g. infarct), described real time struggles around whether or not to give tissue plasminogen activator (tPA), a medication that could potentially restore blood flow to injured parts of the brain but carried the risk of life-threatening bleeding:

"The risks are that she's going to have an infarct and...and have disability from this. That's one of the risks. Another risk is that she would get tPA and have bleeding in her head, whether she was having a stroke or not. That risk maybe varies by magnitude, varies by whether or not she's actually having a stroke, so that's...a variable risk, so there's a variable benefit. And as time goes by, the amount of benefit of the drug is dropping, 10 million neurons a minute or ... something ridiculous like that." (Participant 4)

Second, even when treatment decisions seemed fairly clear, participants sometimes expressed insecurity around whether their own skills were aligned, or sufficiently practiced, to deal with the task at hand. Some expressed tentativeness around whether they were the 'right' person to embark on a management step, particularly if others with these skills were available in their resource-rich environment. As one participant described: 


\section{CHAPTER 3}

"I have placed one suprapubic catheter in my life, one, when I was a resident...Could I if I had to? Yeah. But if it were my dad, would I want the person who's done it once to do it? Probably not." (Participant 1).

Third, on occasion, participants expressed uncertainty about whether a decision was morally appropriate. We observed this uncertainty in two ways: whether they were doing the right thing when patients' preferences or treatment goals were unknown, and whether their actions aligned with being a good steward of the health system. As described by Participant 3, who was wrestling with whether to intubate a minimally responsive and critically ill patient with a terminal illness:

"We potentially can offer other sorts of life sustaining or life support skills. But, that's where the sort of hesitancy and the uncertainty came in: Is that something we actually want to do to this person?" (Participant 3)

The uncertainty about health system stewardship seemed to stem from ambiguity about institutional policies. As one participant described, “I'm not even sure if I'm breaking the guidelines and rules here, but I felt really confident that we were providing the right care for this woman" (Participant 10).

\section{Considerations that influence comfort}

Participants noted a sense of 'comfort' when describing situations where they felt like they could take the next step forward despite unresolved uncertainties. Comfort was not a static state but rather a dynamic cognitive, emotional, and physical experience. This dynamic experience was influenced by the intersection of multiple considerations and was determined in two ways. First, participants described projecting forward to imagine whether they could imagine managing the paths that might ensue as a problem evolved and set boundary conditions that would signal a problem was progressing beyond their capacity to manage it effectively. Second, they gathered signals from their experiences in real time, monitoring the patient's progress, themselves, and their environment to gauge whether the interpretation of the situation was remaining within their capacity to manage and control. 
Projecting Forward and Setting Boundaries. Participants frequently described mental simulations of the kinds of things that might happen as a problem evolved over time. These mental simulations enabled participants to get a sense of whether the range of possible downstream clinical events remained within the boundaries of their knowledge, skills, and resources. When participants interpreted alignment between their skills and the situation, their comfort seemed to reflect a confidence that they were unlikely to get themselves into situations they could not handle. As a part of this process, participants imagined events that signaled the borders of their expertise. Signposting these conditions allowed participants to plan for how they could move forward with deliberate caution, using the manifestation of these boundary conditions as stopping points where they would access help from others. In the context of anticipating a challenging procedure, Participant 5 reflected:

"It was either going to be easy or not, and if it anything other than easy, like I was ready to abort...I'm not going to force this process. Like there's nothing about this where I have to step that far beyond my own comfort zone." (Participant 5)

Interestingly, participants also projected forward as a means to make predictions about how others might analyze and critique their decision-making post-hoc. These projections regarding social judgments served as a proactive means for participants to weigh the defensibility of their actions, and often centered around a sense that they might be deviating from institutional norms or practices-even when they were confident in the appropriateness of their management. As described by Participant 10:

"What am I worried about? I'm worried that in three days from now I'm gonna get some angry email from some angry orthopedist telling me that I'm a bad doctor." (Participant 10)

Monitoring. As participants engaged in decision-making while experiencing uncertainty, they described three ways that they actively monitored these situations, including a) the ways in which their observations were aligned or misaligned with how they predicted a patient's illness 


\section{CHAPTER 3}

to evolve; b) their internal emotional and somatic state as they worked through these problems; and c) observations of their environment-as manifested by the activities of their team members and/or the availability of resources - that allowed them reflect upon whether the environmental conditions would effectively support their management efforts.

First, as participants engaged with problems, they described multiple ways that clinical data signaled whether a patient's status and course were evolving in expected ways. When predicted paths came to fruition, participants' gained confidence in their understanding of a problem. Comfort, as Participant 1 described, was generated when things seemed to be 'on track.'

"Things were fitting, and you do your due diligence to look for other things, right?...it's both finding the evidence that supports it and finding the evidence against the other things. And it all perfectly lined up." (Participant 1)

Second, clinicians seemed to be deliberately monitoring their own internal reactions to these situations. Comfort with the situation was inferred from their experience of a mental state associated with calm feelings and a lack of somatic cues, even when participants described a conscious sense of concern for a patient. These experiences of comfort seemed to arise from a sense of being in control of a situation, as Participant 1 described:

"It's kind of hard to put a feeling on it...It's almost the opposite of emotion. I wasn't feeling particularly scared or happy or sad or worried. I mean I was worried about the patient, but I wasn't feeling worried, if that makes sense." (Participant 1) Conversely, when participants faced problems that were rapidly progressing, insufficiently predictable, or at the borders of their expertise, they described experiencing a sense of fear, worry, or a vague sense that "something's not right" (Participant 11). This lack of comfort was often identified first through the growing awareness of palpable physical symptoms:

"I feel my heart speeding up. I feel like talking faster and louder. I feel like I want to take some deep breaths." (Participant 7) 


\section{CHAPTER 3}

Third, participants frequently described monitoring environmental cues that extended beyond their own direct interactions with patients. Even when they lacked a complete understanding of a situation, participants used these observations to assess whether their team had a sufficiently aligned understanding of the situation such that the team could engage in the most pressing work, align resources, and plan ahead together. As Participant 7 reflected:

"You're worried the nurses don't understand but then you realize they're both putting in large bore 18s in his arms and so then you realize, okay, at least they're with me." (Participant 7)

\section{Moment-by-Moment Interpretations of Relative Comfort}

Importantly, participants saw the experience of comfort as neither dichotomous (comfortable or not) nor stable. As participants moved through problems with which they experienced uncertainty, they seemed to be continuously engaging in a process of projecting forward and monitoring, weighing the relative contributions of a multitude of clinical, metacognitive, somatic, and environmental cues that simultaneously influenced whether they were more, or less, comfortable in a given moment. As participants reflected at the intersection of these cues, they seemed to be working towards holistic judgments about whether they were sufficiently comfortable to take particular diagnostic or management steps forward. This balancing act was described by Participant 12:

"I had competing feelings in my mind. I was both happy, glad, and feeling comfortable that I was moving towards what I thought it was. But still there's this gnawing feeling...[an] uneasiness that you don't want to get burned. What are the high-risk scenarios? What are the things that can go wrong with a patient? It was a duplicitous sense about, or two competing senses or feelings that are held in contrast. It's almost a ratio as to which one is winning at that particular time." (Participant 12)

\section{Discussion}

The data from our study suggest the need to nuance some of our traditional understandings of the notions of 'comfort with uncertainty.' We saw interesting complexities in our participants' 


\section{CHAPTER 3}

experiential representations of uncertainty that were more aligned with what they were uncertain about in the moment rather than the sources of these uncertainties in an epistemological sense. Moreover, our participants' comfort in these moments was more nuanced than a dichotomous sense of being comfortable or not; instead, comfort was an everevolving spectrum, informed by participants' predictions for how a problem was likely to play out and the emerging stimuli that they noticed during these patient care experiences.

In eliciting narratives from clinicians regarding experiences in practice, it became clear that feelings of uncertainty went beyond merely uncertainty regarding the root causes of a patient's illness or in the potential evolution of their disease process. It also pertained to the optimal management of the problem, which was affected by a variety of factors such as the affordances of the environment and the imagined critiques of others. These findings are consistent with survey-based research by Gerrity and colleagues who also identified environmentally- and sociologically-embedded aspects of uncertainty, ${ }^{31}$ and compliment their work by providing a descriptive richness to these phenomena in context. It is our hope that such richness can better support the development of "constructive responses" to uncertainty as promoted by White and Williams. ${ }^{11}$

Our participants' narratives also highlight that comfort was neither a binary nor static phenomenon. Instead, it was a dynamic cognitive, emotional and physical experience that was informed by a multitude of external and metacognitive cues in ways that are reminiscent of Koriat's cue utilization framework. ${ }^{32}$ These cues shifted participants' sense of whether problems were sufficiently predictable and progressing in ways they expected would be aligned with their own capabilities, or alternatively were leading them towards trouble. Participants' confidence in their management plans was often tempered or counterbalanced by deliberate efforts to both imagine potential risks and to monitor (in patients, themselves, and the environment) for responses that suggested they were headed for trouble. The integration of multiple cues seemed to provide participants with a holistic sense of whether they had sufficient comfort to proceed. And, the act of wrestling with and attempting to predict the progression of ill-defined 


\section{CHAPTER 3}

problems provided the necessarily vigilance and attention to notice when problems were going off track. In this way, the maintenance of uncertainty served as a motivating and enabling trigger to assess and re-assess one's comfort in these moments.

Finally, our findings illustrated clear linkages between the different forms of uncertainty that evolved throughout the course of a clinician's engagement with a particular case. Participants in our study frequently paired their considerations of "what is going on?" and "what should I do?" when they discussed their fluid and rapidly cycling efforts to define and respond to the problems in front of them. These efforts to concurrently define and address a problem that lacked obvious solutions encapsulated participants experience of grappling with ill-defined problems, ${ }^{24,25}$ and highlighted the multidimensional, situationally-bound, iterative nature of reasoning in practice. Such an approach to problem solving in ill-defined spaces is reminiscent of paradigms such as soft systems engineering. ${ }^{33-35}$ As Cristancho describes, a core premise of soft systems engineering is that the knowledge gained from trying to understand and solve a complex situation will change the parameters of the system itself. ${ }^{33}$ Thus, effective "problem solving" in the soft systems engineering tradition necessarily involves iterative cycles of problem solving and problem defining. ${ }^{34,36,37}$ Viewing reasoning processes through a soft systems lens, therefore, may offer promise for studying and teaching the fluid and idiosyncratic ways that complex, ill-defined problems are understood and addressed in practice.

\section{Limitations}

Our findings must be interpreted and extrapolated in light of our methodological decisions. We sampled amongst a cohort of urban emergency physicians as a means to understand the experiences of clinicians who regularly work with complex, dynamic, ill-defined problems. Yet this practice setting is importantly distinct from other settings, with patient care relationships that neither predate nor follow from these clinical encounters, access to tests and consultative resources that are unavailable in other contexts, and with training and practice cultures that are embedded in unique professional and institutional norms. These factors may limit the transferability of our findings to other settings where different forms of uncertainty exist or 


\section{CHAPTER 3}

comfort is generated through other mechanisms. In studying participants' experiences with uncertainty and comfort, we also acknowledge that what was consciously available to participants as they reflected upon cases likely offers only a glimpse of the conscious, subconscious, and environmental factors that influenced their experiences in these moments. ${ }^{38-}$

${ }^{40}$ Direct observation in situ coupled with provider reflections may offer promise as a means to get closer to these lived experiences.

Additionally, several questions remain unanswered on the basis of our current work. First, because we gathered post-hoc reflections from our participants without direct observation or knowledge of downstream outcomes, it may be that how comfortable our clinicians determined themselves to be in these situations is different from how an outside observer might have judged how comfortable they should have been. A different paradigm would be necessary to assess the extent to which an individual is effectively utilizing the variety of cues available to them to accurately determine the limits of their abilities in a given situation. ${ }^{41}$ Further, while this cohort of faculty clinicians seemed to judge their comfort level based upon their facilities to make predictions and monitor their progress, the applicability of these cues to othersparticularly those with less experience-remains unclear..$^{42}$ Finally, how clinicians experience and attend to experiences of insufficient comfort or frank discomfort was beyond the scope of this current investigation, as was explorations of how clinicians actively engaged with problems to increase their comfort more purposefully. These questions require future study.

\section{Conclusions}

Despite these limitations, our findings provide an important first step in understanding clinicians' lived experiences with ill-defined problems in practice. By recognizing the ways in which different forms of uncertainty interact with clinicians' judgments of comfort, we can begin to deconstruct the influences at play in these moments. Doing so will provide important insights for how experienced clinicians might attend to these moments more effectively, how novices might experience these moments differently, and how to more effectively train these skills in the future. 


\section{CHAPTER 3}

\section{References}

1. Djulbegovic B, Hozo I, Greenland S. Uncertainty in Clinical Medicine. In: Gifford F, Gabbay D, Thagard P, Woods J. Handbook of Philosophy of Science. Vol 16. Amsterdam, NL: North Holland Publishing Co.; 2011, 299-356.

2. Han PKJ, Klein WMP, Arora NK. Varieties of Uncertainty in Health Care: A Conceptual Taxonomy. Med Decis Making. 2011;31:828-838.

3. Pomare C, Churruca K, Ellis LA, Long JC, Braithwaite J. A revised model of uncertainty in complex healthcare settings: A scoping review. J Eval Clin Pract. 2019;25:176-182.

4. Babrow AS, Kasch CR, Ford LA. The many meanings of uncertainty in illness: toward a systematic accounting. Health Commun. 1998;10:1-23.

5. Fox R. Training for uncertainty. In: Merton RK, Reader G, Kendall PL (Eds.). The student physician. Cambridge: Harvard University Press; 1957, 207-241.

6. Light D. Uncertainty and Control in Professional Training. J Health Soc Behav. 1979;20:310-322.

7. Simpkin AL, Schwartzstein RM. Tolerating Uncertainty - The Next Medical Revolution? N Engl J Med. 2016;375:1713-1715.

8. Cook DA, Durning SJ, Sherbino J, Gruppen LD. Management Reasoning: Implications for Health Professions Educators and a Research Agenda. Acad Med. 2019;94:1310-1316.

9. Cook DA, Sherbino J, Durning SJ. Management Reasoning: Beyond the Diagnosis. JAMA. 2018;319:2267-2268.

10. Ilgen JS, Eva KW, de Bruin A, Cook DA, Regehr G. Comfort with uncertainty: reframing our conceptions of how clinicians navigate complex clinical situations. Adv Health Sci Educ Theory Pract. 2019;24:797-809.

11. White $\mathrm{G}$, Williams $\mathrm{S}$. The certainty of uncertainty: can we teach a constructive response? Med Educ. 2017;51:1200-1202.

12. Luther VP, Crandall SJ. Commentary: Ambiguity and Uncertainty: Neglected Elements of Medical Education Curricula? Acad Med. 2011;86:799-800.

13. Fargason CAJ, Evans HH, Ashworth CS, Capper SA. The importance of preparing medical students to manage different types of uncertainty. Acad Med. 1997;72:688-692. 


\section{CHAPTER 3}

14. Wallsten TS. Physician and medical student bias in evaluating diagnostic information. Med Decis Making. 1981;1:145-164.

15. Croskerry P. The importance of cognitive errors in diagnosis and strategies to minimize them. Acad Med. 2003;78:775-780.

16. Jha S. Stop hunting for zebras in Texas: end the diagnostic culture of "rule-out". BMJ. 2014;348:g2625.

17. Moulton CA, Regehr G, Lingard L, Merritt C, Macrae H. 'Slowing down when you should': initiators and influences of the transition from the routine to the effortful. J Gastrointest Surg. 2010;14:1019-1026.

18. Ilgen JS, Bowen JL, McIntyre LA, et al. Comparing diagnostic performance and the utility of clinical vignette-based assessment under testing conditions designed to encourage either automatic or analytic thought. Acad Med. 2013;88:1545-1551.

19. Mamede S, Schmidt HG, Rikers RM, Penaforte JC, Coelho-Filho JM. Breaking down automaticity: case ambiguity and the shift to reflective approaches in clinical reasoning. Med Educ. 2007;41:1185-1192.

20. Schmidt HG, Mamede S, van den Berge K, van Gog T, van Saase JL, Rikers RM. Exposure to media information about a disease can cause doctors to misdiagnose similar-looking clinical cases. Acad Med. 2014;89:285-291.

21. Sherbino J, Dore KL, Wood TJ, et al. The relationship between response time and diagnostic accuracy. Acad Med. 2012;87:785-791.

22. Kahneman D, Klein G. Conditions for intuitive expertise: a failure to disagree. Am Psychol. 2009;64:515-526.

23. Lebiere C, Anderson JR. Cognitive Constraints on Decision Making under Uncertainty. Front Psychol. 2011;2:305.

24. Schraw G, Dunkle ME, Bendixen LD. Cognitive processes in well-defined and ill-defined problem solving. Appl Cognit Psychol. 1995;9:523-538.

25. Kitchener KS. Cognition, metacognition, and epistemic cognition: a three-level model of cognitive processing. Hum Dev. 1983;4:222-232. 


\section{CHAPTER 3}

26. Charmaz K. Constructing Grounded Theory: A practical guide through qualitative analysis. 2nd ed. London: Sage Publications; 2014.

27. Albert M, Mylopoulos M, Laberge S. Examining grounded theory through the lens of rationalist epistemology. Adv Health Sci Educ Theory Pract. 2019;24:827-837.

28. Flanagan JC. The critical incident technique. Psychol Bull. 1954;51:327-358.

29. Corbin J, Strauss AL. Basics of Qualitative Research: Techniques and Procedures for Developing Grounded Theory. 3rd ed. Los Angeles, CA: Sage; 2008.

30. Malterud K, Siersma VD, Guassora AD. Sample Size in Qualitative Interview Studies: Guided by Information Power. 2016;26:1753-1760.

31. Gerrity MS, White KP, DeVellis RF, Dittus RS. Physicians' reactions to uncertainty: Refining the constructs and scales. Motiv Emot. 1995;19:175-191.

32. Koriat A. Monitoring one's own knowledge during study: A cue-utilization approach to judgments of learning. J Exp Psychol Gen. 1997;126:349-370.

33. Cristancho S. What can we learn from a soft sister? A complementary lens to the systems engineering approach in medical education research. Med Educ. 2014;48:11391141.

34. Checkland P. Soft systems methodology: a thirty year retrospective. Syst Res Behav Sci. 2000;17:S11-S58.

35. Mingers J, White L. A review of the recent contribution of systems thinking to operational research and management science. Eur J Oper Res. 2010;207:1147-1161.

36. Cristancho S, Lingard L, Forbes T, Ott M, Novick R. Putting the puzzle together: the role of 'problem definition' in complex clinical judgement. Med Educ. 2017;51:207-214.

37. Cristancho S, Lingard L, Regehr G. From problem solving to problem definition: scrutinizing the complex nature of clinical practice. Perspect Med Educ. 2017;6:54-57.

38. Norman G. Is the mouth the mirror of the mind? Adv Health Sci Educ Theory Pract. 2018;23:665-669.

39. van der Schaaf M, Bakker A, Ten Cate O. When I say ... embodied cognition. Med Educ. 2019;53:219-220. 


\section{CHAPTER 3}

40. Durning SJ, Artino AR. Situativity theory: a perspective on how participants and the environment can interact: AMEE Guide no. 52. Med Teach. 2011;33:188-199.

41. Ilgen JS, Brydges R. Cues for self-regulation: it's difficult to make predictions, especially about the future. Med Educ. 2017;51:566-568.

42. de Bruin A, Dunlosky J, Cavalcanti R. Monitoring and Regulation of Learning in Medical Education: The Need for Predictive Cues. Med Educ. 2017;51:575-584. 


\section{CHAPTER 4}

\section{Warning bells: How clinicians leverage their discomfort to manage moments of uncertainty}

Published as:

Ilgen JS, Teunissen PW, de Bruin ABH, Bowen JL, Regehr G. Warning bells: How clinicians leverage their discomfort to manage moments of uncertainty. Medical Education. 2021 February; 55(2): 233-241.

(C) 2020 John Wiley \& Sons Ltd and The Association for the Study of Medical Education 


\title{
CHAPTER 4
}

\begin{abstract}
Objectives. It remains unclear how medical educators can more effectively bridge the gap between trainees' intolerance of uncertainty and the tolerance that experienced physicians demonstrate in practice. Exploring how experienced clinicians' experience, appraise, and respond to discomfort arising from uncertainty could provide new insights regarding the kinds of behaviors we are trying to help trainees achieve.
\end{abstract}

Methods. We used a constructivist grounded theory approach to explore how emergency medicine faculty experienced, managed, and responded to discomfort in settings of uncertainty. Using a critical incident technique, we asked participants to describe case-based experiences with uncertainty immediately following a clinical shift. We used probing questions to explore the cognitive, emotional, and somatic manifestations of discomfort, how they appraised and responded to these cues, and how they used available resources to act in these moments of uncertainty. Two investigators coded data line-by-line using constant comparative analysis and organized transcripts into focused codes. The entire research team discussed relationships between codes and categories and developed a conceptual framework that reflected the possible relationships between themes.

Results. Participants identified varying levels of discomfort in their case descriptions. They described multiple cues alerting them to problems that were evolving in unexpected ways or problems with aspects of management that were beyond their abilities. Discomfort served as a trigger for participants to monitor a situation with greater attention, and to proceed more intentionally. It also served as a prompt for participants to think deliberately about the types of human and material resources they might call upon strategically to manage these uncertain situations.

Conclusions. Discomfort served as a dynamic means to manage and respond to uncertainty. To be 'tolerant' of uncertainty thus requires clinicians to embrace discomfort as a powerful tool to grapple with the complex problems pervasive in clinical practice. 


\section{CHAPTER 4}

Physicians frequently experience uncertainty in the patient presentations they face ${ }^{1-3}$ and the ability to manage these "ill-defined problems" ${ }^{4}$ effectively is a hallmark of expert practice. ${ }^{5,6}$ Problem-solving in these spaces requires a more nuanced approach than collecting the right data, finding the diagnosis, then initiating the appropriate, clearly-defined treatment. ${ }^{7}$ Instead, clinicians must engage in a flexible and iterative process of refining and redefining their understanding of the problem, even as they are managing it. ${ }^{8}$ In the educational domain, concerns have been raised regarding learners' ability or willingness to tolerate the uncertainty associated with these ill-defined problems of clinical practice. ${ }^{9-11}$ Yet, it remains unclear how medical educators might more effectively bridge this gap between trainees' intolerance of uncertainty and the tolerance that experienced physicians demonstrate in practice.

One approach to addressing this issue has been to explore clinicians' predispositions toward uncertainty. Taking this approach, researchers have utilized questionnaire-based tools to determine participants' affective reactions and coping mechanisms in response to a variety of scenarios, and to generate a "tolerance of uncertainty" profile for the individual. ${ }^{12-16}$ This investigative approach would suggest that the first step toward improving learners' responses to uncertainty would be identifying "maladaptive phenotypes,"11(p.1201) or perhaps identifying an individual's particular maladaptive "cognitive, emotional and behavioral" responses ${ }^{17(p .70)}$ that are triggered by experiences of uncertainty.

An alternative approach has been to explore how clinicians navigate ill-defined problems in context, expecting that individuals' idiosyncratic reactions to uncertainty will be determined in part by highly contextualized situational factors. ${ }^{18-20}$ Work involving intra-operative observations and reflections from surgeons have, for example, elaborated the ways that expert surgeons "slow down" to think deliberately through complex situations, adapt their plans in response to contextual clues, and purposefully seek advice from colleagues. ${ }^{21,22}$ These types of investigations provide insights for the kinds of approaches and behaviors that might be reinforced in trainees to enable them to effectively navigate uncertain moments specific to their practice, and in this way, help them effectively engage with uncertainty. 
Pursuing this second approach to the study of uncertainty, we have been exploring the concept of 'comfort' as a starting point to understand how clinicians navigate experiences of uncertainty in practice. ${ }^{5,23}$ In this work, we have described clinicians' experiences of uncertainty as arising from two sources-"what is going on?" and "what should I do?"-and conceptualized comfort as one's confidence to manage a situation safely and effectively in these uncertain moments. Reflections from practicing clinicians suggested that they engaged in an appraisal of cognitive, behavioral, and emotional cues gathered from patients, themselves, and the situation to generate a continuous spectrum of comfort and discomfort during experiences of uncertainty. ${ }^{23}$ Although discomfort was not the original focus of the work, it became apparent that participants were expressing discomfort as a sense of tentativeness, an appraisal that particular uncertain situations might 'spin out of control,' evolving in ways that were beyond their abilities to manage safely and effectively. This led us to consider a distinction between this sense of discomfort and the more commonly described notion of distress ${ }^{24}$ which has been defined as a state that arises from a clear determination that one's ability or resources are insufficient to manage a situation.

While it was clear in our previous analysis that this sense of tentativeness did not preclude these clinicians' from engaging with these thorny clinical problems, we did not explicitly examine the ways in which our participants noticed and responded to discomfort arising from uncertainty. In this paper, therefore, we returned to the transcripts of the previous study to explore clinicians' responses to discomfort in settings of uncertainty. We used clinicians' perceptions of these moments to probe how these experiences were manifest cognitively, emotionally and behaviorally, and explore how clinicians leveraged their discomfort to ensure effective patient care despite the inherent uncertainty they were experiencing.

\section{Methods}

This work is part of a larger program of research around how clinicians experience the phenomenon of 'comfort with uncertainty' in practice ${ }^{5,23}$ and is importantly distinct from past 


\section{CHAPTER 4}

work in that our focus here is to explore how clinicians experience, manage, and respond to discomfort in settings of uncertainty. We conducted this study using a constructivist grounded theory (CGT) approach, ${ }^{25}$ a qualitative methodology that uses inductive reasoning to build theory around data generated from complex cognitive and social processes. ${ }^{26}$ Because CGT places value on the subjectivity of investigators as they interact with participants and make meaning from participants' narratives, it is important to note that three study team members are physicians from different clinical fields (J.I., emergency medicine; P.T., obstetrics \& gynecology; J.B., internal medicine), two team members have advanced training in cognitive psychology (A.dB., G.R), and three team members have expertise in qualitative research methods (P.T., J.B., G.R.).

Setting, Population, and Sampling Strategy. Because we were interested in exploring how physicians iteratively manage and respond to moments of discomfort, we hypothesized that clinical work in the emergency department would provide frequent experiences around our phenomenon of interest. Clinicians working in this setting care for patients with a wide variety of complaints and acuity, and make management decisions with limited information about what might be causing patients' symptoms and how these disease processes might respond to initial treatments. We purposefully sampled amongst a cohort of emergency physicians with a spectrum of experience in practice who worked at two resource-rich, urban teaching hospitals because we were interested to see how clinicians used consultative and material resources to manage moments where the clinical problems they faced were at the borders of their idiosyncratic skills and past experiences. Importantly, the principal investigator (J.I.) is a faculty member in the same academic department as these participants and thus was familiar their backgrounds and practice context. Participants were enrolled by targeted emails emphasizing that their participation was voluntary and that their narratives would be anonymized. This investigation was reviewed by the Human Subjects Division at the University of Washington and deemed to meet exempt status. 


\section{CHAPTER 4}

Procedures. The principal investigator conducted hour-long semi-structured interviews with participants over a 4-month period (December 2018 to April 2019) using a critical incident technique ${ }^{27}(\mathrm{CIT})$ to explore their experiences immediately after they finished their clinical shifts. Following a brief introduction to the study purposes, participants were asked to engage in approximately 10 minutes of independent reflection while drawing two pictures: the first concerning a case from their preceding shift that 'made them sweat' (e.g. had aspects that made them feel anxious or concerned) and a second regarding a case that they felt they could handle without the assistance of other physicians. After asking the participants to describe their drawings, we used probing questions to explore their experiences of discomfort in these moments, elaborating the cognitive, emotional, and somatic cues that they identified during these experiences, how they managed and responded to these cues, and how they used resources available to them to act in these moments of uncertainty. We subsequently used a similar set of questions to explore additional cases from their preceding clinical shift that had generated various levels of uncertainty and discomfort. In the tradition of constructivist grounded theory, we specifically sought cases that offered the opportunity to enrich and expand, or challenge and disconfirm, our evolving conceptual framework. Interviews were audio recorded and transcribed for analysis, and we used constant comparative analysis ${ }^{28}$ to develop, refine, and scrutinize emerging theories. We made changes to our interview guide iteratively to enable theoretical sampling of the categories and themes that emerged from the data.

Analysis. Our analysis focused on the transcripts of the interviews rather than the pictures the participants drew. While the drawings were valuable for priming reflections, they were sufficiently sparse that we deemed treating them as a separate data source unreasonable. Two investigators (J.I., J.B.) used Dedoose (SocioCultural Research Consultants, Manhattan Beach, CA) to code transcript data line-by-line, organizing data into focused codes, key conceptual categories, and major themes. Using constant comparison, these analyses were conducted concurrently with data collection. The entire team met regularly to discuss axial and selective coding, identifying relationships between codes and categories, and developing a conceptual 


\section{CHAPTER 4}

framework that reflected possible relationships between themes. The principal investigator conducted a total of 12 interviews. After 10 interviews, the subsequent 2 interviews yielded no additional insights or counterexamples. At that point, we felt that our sample was sufficient for the study purpose. ${ }^{29}$

\section{Results}

We enrolled twelve emergency medicine faculty with a spectrum of clinical experience (2-32 years in practice) who discussed a range of 3-7 cases per interview, for a total of 55 unique clinical cases in the final data set. Participants identified elements of discomfort as part of each of these cases descriptions, and often linked these appraisals of discomfort to cues that alerted them to a problem that was evolving in unexpected ways and/or the possibility that the problem might evolve beyond their ability to manage. In some cases, our participants' descriptions of discomfort were linked to specific risks they were thinking about, from identifying discordant data, to imagining the potential complications of specific illnesses they were considering, to self-assessments of their own skills. In other cases, their discomfort was cued by vague somatic or emotional signals that something was awry, such as a "feeling of noticing that maybe somebody's following you down the street...that something doesn't feel $100 \%$ safe here or $100 \%$ right here" (Participant 1 ).

Discomfort served as a trigger for two over-arching themes of responses. First, participants seemed to invest greater cognitive resources into these moments, monitoring with greater attention, moving forward with more intentionality, and thinking deliberately about the resources they might call upon. Second, participants used their discomfort as a trigger for invoking resources-human resources in particular-to lean on as a way to strategically manage these situations. These themes are discussed in greater detail below.

\section{Discomfort as a trigger for attention and intention}

Our participants' narratives included numerous descriptions of how noting discomfort prompted them to respond in the moment with greater attention and intention. This took the 


\section{CHAPTER 4}

form of the approaches they used to understand a situation and prioritize emergent tasks, as well as the ways that they strategically considered resources in their environment that they could call upon in their efforts to deliver safe and effective care. These subthemes are discussed below.

Perking up. Participants described how their sense of discomfort prompted them to focus their attention on the problem(s) at hand. There was a sense that participants heightened their degree of monitoring during these moments of discomfort, bringing their cognitive resources to bear on a situation in more purposeful ways. Participant 8 described this experience of 'perking up' when caring for a patient whose clinical evolution proceeded in unexpected ways:

"Definitely [the low blood pressure] made me more nervous. A patient who supposedly had been resuscitated and had had an intervention completed that should have worked, but now is showing signs of instability ... It made me wanna make sure that I'm really paying attention to all the parameters and making sure everything's taken care of." (Participant 8)

Stepping back. In directing their attention towards problems that were generating discomfort, participants also seemed to engage in more deliberate problem-solving activities. For example, they drew on well-established algorithms to invoke more strategic and deliberate approaches to information-gathering. These 'tried and tested' approaches seemed to be a calming ritual for participants, enabling them to weather the emotional cues they were noticing in these moments. This, in turn, seemed to enable them to 'step back' and redefine the situation in new ways. Participant 2 described this process in the context of a patient who had sustained major trauma:

That happens classically... when you get a sick trauma patient, and a whole lot of things are going on and multiple things come in that are unexpected and it throws you off. And sometimes you get like, "F\#*k, I'm in the forest! I've got to get out of this forest!" right? And the anxiety can kill you...you buckle...In my limited experience I just go back to my $A B C s$ [airway, breathing, circulation], go back to my primary and secondary survey, 
restart over then. Sometimes you just have to-like the computer-just unplug the power and plug it back in...Sometimes you've just got to say, "Okay, I've got to start fresh here." (Participant 2)

Ensuring that necessary resources are in place. Participants' increased intentionality in thinking about the situation also involved a deliberate consideration of downstream clinical events that might pose risk(s) to their patients, and an associated consideration of the kinds of resources they might need to deal with these situations (both equipment and people). Participants drew frequent linkages between hypothesized risks and the management tools available to them. Some material resources were known entities in these clinicians' work environments (e.g. they knew the typical locations of code carts), and this seemed to provide an implicit sense of comfort that those types of resources could be accessed quickly and easily. In contrast, when participants talked about rarely performed procedures, they described having to more explicitly consider what they might need to put in place and how to access the necessary equipment. Interestingly, this created additional forms of uncertainty that added to, rather than reduced, their sense of discomfort. Participant 7 described this sense of increased discomfort as she thought through how to manage a patient with cirrhosis who presented with a massive upper gastrointestinal hemorrhage:

"When I saw him start vomiting blood, I thought about a Minnesota tube, which I haven't placed in years and certainly didn't know where one was. I was immediately thinking worst case scenario, like "what if?" and...that isn't something you think about much and [it] definitely raises your stress level." (Participant 7)

Participants also described the ways that they viewed other healthcare professionals as resources when thinking through diagnostic and management plans that generated discomfort. They described judgments about the abilities of their emergency department team memberse.g. "I knew that I was working with a resident that I felt that I could trust" (Participant 3)-as well as whether they had faith in the expertise of consultants from other services. When participants sensed that others would be available to help them to effectively tackle a 


\section{CHAPTER 4}

challenging situation, this seemed to mitigate some of their discomfort; the opposite was true when they sensed that their consultative resources were also struggling in these situations. This was particularly evident in our participants' work context when they depended on consultant trainees to act as surrogates for expert supervisors who were providing guidance remotely by phone. For example, while listening to one end of a telephone consultation, Participant 4 had concerns that a resident consultant was not adequately describing the nuances of a situation to an attending physician, and this generated discomfort about the time-sensitive, high-risk treatment that was being considered:

"It's not clear if [the resident] is adequately and completely explaining everything [to the attending]. And I had no knowledge of what the other half of the conversation was...That causes some anxiety, but more like frustration that it feels like it's slowing the process down and injecting uncertainty into, like, how to move forward here."

(Participant 4)

\section{Discomfort as a trigger for leaning on others}

In many instances, participants' discomfort triggered them to actively engage the help of colleagues both within and outside of the emergency department. In some instances, participants used these consultations as a means to 'check' whether their diagnostic or management plans were aligned with how others would approach the same problem (what we have termed 'borrowing comfort'). At other times, they drew from their discomfort to signpost instances when they needed others' input, that is when they needed to 'hand over' problemsor specific aspects of problems-to colleagues.

Borrowing comfort. There were times when participants struggled to prioritize their own hypotheses about the ways that a problem might be interpreted or the multiple management approaches they might take. To enact a plan with greater confidence, they 'borrowed comfort' from others by checking whether their reasoning and management approaches were aligned with how others would think about the problem. Getting reassurance from physician colleagues or from other members of their ED team (e.g. nurses, social workers) in this fashion seemed to 


\section{CHAPTER 4}

proactively buoy participants' comfort that their approaches were defensible in the eyes of others, particularly if risks they were thinking about came to fruition as a problem progressed. Participant 1 described how discussions with colleagues informed the difficult decision to restrain a patient with decompensated mental illness.

"I think I needed to hear from other people that this was okay... I wanted somebody to reassure...I don't necessarily want all the responsibility for this decision. And it is ultimately my decision. I'm responsible. But, I don't know, I just wanted us as a team to own this plan of care." (Participant 1)

Handing over. In other situations, participants interpreted their discomfort as a signal that problems were progressing in ways they could no longer handle independently. They responded to these instances by 'handing over' part of a problem, or the problem in its entirety, relinquishing control of diagnostic and management decisions to others with expertise around the issue that was generating discomfort. Sometimes this involved targeted consultations with colleagues around a specific aspect of a case they needed help with; when asking for help in these instances, participants continued to manage the other aspects of the case that they felt they could handle without assistance. An example of seeking guidance in this focused way was illustrated in an anecdote by Participant 6 who sought help from a hematologist to manage an instance of blast crisis (markedly elevated white blood cell counts beyond the normal values of approximately 8-10 thousand) from chronic myelogenous leukemia while continuing to manage the other aspects of care for a critically ill patient:

"I would say I don't think I know how to handle or treat blast crisis off the cuff...so I recruit[ed] the help of the hematologists...[The patient] had many things going on because he also may have been septic, he was also extremely dehydrated. That would need to be sorted, and that part I can handle. I don't usually treat white cell counts of 600 [thousand] by myself. I don't consider that in the realm of ER." (Participant 6) In other cases, participants described reaching points where they could not think of any further ways to differentiate the problem(s) or identify treatments they felt would be safe and effective. They thus handed the care of these cases over to colleagues with different training or 


\section{CHAPTER 4}

resources (e.g., hospitalists, intensivists, specialists). In handing off these cases, participants often articulated their ongoing sense of discomfort to others, as Participant 5 described during his phone conversation with a colleague who was admitting a critically ill patient to the hospital:

"I have no path. I'm staring over this cliff of my own experience into the great wide unknown. I've got nothing else [I can] do. I need you to show up so that we can either jump off this together or you build me a bridge of some sorts to wherever we're going to go next." (Participant 5)

In asking for help in these ways, participants emphasized the importance of working through problems to a point where they could ask for specific guidance or assistance from their colleagues. This helped them to guide others towards the specific aspects of a problem for which they were seeking support:

"Our job is to help consultants help us help our patients... [it is] how you point them so that they can provide the answer to the question that you're asking" (Participant 10)

\section{White knuckling}

Finally, it is worth noting that participants described rare instances where they experienced strong feelings of discomfort regarding high-risk problems that they would typically have handed off, but where help was not available. Lacking this help, they 'white knuckled' their way through these challenging situations, taking action despite sensing that a problem was at the borders-or outside-of their expertise. These moments typically took place in the context of rapidly evolving situations that required clinicians to intervene quickly, addressing problems that posed imminent risk to their patients. Participant 2 described this experience of being called into action to perform a surgical airway-a rare event, and one he had only performed once previously-and the challenges of performing well under these circumstances.

"In the ER we're asked to do things we rarely do... And we have to. That's part of emergency medicine. We have to do that. There's not any way around that...I thought, "I've got to get it in, and I've got to get a tube in this guy. He's going to lose his brain. 


\section{CHAPTER 4}

He's going to get hypoxic and lose his brain." So I felt like the clock was ticking and...then when I went for it, I felt I had to be fast." (Participant 2)

\section{Discussion}

These results suggest that discomfort may be more central to how physicians manage uncertain clinical experiences than current conceptualizations would imply. Our participants reflected on their discomfort in deliberate ways, describing specific risks they were thinking about at that instant or risks they felt to be sufficiently possible in the future. They also experienced somatic or emotional signals such as fear or apprehension that alerted them to the possibility that clinical problems were evolving in ways that were either risky or at the borders of their expertise. By noticing their discomfort, our participants seemed able to use it as a signal for when they needed to pay greater attention, think through problems more deliberately, or brainstorm how resources in their environment could be used to ensure safe, high quality care. Thus, they were able to 'manage' experiences of uncertainty by monitoring the evolving balance between discomfort and comfort during these moments, continually revisiting and revising their sense of whether their management approaches were working. When discomfort persisted and was appraised to be significant, they pivoted towards new approaches or strategically engaged the help of others.

These findings add to our evolving understanding of discomfort as an important phenomenon in clinical reasoning. Our results suggest that discomfort exists as a liminal state, ${ }^{30}$ an awareness that the problem one is facing is not straightforwardly predictable or manageable. It therefore reflects a sense of "tentativeness" in settings of uncertainty, triggering clinicians to consider that events might evolve in ways that would challenge their capacity to manage safely and effectively. We see this as distinct from the clearly negative state of "distress", ${ }^{24(\text { p. } 526)}$ which represents strong emotional or somatic responses to an explicit recognition that the situation is beyond one's capacity but nonetheless still one's responsibility to manage (i.e. "white knuckling"). This distinction has led us to more fully appreciate the binary construction of the "eustress" and "distress" paradigm, which implies a certainty about whether one can rise to the 


\section{CHAPTER 4}

challenge of an uncertain situation. ${ }^{24}$ Thus, we see discomfort as analogous to a quantum state between eustress and distress, a heightened awareness and recognition that a problem has elements of unpredictability that might lead to a situation that exceeds one's capacity to manage with control and confidence given the available resources in that moment.

The ways in which our participants marshalled additional cognitive resources and proceeded with intentionality around problems generating discomfort aligns with past descriptions of how expert surgeons navigated moments of intraoperative uncertainty. Moulton and colleagues have elaborated the notion of "slowing down when you should" as a description of how expert surgeons shift from automatic to more effortful reasoning when encountering intraoperative complexity. ${ }^{22,31,32}$ Our participants' responses to uncertainty are also reminiscent of what Cristancho and colleagues noted in their observations of expert surgeons who were experiencing intraoperative uncertainty, namely that they actively sought and transformed information into new meaning, ${ }^{33}$ considered risks and alternative approaches, reevaluated and adapted their plans, and sought advice from colleagues when their initial approaches did not seem to improve a situation. ${ }^{21}$ Importantly, our work advances our understanding of how clinicians respond to uncertainty by identifying perceptions of discomfort as a trigger that clinicians used to question and reconsider their understanding of-and approach to-a situation, think deliberately about moments where they might get in over their heads, and strategize how they could enact available resources effectively. Thus, monitoring for-and explicating the sources of-clinicians' discomfort offers a novel means by which investigators can study how clinicians work through ill-defined problems.

These results highlight the importance of investigating physicians' work with ill-defined problems ${ }^{3}$ in situ. Clinicians in our study described approaches that were exploratory, guided by ever-changing metacognitive judgments, and sensitive to the resources (both material and human) that were inherent to their work environment. This stands in stark contrast to traditional problem-solving approaches where solitary clinicians employ Bayesian frameworks to estimate probabilities for well-defined problems with knowable solutions. ${ }^{3}$ These results 


\section{CHAPTER 4}

instead emphasize the iterative, situated nature of reasoning in practice, ${ }^{34}$ particularly how knowledge and expertise are distributed between clinicians ${ }^{35}$ and the strategic ways that clinicians tackle complex problems using their knowledge of resources available in their environments. This aligns with work demonstrating that obstetricians considered organizational affordances when navigating uncertainty around their management of labor in patients who had previously undergone cesarean sections. ${ }^{32}$

If discomfort is an important trigger for how experienced clinicians manage and respond to uncertainty, this also shifts our thinking for how we might more effectively design curricula to prepare trainees for these experiences in practice. Instead of striving to remediate or eliminate the problematic 'phenotypic' responses in trainees, ${ }^{11}$ the focus would instead shift towards more intentionally noticing discomfort, explicating the root cause of this discomfort (when possible), then leveraging that discomfort strategically in the moment. Further, we need to recognize the "cognitive, emotional and behavioral"17(p. 70) responses to uncertainty described by Hillen and colleagues as deeply situated cues that clinicians are noticing in these moments. That is, these responses may not be generic predispositions to uncertainty but rather serve as a means to inform more holistic appraisals to determine whether they can rise to the challenge in front of them. Helping trainees to more intentionally monitor and respond to these metacognitive experiences in the moment may thus be a useful way to prepare them for the idiosyncratic, ill-defined, contextually embedded experiences with uncertainty that they are likely to encounter in practice. ${ }^{36}$

Taken together, we believe that managing uncertainty entails recognizing discomfort as a powerful tool, and that harnessing the cognitive, emotional, and behavioral cues within the confines of a specific moment enables individuals to deliberately increase their attention and intentionality while working towards context-specific responses. Thinking about reasoning in this way also shifts teaching, learning, and assessment practices towards the strategies that clinicians use when asking for help or handing over responsibility when they have persistent discomfort regarding 'what is going on' or 'what they should do.'23 


\section{Limitations}

Our methodological decisions place limitations on our findings and interpretations. First, and most importantly, the narratives from this study were from clinicians who work in two academic emergency departments that were rich with both consultative and material resources. The situated aspects of uncertainty and discomfort described here may thus not be transferrable to different practice settings or to learners with less experience. We would expect that clinicians' responses to discomfort would look quite different in more austere medical settings, and would also expect to see variations in responses within the same healthcare system (e.g. if a patient with the same complaints presented to an outpatient clinic visit). It is further quite likely that novice clinicians experience very different sources of uncertainty, and we might expect that they would respond to their discomfort in ways that are distinct from the experiences described herein. Second, in collecting post-hoc narratives from our participants, we recognize that these data may not fully capture the conscious, subconscious, and situational influences that played into their in-the-moment experiences, and our design precludes any commentary on the quality of care that was delivered or eventual clinical outcomes. ${ }^{34,37,38}$ Conducting these types of interviews in real time or coupling them with direct observations within a clinical environment would likely offer additional nuance to these phenomena. Finally, in exploring uncertainty and discomfort from the vantage point of emergency physicians, our narratives reflect only one side of these resource-utilization conversations. It thus remains unclear whether consultants had a shared understanding of why they were being involved in the care of these patients and their perspectives on the ways that they conceptualized their role in these patient care interactions. If effective clinical reasoning is to be viewed as a shared responsibility within system of care, ${ }^{39,40}$ it would be important to explore the perspectives of team members from multiple health professions and medical specialties as they engaged concurrently around a particular patient's care. 


\section{CHAPTER 4}

\section{Conclusions}

These limitations notwithstanding, this work provides an important step towards explicating the ways in which clinicians use their graded, ever-evolving sense of discomfort as a means to dynamically modulate their responses to uncertainty. In facing ill-defined problems at work, the extent to which clinicians are likely to 'tolerate' uncertainty thus has more to do with the strategies they use to address idiosyncratic and contextually embedded situations than generic predispositions towards uncertainty overall. To be 'tolerant' of uncertainty requires clinicians to embrace their discomfort as a tool that enables them to grapple with the complex situations they face in authentic clinical settings. 


\section{References}

1. Simpkin AL, Schwartzstein RM. Tolerating Uncertainty - The Next Medical Revolution? N Engl J Med. 2016;375:1713-1715.

2. Han PKJ, Klein WMP, Arora NK. Varieties of Uncertainty in Health Care: A Conceptual Taxonomy. Med Decis Making. 2011;31:828-838.

3. Djulbegovic B, Hozo I, Greenland S. Uncertainty in Clinical Medicine. In: Gifford F, Gabbay D, Thagard P, Woods J. Handbook of Philosophy of Science. Vol 16. Amsterdam, NL: North Holland Publishing Co.; 2011, 299-356.

4. Schraw G, Dunkle ME, Bendixen LD. Cognitive processes in well-defined and ill-defined problem solving. Appl Cogn Psychol. 1995;9:523-538.

5. Ilgen JS, Eva KW, de Bruin A, Cook DA, Regehr G. Comfort with uncertainty: reframing our conceptions of how clinicians navigate complex clinical situations. Adv Health Sci Educ Theory Pract. 2019;24:797-809.

6. Cook DA, Durning SJ, Sherbino J, Gruppen LD. Management Reasoning: Implications for Health Professions Educators and a Research Agenda. Acad Med. 2019;94:1310-1316.

7. Ilgen JS, Eva KW, Regehr G. What's in a Label? Is Diagnosis the Start or the End of Clinical Reasoning? J Gen Intern Med. 2016;31:435-437.

8. Cristancho S, Lingard L, Regehr G. From problem solving to problem definition: scrutinizing the complex nature of clinical practice. Perspect Med Educ. 2017;6:54-57.

9. Fargason CAJ, Evans HH, Ashworth CS, Capper SA. The importance of preparing medical students to manage different types of uncertainty. Acad Med. 1997;72:688-692.

10. Luther VP, Crandall SJ. Commentary: Ambiguity and Uncertainty: Neglected Elements of Medical Education Curricula? Acad Med. 2011;86:799-800.

11. White $G$, Williams $S$. The certainty of uncertainty: can we teach a constructive response? Med Educ. 2017;51:1200-1202.

12. Budner S. Intolerance of ambiguity as a personality variable. J Pers. 1962;30:29-50.

13. Gerrity MS, Devellis RF, Earp JA. Physicians Reactions to Uncertainty in Patient Care. A new measure and new insights. Med Care. 1990;28:724-736. 
14. Gerrity MS, White KP, DeVellis RF, Dittus RS. Physicians' reactions to uncertainty: Refining the constructs and scales. Motiv Emot. 1995;19:175-191.

15. Geller G, Tambor ES, Chase GA, Holtzman NA. Measuring physicians' tolerance for ambiguity and its relationship to their reported practices regarding genetic testing. Med Care. 1993;31:989-1001.

16. Carleton RN, Norton MA, Asmundson GJ. Fearing the unknown: a short version of the Intolerance of Uncertainty Scale. J Anxiety Disord. 2007;21:105-117.

17. Hillen MA, Gutheil CM, Strout TD, Smets EMA, Han PKJ. Tolerance of uncertainty: Conceptual analysis, integrative model, and implications for healthcare. Soc Sci Med. 2017;180:62-75.

18. Bowen JL. Educational strategies to promote clinical diagnostic reasoning. N Engl J Med. 2006;355:2217-2225.

19. Eva KW. What every teacher needs to know about clinical reasoning. Med Educ. 2005;39:98-106.

20. Norman GR, Monteiro SD, Sherbino J, Ilgen JS, Schmidt HG, Mamede S. The Causes of Errors in Clinical Reasoning: Cognitive Biases, Knowledge Deficits, and Dual Process Thinking. Acad Med. 2017;92:23-30.

21. Cristancho SM, Apramian T, Vanstone M, Lingard L, Ott M, Novick RJ. Understanding clinical uncertainty: what is going on when experienced surgeons are not sure what to do? Acad Med. 2013;88:1516-1521.

22. Moulton CA, Regehr G, Lingard L, Merritt C, MacRae H. Slowing down to stay out of trouble in the operating room: remaining attentive in automaticity. Acad Med. 2010;85:1571-1577.

23. Ilgen JS, Bowen JL, de Bruin A, Regehr G, Teunissen PW. "I was worried about the patient, but I wasn't feeling worried": How physicians judge their comfort in settings of uncertainty. Acad Med. 2020; 95(11S): S67-S72.

24. LeBlanc VR. The effects of acute stress on performance: implications for health professions education. Acad Med. 2009;84:S25-33. 
25. Charmaz K. Constructing Grounded Theory: A practical guide through qualitative analysis. 2nd ed. London: Sage Publications; 2014.

26. Albert M, Mylopoulos M, Laberge S. Examining grounded theory through the lens of rationalist epistemology. Adv Health Sci Educ Theory Pract. 2018;24:827-837.

27. Flanagan JC. The critical incident technique. Psychol Bull. 1954;51:327-358.

28. Corbin J, Strauss AL. Basics of Qualitative Research: Techniques and Procedures for Developing Grounded Theory. 3rd ed. Los Angeles: Sage; 2008.

29. Malterud K, Siersma VD, Guassora AD. Sample Size in Qualitative Interview Studies: Guided by Information Power. Qual Health Res. 2015;26:1753-1760.

30. Stenner P. Affectivity, Liminality and Psychology Without Foundations. In: Straub P, Sørensen E, Chakkarath P, Rebane G. Cultural Psychology, Aesthetics and Postmodernity. Giessen: Psychosozial Verlag; 2013.

31. Moulton CA, Regehr G, Lingard L, Merritt C, Macrae H. 'Slowing down when you should': initiators and influences of the transition from the routine to the effortful. J Gastrointest Surg. 2010;14:1019-1026.

32. Moulton CA, Regehr G, Mylopoulos M, MacRae HM. Slowing down when you should: a new model of expert judgment. Acad Med. 2007;82:S109-116.

33. Cristancho SM, Apramian $\mathrm{T}$, Vanstone $\mathrm{M}$, et al. Thinking like an expert: surgical decision making as a cyclical process of being aware. Am J Surg. 2016;211:64-69.

34. Durning SJ, Artino AR. Situativity theory: a perspective on how participants and the environment can interact: AMEE Guide no. 52. Med Teach. 2011;33:188-199.

35. Hutchins E. Cognition in the wild. Cambridge: MIT Press; 1995.

36. Kitchener KS. Cognition, metacognition, and epistemic cognition: a three-level model of cognitive processing. Hum Dev. 1983;4:222-232.

37. Norman G. Is the mouth the mirror of the mind? Adv Health Sci Educ Theory Pract. 2018;23:665-669.

38. van der Schaaf M, Bakker A, Ten Cate O. When I say...embodied cognition. Med Educ. 2019;53:219-220. 
39. Pimmer C, Pachler N, Genewein U. Reframing clinical workplace learning using the theory of distributed cognition. Acad Med. 2013;88:1239-1245.

40. Cristancho S. What can we learn from a soft sister? A complementary lens to the systems engineering approach in medical education research. Med Educ. 2014;48:11391141. 


\section{CHAPTER 5}

\section{Skeptical self-regulation: Resident experiences of uncertainty about uncertainty}

Published as:

Ilgen JS, Regehr G, Teunissen PW, Sherbino J, de Bruin ABH. Skeptical self-regulation: Resident experiences of uncertainty about uncertainty. Medical Education. 2021 June; 55(6):749-757.

(C) 2021 John Wiley \& Sons Ltd and The Association for the Study of Medical Education 


\title{
CHAPTER 5
}

\begin{abstract}
Objectives. Managing uncertainty is central to expert practice, yet how novice trainees navigate these moments is likely different than what has been described by experienced clinicians. Exploring trainees' experiences with uncertainty could therefore help explicate the unique cues that they attend to, how they appraise their comfort in these moments, and how they enact responses within the affordances of their training environment.
\end{abstract}

Methods. Informed by constructivist grounded theory, we explored how novice emergency medicine trainees experienced and managed clinical uncertainty in practice. We used a critical incident technique to prompt participants to reflect on experiences with uncertainty immediately following a clinical shift, exploring the cues they attended to and the approaches they used to navigate these moments. Two investigators coded line-by-line using constant comparison, organizing the data into focused codes. The research team discussed the relationships between these codes and developed a set of themes that supported our efforts to theorize about the phenomenon.

Results. We enrolled 13 trainees in their first two years of postgraduate training across two institutions. They expressed uncertainty about the root causes of the patient problems they were facing and the potential management steps to take, but also expressed a pervasive sense of uncertainty about their own abilities and their appraisals of the situation. This, in turn, led to challenges with selecting, interpreting, and using the cues in their environment effectively. Participants invoked several approaches to combat this sense of uncertainty about themselves, rehearsing steps before a clinical encounter, checking their interpretations with others, and implicitly calibrating their appraisals to those of more experienced team members.

Conclusions. Trainees' struggles with the legitimacy of their interpretations impact their experiences with uncertainty. Recognizing these ongoing struggles may enable supervisors and other team members to provide more effective scaffolding, validation, and calibration of clinical judgments and patient management. 


\section{CHAPTER 5}

For experienced clinicians, navigating clinical uncertainty in practice is similar to walking down a familiar dark path. ${ }^{1}$ One may draw upon past experiences to imagine and plan ahead for hazards-such as ducking one's head in anticipation of low-hanging branches-while also remaining attentive to the pitch of the trail or the consistency of the ground underfoot as signals for whether one is on track. In practice, these types of forward planning and monitoring activities enable experienced clinicians to steer clear of trouble even when problems remain poorly defined, ${ }^{2-4}$ gathering clues about the root causes of a situation and concurrently thinking through steps they might try to address and disambiguate these challenging clinical moments. ${ }^{1}$

Traditionally, clinical uncertainty has been conceptualized in a variety of ways, ${ }^{5-14}$ and research has focused on predispositions that may shape how clinicians respond to stimuli at work. ${ }^{15-20}$ Recently, more situationally embedded constructions of uncertainty have focused on the iterative ways that clinicians negotiate problems in authentic practice, ${ }^{4,21-24}$ including how clinicians' real-time appraisals of clinical problems help them to think through what might happen, whether things are on track and what they might do in a given moment. ${ }^{1,25,26}$ It is believed that expert clinicians effectively navigate their way through these planning and monitoring activities by drawing upon their own idiosyncratic past clinical experiences ${ }^{27-29}$ and that these experiences enable them to notice, appraise and respond to cues in their environment with greater nuance. ${ }^{20}$ Koriat's cue utilization framework $^{9,10}$ - developed originally to understand how individuals make judgments about learning-provides a helpful model to understand how both theory-based and situational cues interact in a given moment. ${ }^{30-32}$ In the most recent description of this framework, ${ }^{31}$ theory-based cues involve the application of metacognitive beliefs-such as one's sense that they have successfully managed a similar situation before-to enable clinicians to make reasonable predications about how a situation might evolve. In contrast, situation-based cues emerge from the experience itself. We note that Koriat and colleagues referred to this category as 'experience-based' cues (i.e. cues arising from the experience), however, this term can be easily misinterpreted as representing cues arising from accumulated experience (i.e. theory-based cues). Thus, we have used the term 'situationbased' cues to emphasize that these cues are generated as part of an experience in the 


\section{CHAPTER 5}

moment. ${ }^{1}$ In the clinical context, situation-based cues might include indications such as noticing a dip in a patient's blood pressure, feeling one's own heart racing, or sensing that other members of the care team appear nervous, and provide real-time clues about what might be happening in the moment. Taken together, theory-based cues and situation-based cues inform experienced clinicians' appraisals of their sense of control at a given moment, imagine what might happen as a problem evolves and think about ways that they can respond safely to the situation at hand.

In previous work, we have described how theory-based and situation-based cues informed experienced clinicians' dynamic appraisals of comfort and discomfort under conditions of clinical uncertainty. ${ }^{1,25,26}$ These clinicians drew from past experiences to make predictions about the risks a problem might pose to a patient and used their institutional knowledge to think ahead for the resources they might need to call upon. At the same time, they noticed, interpreted and responded to cues from their patients, from others in their environment, and within themselves to get a sense of whether things seemed to be on track. This required an inherent trust in their own theory-based and situation-based cues, which might have implications for the ways in which novice trainees, who are still working to define their own roles, capabilities and identities within the complex ecosystem of their training environment, ${ }^{33-}$ ${ }^{37}$ might deal with these situations. If past clinical experiences and institutional practices are central to how experts manage uncertainty, how do trainees safely plan ahead and monitor their progress when walking down dark paths that they have never walked down before? The purpose of this study is to explore the experiences of novice trainees as they work through clinical moments that generate uncertainty. We aim to uncover and understand the unique cues that they attend to, how they appraise their level of comfort given the multitude of cues available to them in these moments and how they think about potential responses given their sense of the challenges and affordances in the situation. 


\section{CHAPTER 5}

\section{Method}

This study was designed using a constructivist grounded theory (CGT) approach, a qualitative methodology that is well suited to exploring the cognitive and social processes at the root of complex human phenomena. ${ }^{38}$ Using a CGT approach enabled us to inductively analyze our participants' stories as a means to build interpretive theory, placing value on our investigators' subjective interpretations of what they heard from participants. ${ }^{39}$ Because this subjectivity is a core element of our methodological orientation, it is important to note that three members of the study team are practicing clinicians (JI, PT, JS) and two have backgrounds in cognitive psychology (GR, AdB). These diverse backgrounds enabled members of our group to both individually and collectively reflect upon our own uncertainty experiences as clinicians and researchers during the collection and analysis of these data, which informed our interpretation of the data and construction of the themes.

Conceptual Framework. This study is part of a larger program of research exploring how clinicians appraise their comfort when experiencing uncertainty in authentic clinical settings. In past work with experienced clinicians, we found these appraisals existed on a dynamic spectrum, informed by how clinicians felt able to proactively imagine various possible evolution(s) of a problem, plan ahead for potential treatments and risks, and monitor the situation as it progressed..$^{25}$ When experienced clinicians found themselves in situations that were evolving in unexpected ways, or identified aspects of a problem that were beyond their capabilities, they described how they harnessed their sense of 'discomfort' to monitor with greater attention, proceed more intentionally and call upon resources in their environment to provide support.26 Within these stories, clinicians frequently elaborated how they noticed, monitored and appraised cues from them- selves, their patients and their environment, and we thus found the cue utilization framework ${ }^{30-32}$ to be a particularly helpful way to understand and analyze these experiences of uncertainty. Because the focus of the current work is centered around the unique ways that trainees experience and manage uncertainty in practice, these past results and cue utilization theory served as sensitizing concepts for how we interpreted, organized and understood the accounts from our participants in this study..$^{40,41}$ 
Setting, Population, and Sampling Strategy. We hypothesized that work in the emergency department would provide rich opportunities to explore novice clinicians' experiences with uncertainty. Patients who seek care in this environment frequently present with dynamic, poorly differentiated problems that span a range of acuity and symptoms. We thus felt that trainees caring for patients in this setting could provide stories and reflections that were exemplary for the ways that novices notice, appraise, and respond to cues during experiences with uncertainty. We felt that stories from clinicians who were early on in their specialty training experiences would provide the richest examples of how uncertainty plays out in the minds of novices, and also hypothesized that different training structures might influence our participants' experiences. We thus purposefully sampled amongst a cohort of trainees who were in their first (PGY1) or second (PGY2) postgraduate years at two urban, universityaffiliated emergency medicine training programs, one in the United States (University of Washington) and one in Canada (McMaster University). Because the data collection took place between July and September 2020, all of these trainees were in the first 15 months of their postgraduate training experiences. Although this data collection period overlapped with the period of COVID-19 protocols in both hospitals, this was not a focus of discussion during the interviews. Of note, two investigators (J.I., J.S.) are practicing clinician-educators at these training sites, and are thus well-acquainted with the clinical problems, team dynamics, and organizational structures that impact these trainees' experiences. We identified days when the principal investigator was available to perform interviews and sent emails to trainees who were working 8- or 9- hour shifts in the emergency department during the daytime on these dates (thereby facilitating interviews in the afternoon and early evening hours). These emails emphasized that participation was voluntary, that the transcribed accounts of their experiences would be deidentified prior to analysis, and that these conversations had no connection to their training program. They were provided with a $\$ 50$ gift card for their participation. This study was reviewed and deemed to meet exempt status by the Human Subjects Division at the University of Washington and the Hamilton Integrated Research Ethics Board. 


\section{CHAPTER 5}

Procedures. Using a critical incident technique, ${ }^{42}$ the principal investigator (JI) conducted hourlong semi-structured interviews with participants immediately following a clinical shift. These one-on-one interviews were conducted using a videoconferencing software (Zoom Video Communications, Inc., San Jose, CA) with privacy and security standards designed to ensure the confidentiality of protected health information; no patient names were used during these discussions. After a brief orientation to the interview process, the interviewer employed a drawing exercise borrowed from the rich picture methodology. ${ }^{43,44}$ Participants were asked to reflect independently on two cases that had generated uncertainty during their preceding shift, the first where they felt challenged but able to 'handle' a situation, and the second where a situation 'made them sweat,' where they felt like things were over their head, or where they needed to hand over control of a problem to someone else. Participants were given approximately 10 minutes to reflect and pictorially represent these two scenarios and were then asked to describe these drawings. Probing questions encouraged them to reflect upon the cues that that they had noticed from patients, others in their environment, and themselves as they worked through these situations, as well as what how they responded in the moment. In the remainder of the interview time, the interviewer explored additional experiences of uncertainty that had been generated from interactions with other patients during their preceding (and previous) shifts. The interview guide evolved as the interviews progressed, and consistent with the CGT paradigm, we were particularly alert for cases that expanded, challenged, or disconfirmed our emerging conceptual understanding. ${ }^{38}$ The audio recordings from these interviews were transcribed for analysis.

Analysis. We conducted data analysis and data collection concurrently using constant comparison. We felt that our participants' drawings-while useful for stimulating reflectiondid not provide sufficient detail for independent analysis ${ }^{44}$; we thus focused our analyses entirely on narrative accounts. Transcripts were coded line-by-line by two investigators (JI, AdB) using Dedoose (SocioCultural Research Consultants, Manhattan Beach, CA) and organized into focused codes, conceptual categories, and major themes. The entire research team met regularly to discuss the codes, the relationships between codes and categories, and the 


\section{CHAPTER 5}

interactions between themes that informed our emerging conceptual understanding. We used notes to create an audit trail of our data collection decisions, and kept memos to track our evolving understanding of our data throughout the analytic process. ${ }^{38}$ After nine interviews, the coding framework sufficiently represented the interview data. Finding no counterexamples or additional insights in four subsequent interviews, we felt that our sample was sufficient for the study purpose. ${ }^{45}$

\section{Results}

We interviewed a total of 13 resident participants (nine female) from two emergency medicine training programs (four from McMaster University; nine from the University of Washington). All participants were within the first 15 months of their training programs (5 PGY1; 8 PGY2).

Participants discussed a total of 56 cases with a range of 2-6 cases per interview. Within each of these case discussions, residents described a variety of cues that they were attending to during their experiences with clinical uncertainty, as well as the ways that they appraised their levels of comfort in these moments. They also described unique ways that they were able to manage these experiences of uncertainty within the parameters of their evolving clinical expertise and training ecosystem. While these discussions had certain resonances with the sensitizing concepts identified from our previous work with experienced clinicians (e.g., uncertainty about what might happen and what they might do next), they additionally described uncertainty with regard to their own abilities and their own appraisals of a situation. This in turn led to distortions-relative to the experienced clinicians-in their approach to appraising and managing the situation. These themes are described below.

\section{Uncertainty about their appraisals of the situation.}

As expected, our participants expressed a lack of confidence in their own knowledge and skills, and frequently reflected upon how this impacted their confidence in accurately interpreting a situation. This was exacerbated by instances where trainees felt like they had a problem under control only to learn from others that they had missed important details. These experiences instilled a skepticism about their own judgments of comfort (and discomfort) with the situation. 


\section{CHAPTER 5}

Thus, as trainees processed the spectrum of cues available to them, they frequently questioned whether their appraisals of these situations were legitimate:

"I was like, this seems too easy...I feel like I am on high alert for trying to not miss things. But then again, when you don't know what you don't know, you can't really be on alert for it sometimes, which is like the really scary part." (Participant 12)

Participants reflected on whether their sense of discomfort, was a reflection of their abilities (e.g., a problem caused them to struggle because they lacked sufficient knowledge and experience) or whether the problem itself was inherently complex and difficult (e.g., instances where experienced providers would have discomfort too). This tension was particularly apparent when a problem played out in ways that they had not anticipated, as one participant reflected:

"The first time around when l'd done her history and physical, I'd left the room thinking I was very thorough and I had asked all of my red flag questions. I was confident that it wasn't something scary, which is why I didn't want to get imaging or further tests for the headache. But when the headache got worse, it made me question, you know, did I do a good job in that history? Am I missing something? Was I confident without being entitled to be confident in the job that I had done? Is this patient actually really sick and I'm underestimating how unwell they are? And all of those kinds of thoughts went through my mind. And in that moment, feeling those things, I was kind of like, but what else do I do? Because the first time around I thought I did a great job and I was quite confident in the history that I had taken." (Participant 8)

In trying to figure out whether their discomfort was legitimate or not, participants also wrestled with a cyclical process of questioning whether the root cause of their discomfort stemmed from their own (mis)interpretation of a situation or whether they should be working proactively to help others to see a problem differently. This quandary was particularly apparent when 


\section{CHAPTER 5}

participants' appraisals of a situation differed from those around them, such as when one participant caring for a patient whom he thought had a necrotizing soft tissue infection (NSTI)a problem that the participant had never diagnosed before-described his efforts to convince a general surgery resident that his patient needed an emergent operation:

"This is a Gen Surg PGY3 who like has seen a bunch and was telling me how often he's in the OR debriding [NSTIs]...So I'm like, okay, this person has clearly seen a ton of these, and this is his specialty, his forte. And I was like, I've never seen one. Like I think this is what it looks like [and] if I had to guess, this is exactly how I would describe the situation of an NSTI. But I was like, he knows what he's talking about so how am I gonna, you know, try to say like, "well I've never seen one, but this is bad," you know? So I was definitely like, okay, I guess I'm wrong, but I still kind of felt it in the back of my head, this just looks gnarly." (Participant 12)

\section{Difficulties with selecting, interpreting, and using cues}

When trainees described struggles with their appraisals of a given moment, they also seemed to be struggling with the selection and interpretation of the cues that informed these appraisals. In trying to get a better handle on these moments, they frequently questioned the veracity of the cues they had gathered and concurrently re-engaged in redundant and less strategic approaches to gathering more information. This was illustrated by one participant's experience caring for a complex patient who was short of breath:

"I just felt really scared, like I was like bracing for disaster to happen. Um, and I was like running through you know the ABCS of BLS [basic life support] in my head and just making sure, like have I actually done them all? Like is her airway actually patent? Oh yeah, she was actually just talking to me, okay... And I don't really have a good reason for why she's short of breath. And I, yeah, I felt stuck...It didn't make sense to me, and I felt like I couldn't fall back on the knowledge that I have to take me through that. And I 


\section{CHAPTER 5}

think I was just so like physiologically keyed up from it that I think that I was like having catecholamine block." (Participant 6)

Participants often cited their lack of past experience-either caring for a particular problem or working within new systems of care-as a barrier to comprehending and interpreting the cues they were noticing in a given moment. This was particularly evident to participants when other members of the care team seemed to be interpreting cues quite differently, as was illustrated by one trainee who felt that her patient was experiencing significant pain but was meeting resistance from a nurse who felt that the patient was feigning symptoms in order to receive narcotic medications:

"I want to give this guy something because I can tell he's really uncomfortable, but I don't want to make the nurses uncomfortable. If he is drug seeking, like, I don't want to reward that behavior, but at the same time he has legit findings and like needs surgery and needs help...it bothers me that he so instantly had this target on his back of "this guy's a drug seeker", but again...I'm more inexperienced and like the nurse probably knows better than I do about the drug seeking behavior and... what would be best for him. So, I also want to kind of defer in that sense to her because maybe I'm just not recognizing it when to everyone else it's really obvious." (Participant 10)

These uncertainties about their own abilities and judgement led to their selection and use of cues to appraise how comfortable they should be (in addition to how comfortable they were). For example, in addition to cues from the patient such as noticing a patient's general appearance, they also described gauging whether patients seemed to trust them in their roles as physicians. Further, in addition to judging their own internal cues, such as noting that their goggles were fogging up as they struggled through a challenging procedure, they also described noting cues from others in their environment, such as whether nurses seemed to share their concerns about patients they were worried about. 


\section{CHAPTER 5}

\section{Influences on their responses to the uncertainty of the situation}

Our participants' persistent sense of skepticism about their interpretations of cues and their appraisals of a situation seemed to influence how they strategically planned ahead and monitored a situation. They engaged in efforts to give themselves the best chance of gathering data that would be most useful to them, checked their interpretation of cues against the interpretations of those around them, and calibrated their appraisals of a situation based upon the behaviors of others. These responses are described below.

Mental Rehearsals. In thinking through how they might approach problems with which they had limited or no prior experience, participants described 'mental rehearsals' of what they might ask their patients and what they might look for before entering a patient's room. This seemed to be both a calming ritual and a way for them to set themselves up for a successful encounter. One participant, in the context of restarting clinical experiences after a long period without patient contact due to the COVID-19 pandemic reflected,

"This is only my fifth shift back. So...before I went into the room I was like, okay, what do I remember about abdominal pain? What are like the big things that I have to look out for? What are my big concerns? And I like to build up my differential, so I had on my differential like 10-15 things that, like, I have to cross out, and most common and interesting things that I need to check for. OK, I can actually do this. I remember how to do this." (Participant 4)

Cross-checking. To combat their nagging uncertainty about how they interpreted cues, our participants cross-checked their confidence in their own judgments by putting their real-time interpretations side-by-side with the judgments of others around them. This provided explicit checks around specific cues and seemed to build confidence around their own interpretations. This phenomenon was illustrated by a first-year trainee who had asked a senior resident to look at a chest $\mathrm{x}$-ray that she thought had findings consistent with pneumonia: 


\section{CHAPTER 5}

"I think having the senior agree like, "hey that does look abnormal," solidified, you know, the confidence I was having previously about "yeah I can handle this," that this is within my grasp, that the experiences that I've had before helped me make decisions in this scenario. I think that was probably an experience in the future that will help me be more confident in calling things like that too." (Participant 8)

Drafting. Participants monitored the behaviors of others-particularly their supervisors-for more holistic appraisals about whether they were in control of a situation. Akin to how bicyclists intentionally trail riders in front of them to improve their aerodynamics, trainees 'drafted' behind others around them, relying on the appraisals of those others to determine whether they were still able to effectively control the situation. Sometimes this took the form of an absence of redirection, such as one participant feeling tentatively sure that she had managed a situation adequately "because my attending didn't correct me?" (Participant 1). In other cases, participants observed their supervisors' affective reactions to get a sense of whether things were going well, as described by another participant:

"I think that maybe if [the supervisor] had reacted differently, like if he would have seemed more anxious, I definitely would have been anxious. But he was very chill, and I do think that affects the way that I react wholeheartedly. So yeah, the way he was behaving made me feel more comfortable." (Participant 3)

\section{Discussion}

This study offers important insights into the ways in which clinical uncertainty is experienced by novice trainees. While these developing clinicians used similar mechanisms to wade into moments of uncertainty as those used by more experienced physicians-projecting forward to try to predict how a problem might play out, and monitoring cues in the moment to make sure that they were staying on track ${ }^{25,26}$ - these processes were colored by a persistent and nagging sense that they should be skeptical of their own appraisals in these moments. This inherent uncertainty about their own judgments changed how our participants identified, attended to, 


\section{CHAPTER 5}

and understood cues in their environment, triggering a cyclical process where this skepticism about themselves led them to question the veracity of the cues that they had collected and whether they were appropriately filtering the multitude of cues available to them. To move ahead in these moments of uncertainty, our participants rehearsed their approaches to set themselves up for success, relied on others in their environment to verify their interpretations of cues, and attended carefully to implicit signals from others' behaviors to recalibrate their own appraisals.

These reactions to uncertainty amongst trainees are reminiscent of Renee Fox's groundbreaking work on the medical students' experiences with uncertainty, namely that they are "less sure than a mature clinician about where to draw the line between [their] own limitations and those of medical science." $\left.{ }^{\prime(p g .215}\right)$ They also illustrate important and understandable differences in the ways that novice clinicians and their more experienced team members' approach these moments. Because these trainees were unable to draw from past experiences to have a clear sense of 'what is going on' and 'what they might do' for a given situation, ${ }^{16}$ their acts of forward planning were intriguingly distorted. Acts of mental rehearsal before they began a clinical encounter seemed to provide scaffolding for them to engage with situations strategically, concurrently building confidence that they were up to the task. This starkly contrasts with reflections from more experienced clinicians where forward planning was much more about anticipating patient-specific risks at play in a given situation, putting resources in place to preemptively steer clear of trouble, and setting boundary conditions for when they need to engage the help of others. ${ }^{25}$ Our novice participants seemed to make attempts to do these more advanced forms of forward planning, but remained skeptical of their own abilities to predict what might happen, what they should be worried about, and whether to invoke the resources available to them in these moments.

The ways in which our participants monitored these dynamic experiences of uncertainty were also importantly distinct from what has been described amongst experienced clinicians. ${ }^{25,26}$ Experienced clinicians-equipped with a bounty of past experience and a greater sense of trust 


\section{CHAPTER 5}

in their abilities to accurately collect the right cues from a situation-seem much more equipped to recognize and filter the typical and atypical aspects of a situation, revise their appraisals accordingly, and make new plans for what to look for thereafter. ${ }^{4,21-26}$ Similarly, our novice trainees attended to theory-based cues based upon their limited past experiences and book knowledge of particular problems, and noticed situational cues from patients, their environment, and themselves as they worked through these evolving situations. But because they expressed uncertainty in their own abilities to accurately collect, filter, and sort their theory- and situation-based cues, they made more deliberate efforts to 'cross-check' their initial impressions or 'draft' off of the behaviors of others to overcome their persistent sense of uncertainty about interpretations and appraisals. While their approaches are logical responses to combat uncertainty about oneself and one's abilities, these types of trainee behaviors may be interpreted by supervisors as 'hesitation'46 or an 'intolerance' of uncertainty. ${ }^{47,48}$ It is further possible that instances where supervisors believe that trainees "plough through" moments of uncertainty with brazen disregard of details ${ }^{24}$ may instead reflect trainees' inherent uncertainty about which cues they should attend to in a given moment rather than a failure to notice the cues altogether.

Our participants expressed uncertainty in the legitimacy of their situational appraisals also highlights the challenge of asking novice trainees to self-regulate in moments of uncertainty. ${ }^{49-}$ ${ }^{51}$ For example, their narratives - particularly those from the first-year residents-described strong feelings of fear and anxiety in the moment as signals for when they may be getting over their head, with reactions similar to those described in other settings. ${ }^{52,53}$ Lacking guidance from others, our trainees seemed to struggle with whether these emotions were situational (e.g. signs that they should engage in adaptive behaviors to manage these moments akin to their supervisors) or personal (e.g. that these struggles were a natural part of their ongoing learning). As a result, they described experiences of distress as a manifestation of perceived misalignment between self and situation. ${ }^{54,55}$ These experiences of distress could signpost instances where shared regulation ${ }^{56(p .272)}$ between trainees and their supervisors is necessary. ${ }^{57,58}$ Vermunt and Verloop have described 'constructive frictions' as situations in 


\section{CHAPTER 5}

which learners are unable to take full advantage of a learning activity independently but are able to do so with the guidance of an expert. ${ }^{56}$ This aligns with Vygotsky's notion of a 'zone of proximal development ${ }^{\prime 59,60}$ - the cognitive space that exists between a learner's current developmental level and the level that they perceive to be possible to attain with assistance. Our participants' efforts of 'cross-checking' and 'drafting' may thus serve as signals for novices and their supervisors alike for these opportunities of constructive friction which, if managed well, could provide a path towards greater trainee self-regulation and enhanced supervisory entrustment.

Taken together, the struggles illustrated by our participants raise important questions about how supervisors can best support trainees during moments of uncertainty, aiming for the sweet spot of trainees' zones of proximal development while concurrently maintaining patient safety. For example, how can supervisors help trainees distinguish situations where anxiety is developmentally appropriate (e.g., a signal that they are being challenged but maintaining safety) from situations where they appropriately interpret these warning signals as triggers to engage the help of others or hand over a problem? If trainees perceive a mismatch between their interpretations of a situation and the interpretations of others on their care team, how can supervisors support trainees' growth into approachable, altruistic, and effective leaders within their training environment? And finally, how can supervisors support trainees' growth towards independent practice, gathering and filtering cues towards judgments that they can trust and respond to in ways that are similar to those exhibited by experienced clinicians? These questions warrant further exploration as a means to clarify for how members of the healthcare team can more effectively verify, validate, and calibrate novice trainees' clinical judgments.

\section{Limitations}

These results and interpretations should be placed within context of our methodological decisions. First, while the situated aspects of our principal investigator's role as an emergency medicine clinician educator enabled exploration and interpretations of situations germane to 


\section{CHAPTER 5}

supervised work in this clinical setting, it is possible that our participants were reticent to fully elaborate their experiences with this faculty member. The narratives were very similar between participants at both training sites, and they shared many stories that reflected strong emotions and uncertainty in the moment-supporting the assumption that this impact was minimal-but this may have skewed participants' responses towards stories that protected their self-image. Second, experiences with uncertainty are likely to be contextually embedded, ${ }^{61}$ and these trainees' experiences at urban, university-affiliated emergency departments may differ from work in other settings. We would hypothesize that more longitudinal care experiences with patients might change how clinicians approach moments of uncertainty, as would care in more resource-limited settings. Third, in collecting retrospective accounts of these clinicians' experiences with uncertainty immediately following their shifts, it is possible that additional conscious, subconscious, and contextual factors impacted these moments, ${ }^{62}$ or that our participants' post-hoc reflections were biased towards hindsight or availability. ${ }^{63,64}$ As a result, our data do not allow us to speculate on the frequency with which these experiences are problematic for trainees. Fourth, because this study took place during the coronavirus disease 2019 (COVID-19) pandemic, it is possible that these conditions added other layers of uncertainty to these participants' practice experiences. Yet it is notable that none of our participants explicitly noted these conditions and we did not explore them further; as such, the influences of the pandemic on these results remain unclear. Finally, lacking the benefit of direct observation or clinical data, our study design does not permit commentary on the quality of care, team leadership, resource utilization, or decision-making that was enacted by our participants in these moments with uncertainty.

\section{Conclusions}

Our study offers important insights into the ways that novice clinicians experience uncertainty in practice. Recognizing that trainees are struggling with the legitimacy of their interpretations offers new ways for other members of the healthcare team to think about their roles as support systems for verification, validation, and calibration of clinical judgments. Doing so will help 
CHAPTER 5

trainees to more effectively collect, filter, and interpret the cues they experience during these complex moments of uncertainty. 


\section{CHAPTER 5}

\section{References}

1. Ilgen JS, Eva KW, de Bruin A, Cook DA, Regehr G. Comfort with uncertainty: reframing our conceptions of how clinicians navigate complex clinical situations. Adv Health Sci Educ Theory Pract. 2019;24:797-809.

2. Cristancho S, Lingard L, Forbes T, Ott M, Novick R. Putting the puzzle together: the role of 'problem definition' in complex clinical judgement. Med Educ. 2017;51:207-214.

3. Cristancho S, Lingard L, Regehr G. From problem solving to problem definition: scrutinizing the complex nature of clinical practice. Perspect Med Educ. 2017;6:54-57.

4. Moulton CA, Regehr G, Lingard L, Merritt C, MacRae H. Slowing down to stay out of trouble in the operating room: remaining attentive in automaticity. Acad Med. 2010;85:1571-1577.

5. Atkinson P. Training for certainty. Soc Sci Med. 1984;19:949-956.

6. Babrow AS, Kasch CR, Ford LA. The many meanings of uncertainty in illness: toward a systematic accounting. Health Commun. 1998;10:1-23.

7. Djulbegovic B, Hozo I, Greenland S. Uncertainty in Clinical Medicine. In: Gifford F, Gabbay D, Thagard P, Woods J. Handbook of Philosophy of Science. Vol 16. Amsterdam, NL: North Holland Publishing Co.; 2011, 299-356.

8. Fox R. Training for uncertainty. In: Merton RK, Reader G, Kendall PL (Eds.). The student physician. Cambridge: Harvard University Press; 1957, 207-241.

9. Light D. Uncertainty and Control in Professional Training. J Health Soc Behav. 1979;20:310-322.

10. Lipshitz R, Strauss O. Coping with Uncertainty: A Naturalistic Decision-Making Analysis. Organ Behav Hum Perform. 1997;69:149-163.

11. Schraw G, Dunkle ME, Bendixen LD. Cognitive processes in well-defined and ill-defined problem solving. Appl Cogn Psychol. 1995;9:523-538.

12. Schwartz S, Griffin T. Medical thinking: The psychology of medical judgment and decision making. New York: Springer-Verlag; 1986.

13. Simpkin AL, Schwartzstein RM. Tolerating Uncertainty - The Next Medical Revolution? N Engl J Med. 2016;375:1713-1715. 


\section{CHAPTER 5}

14. Simpson DE, Dalgaard KA, O'Brien DK. Student and faculty assumptions about the nature of uncertainty in medicine. J Fam Pract. 1986;23:468-472.

15. Budner S. Intolerance of ambiguity as a personality variable. J Pers. 1962;30:29-50.

16. Carleton RN, Norton MA, Asmundson GJ. Fearing the unknown: a short version of the Intolerance of Uncertainty Scale. J Anxiety Disord. 2007;21:105-117.

17. Geller G. Tolerance for ambiguity: an ethics-based criterion for medical student selection. Acad Med. 2013;88:581-584.

18. Gerrity MS, Devellis RF, Earp JA. Physicians Reactions to Uncertainty in Patient Care. A new measure and new insights. Med Care. 1990;28:724-736.

19. Gerrity MS, White KP, DeVellis RF, Dittus RS. Physicians' reactions to uncertainty: Refining the constructs and scales. Motiv Emot. 1995;19:175-191.

20 Hillen MA, Gutheil CM, Strout TD, Smets EMA, Han PKJ. Tolerance of uncertainty: Conceptual analysis, integrative model, and implications for healthcare. Soc Sci Med. 2017;180:62-75.

21. Cristancho SM, Apramian T, Vanstone M, Lingard L, Ott M, Novick RJ. Understanding clinical uncertainty: what is going on when experienced surgeons are not sure what to do? Acad Med. 2013;88:1516-1521.

22. Cristancho SM, Apramian $T$, Vanstone $M$, et al. Thinking like an expert: surgical decision making as a cyclical process of being aware. Am J Surg. 2016;211:64-69.

23. Cristancho $S M$, Vanstone $M$, Lingard $L$, LeBel ME, Ott $M$. When surgeons face intraoperative challenges: a naturalistic model of surgical decision making. Am J Surg. 2013;205:156-162.

24. Moulton CA, Regehr G, Lingard L, Merritt C, Macrae H. 'Slowing down when you should': initiators and influences of the transition from the routine to the effortful. J Gastrointest Surg. 2010;14:1019-1026.

25. Ilgen JS, Bowen JL, de Bruin ABH, Regehr G, Teunissen P. "I Was Worried About the Patient, But I Wasn't Feeling Worried": How Physicians Judge Their Comfort in Settings of Uncertainty. Acad Med. 2020;95:S67-S72. 


\section{CHAPTER 5}

26. Ilgen JS, Teunissen PW, de Bruin ABH, Bowen JL, Regehr G. Warning bells: How clinicians leverage their discomfort to manage moments of uncertainty. Med Educ. 2021;55:233241.

27. Bowen JL. Educational strategies to promote clinical diagnostic reasoning. N Engl J Med. 2006;355:2217-2225.

28. Eva KW. What every teacher needs to know about clinical reasoning. Med Educ. 2005;39:98-106.

29. Norman G, Young M, Brooks L. Non-analytical models of clinical reasoning: the role of experience. Med Educ. 2007;41:1140-1145.

30. Koriat A. Monitoring one's own knowledge during study: A cue-utilization approach to judgments of learning. J Exp Psychol Gen. 1997;126:349-370.

31. Koriat A, Bjork RA, Sheffer L, Bar SK. Predicting one's own forgetting: the role of experience-based and theory-based processes. J Exp Psychol Gen. 2005;133:643-656.

32. de Bruin A, Dunlosky J, Cavalcanti R. Monitoring and Regulation of Learning in Medical Education: The Need for Predictive Cues. Med Educ. 2017;51:575-584.

33. Jarvis-Selinger S, Pratt DD, Regehr G. Competency is not enough: integrating identity formation into the medical education discourse. Acad Med. 2012;87:1185-1190.

34. Norman G. Research in clinical reasoning: past history and current trends. Med Educ. 2005;39:418-427.

35. Cruess RL, Cruess SR, Boudreau JD, Snell L, Steinert Y. A schematic representation of the professional identity formation and socialization of medical students and residents: a guide for medical educators. Acad Med. 2015;90:718-725.

36. Monrouxe LV. Identity, identification and medical education: why should we care? Med Educ. 2010;44:40-49.

37. Teunissen PW. Experience, trajectories, and reifications: an emerging framework of practice-based learning in healthcare workplaces. Adv Health Sci Educ Theory Pract. 2015;20:843-856.

38. Charmaz K. Constructing Grounded Theory: A practical guide through qualitative analysis. 2nd ed. London: Sage Publications; 2014. 


\section{CHAPTER 5}

39. Albert M, Mylopoulos M, Laberge S. Examining grounded theory through the lens of rationalist epistemology. Adv Health Sci Educ Theory Pract. 2018;24:827-837.

40. Glaser BG. Theoretical sensitivity : advances in the methodology of grounded theory. Mill Valley: Sociology Press; 1978.

41. Bowen GA. Grounded Theory and Sensitizing Concepts. Int. J. Qual. Methods. 2006;5:1223.

42. Flanagan JC. The critical incident technique. Psychol Bull. 1954;51:327-358.

43. Cristancho $S$, Bidinosti S, Lingard L, Novick R, Ott M, Forbes $T$. Seeing in different ways: introducing "rich pictures" in the study of expert judgment. Qual Health Res. 2015;25:713-725.

44. Cristancho SM, Helmich E. Rich pictures: a companion method for qualitative research in medical education. Med Educ. 2019;53:916-924.

45. Malterud K, Siersma VD, Guassora AD. Sample Size in Qualitative Interview Studies: Guided by Information Power. Qual Health Res. 2015;26:1753-1760.

46. Ott M, Schwartz A, Goldszmidt M, Bordage G, Lingard L. Resident hesitation in the operating room: does uncertainty equal incompetence? Med Educ. 2018;52:851-860.

47. White $\mathrm{G}$, Williams S. The certainty of uncertainty: can we teach a constructive response? Med Educ. 2017;51:1200-1202.

48. Geller G, Tambor ES, Chase GA, Holtzman NA. Measuring physicians' tolerance for ambiguity and its relationship to their reported practices regarding genetic testing. Med Care. 1993;31:989-1001.

49. Eva KW, Regehr G. Exploring the divergence between self-assessment and selfmonitoring. Adv Health Sci Educ Theory Pract. 2011;16:311-329.

50. Brydges R, Butler D. A reflective analysis of medical education research on selfregulation in learning and practice. Med Educ. 2012;46:71-79.

51. Hautz WE, Schubert S, Schauber SK, et al. Accuracy of self-monitoring: does experience, ability or case difficulty matter? Med Educ. 2019;53:735-744.

52. Helmich E, Diachun L, Joseph R, et al. 'Oh my God, I can't handle this!': trainees' emotional responses to complex situations. Med Educ. 2018;52:206-215. 
53. Groot F, Jonker G, Rinia M, Ten Cate O, Hoff RG. Simulation at the Frontier of the Zone of Proximal Development: A Test in Acute Care for Inexperienced Learners. Acad Med. 2020;95:1098-1105.

54. LeBlanc VR. The effects of acute stress on performance: implications for health professions education. Acad Med. 2009;84:S25-33.

55. LeBlanc VR, McConnell MM, Monteiro SD. Predictable chaos: a review of the effects of emotions on attention, memory and decision making. Adv Health Sci Educ Theory Pract. 2015;20:265-282.

56. Vermunt JD, Verloop N. Congruence and friction between learning and teaching. Learn Instr. 1999;9:257-280.

57. ten Cate O. Entrustability of professional activities and competency-based training. Med Educ. 2005;39:1176-1177.

58. ten Cate $\mathrm{O}$, Hart D, Ankel F, et al. Entrustment Decision Making in Clinical Training. Acad Med. 2016;91:191-198.

59. Chaiklin S. The Zone of Proximal Development in Vygotsky's Analysis of Learning and Instruction. In: Kozulin A, Gindis B, Miller SM, Ageyev VS. Vygotsky's Educational Theory in Cultural Context. Cambridge: Cambridge University Press; 2003.

60. Vygotsky LS. Mind in Society: The Development of Higher Psychological Processes. Cambridge: Harvard University Press; 1978.

61. Durning SJ, Artino AR. Situativity theory: a perspective on how participants and the environment can interact: AMEE Guide no. 52. Med Teach. 2011;33:188-199.

62. Norman G. Is the mouth the mirror of the mind? Adv Health Sci Educ Theory Pract. 2018;23:665-669.

63. Wears RL, Nemeth CP. Replacing hindsight with insight: toward better understanding of diagnostic failures. Ann Emerg Med. 2007;49:206-209.

64. Croskerry P. The importance of cognitive errors in diagnosis and strategies to minimize them. Acad Med. 2003;78:775-780. 


\section{CHAPTER 6}

\section{Supported independence: The role of supervision to help trainees manage uncertainty}

Published as:

Ilgen JS, de Bruin ABH, Teunissen PW, Sherbino J, Regehr G. Supported independence: The role of supervision in helping trainees manage uncertainty. Academic Medicine. 2021 November; 96(11): S81-S86.

(C) 2021 the Association of American Medical Colleges 


\title{
CHAPTER 6
}

\begin{abstract}
Purpose. Safe and effective supervised practice requires a negotiated partnership between trainees and their supervisors. Substantial work has explored how supervisors make judgments about trainees' readiness to safely engage in critical professional activities, yet less is known about how trainees leverage the support of supervisors when they perceive themselves to be at the limits of their abilities. The purpose of this study is to explore how trainees use supervisory support to navigate experiences of clinical uncertainty.
\end{abstract}

Method. Using a constructivist grounded theory approach, the authors explored how novice emergency medicine trainees conceptualized the role of their supervisors during experiences of clinical uncertainty. They employed a critical incident technique to elicit stories from participants immediately following clinical shifts between July and September 2020, and asked participants to describe their experiences of uncertainty within the context of supervised practice. Using constant comparison, two investigators coded line-by-line and organized these stories into focused codes. The relationships between these codes were discussed by the research team, and this enabled them to theorize about the relationships between the emergent themes.

Results. Participants reported a strong desire for supported independence, where predictable and accessible supervisory structures enabled them to work semi-autonomously through challenging clinical situations. They described a process of borrowing their supervisors' comfort during moments of uncertainty and mechanisms to strategically broadcast their evolving understanding of a situation to implicitly invoke (the right level of) support from their supervisors. They also highlighted challenges they faced when they felt insufficiently supported.

Conclusions. By borrowing comfort from-or deliberately projecting their thinking tosupervisors, trainees aimed to strike the appropriate balance between independence for the purposes of learning and support to ensure safety. Understanding these strategic efforts could help educators to better support trainees in their growth towards self-regulation. 


\section{CHAPTER 6}

Trainees face a multitude of conflicting identities and paradoxes in the clinical workplace. ${ }^{1}$ They are expected to "learn by doing"2(pg. 763) and learn from mistakes ${ }^{3,4}$ while simultaneously engaging in practices that ensure patient safety..$^{5-7}$ They are expected to function semi-autonomously, while simultaneously aligning with the idiosyncratic expectations of their supervisors and other health professionals in their training ecosystem. ${ }^{7-10}$ And they are expected to assume responsibility for patient care while often being the least experienced member of a healthcare team. Supervisors ultimately face the challenging task of helping trainees balance these competing tensions of experiential learning, patient safety, and professional identity formation. ${ }^{11}$

The notion of entrustment figures heavily into current constructions of how supervisors can provide graduated independence to trainees, ${ }^{12,13}$ and substantial work has explored how supervisors make judgments about trainees' readiness to safely engage in critical professional activities. . $, 6,8,10,14-17$ One concept that appears central to supervisors' trustworthiness judgments is discernment, the notion trainees have the capacity to identify the limits of their knowledge and skills. ${ }^{18(\mathrm{pg} .}$. 590) If such discernment is possible, trainees could engage supervisors strategically when they need them most, signposting the borders of their cognitive space where - in the language of Vygotsky's 'zone of proximal development' ${ }^{19}$ - what they felt capable doing independently could be stretched towards new capabilities in conjunction with others' assistance..$^{20}$

Yet, in past work exploring trainees' in-the-moment experiences with uncertainty in clinical practice, ${ }^{21}$ we found that trainees expressed a pervasive distrust in their own acts of discernment. As they experienced uncertainty about how to make sense of and handle complex clinical cases, they also questioned whether this uncertainty was justified. This led them to question whether, in situations when they felt over their head, their discomfort represented expected experiences of learning or heralded threats to patient safety. ${ }^{21}$ To cope with these difficult moments, trainees relied on cues from others in their environment, particularly their supervisors, to get a sense whether a situation was adequately under control. This raises 


\section{CHAPTER 6}

interesting questions about how trainees understand the role of supervisors in supporting them when they perceive themselves to be at the limits of their abilities, and how they can effectively leverage supervisory support when it is felt to be necessary. Therefore, the purpose of this study is to explore how supervision impacts trainees' experiences with uncertainty, and how trainees perceive and balance the competing tensions of clinical independence, supervisory support, and patient safety.

\section{Methods}

We used a constructivist grounded theory (CGT) approach for this study, ${ }^{22}$ a qualitative methodology that uses inductive analyses to understand complex social and cognitive processes. Subjectivity is a central and valued component of the CGT orientation, ${ }^{23}$ and we deliberately assembled a team of investigators with varied professional backgrounds to ensure a diversity of interpretations. Three members of the study team are clinicians who supervise trainees (J.I., P.T., J.S.) - each in unique practice environments in three different countries-and two of these investigators (J.I., J.S.) supervise trainees in the environments described in this dataset. The two remaining team members (A.dB., G.R.) have training in cognitive psychology. Throughout the data collection and analytic processes, our team individually and collectively reflected upon the ways that our past experiences impacted how we made meaning from our participants' narratives.

\section{Conceptual framework}

This study was conducted as part of a larger program of research exploring physicians' experiences with uncertainty in clinical practice. ${ }^{21,24-26}$ In past work, we found that clinicians used dynamic appraisals of comfort and discomfort in settings of uncertainty as a mechanism to understand, make predictions about, and monitor evolving clinical problems. ${ }^{24,26}$ Yet when we explored this phenomenon in trainees, we found that their experiences were confounded by an inherent distrust in the legitimacy of their own such appraisals, leading these clinicians to rely on the implicit behaviors of others in their clinical environment as a means to make sure that they were on track. ${ }^{21}$ This led us to consider the unique ways that Vygotsky's zone of proximal 


\section{CHAPTER 6}

development ${ }^{19}$ might help us to understand what is happening in the minds of trainees as they engage in workplace learning that is at the borders of their abilities. Further, it led us to wonder about how notions such as 'shared regulation' - "situations in which students are unable to use a certain learning activity independently but are able to do so with the guidance of an expert"20(p.272) - might manifest as trainees interact with supervisors during these moments. Our past results and their relation to these theories thus served as sensitizing concepts for how we understood and analyzed data in the current study. ${ }^{27,28}$

\section{Population, setting, and sampling strategy}

We enrolled first (PGY1) or second (PGY2) post graduate year emergency medicine trainees at McMaster University and the University of Washington. We purposefully sampled within this cohort of early trainees because their daily work was likely to be filled with uncertainty. In these two urban centers, junior residents cared for patients with a wide variety of acute, poorly differentiated medical problems. Further, in the relatively flat hierarchy of these training programs, junior residents are expected to interact directly with their supervisors to support safe and effective practice. Moreover, these trainees interact with a large number of clinical supervisors. We sampled across two training sites in Canada and the United States to see if training structures and institutional practices might instill important variance in these traineesupervisor interactions. Of note, two members of the study team (J.I., J.S.) are practicing emergency physicians at these institutions, familiar with the training structures and practice settings. We enrolled participants between July and September 2020 using targeted emails that emphasized that their narratives would be deidentified prior to analysis and that their participation would have no bearing on their standing in their training program. Participants were reimbursed for their time with a $\$ 50$ gift card. This study was reviewed and deemed to meet exempt status by the Hamilton Integrated Research Ethics Board and the Human Subjects Division at the University of Washington. 


\section{CHAPTER 6}

\section{Procedures}

The principal investigator (J.I.) interviewed participants immediately following a clinical shift and used a critical incident technique ${ }^{29}$ to elicit stories that were illustrative of experiences of uncertainty within the confines of supervised practice. These hour-long, semi-structured, oneon-one interviews were performed via videoconferencing software (Zoom Video Communications, Inc., San Jose, CA), with settings that safeguarded the confidentiality of protected health information. Participants were given a brief orientation to the study and then asked to reflect independently on two scenarios from the preceding shift: a) an instance where they felt challenged but able to 'handle' a situation; and b) a situation that 'made [them] sweat', when a problem felt over their head, or when they needed to relinquish control of a problem to someone else. Borrowing from the rich picture methodology, ${ }^{30,31}$ we gave participants approximately 10 minutes to draw pictorial representations of these situations, then asked them to describe these scenarios in the context of their drawings. We used probing questions to explore participants' uncertainties, how they appraised their comfort and discomfort, and how they perceived the role of their supervisors during these challenging moments. We used the remaining interview time to elucidate similar experiences during the prior and preceding shifts. Audio recordings were transcribed for analysis. We adapted our interview guide as the interviews progressed so as to gather data relevant to our evolving categories and themes, and consistent with the CGT methodology ${ }^{22}$ we were particularly attentive for instances that disconfirmed or challenged the concepts that emerged from our participants' narratives.

\section{Analysis}

Data collection and data analysis were performed concurrently using constant comparison. ${ }^{32}$ While the drawing exercise was a useful means to stimulate participants to reflect upon important dimensions of their preceding clinical shift, the pictures themselves did not provide sufficient richness for independent analysis; ${ }^{31}$ our analyses therefore focused entirely on the narrative reflections from our participants. Two investigators (J.I., A.dB.) used Dedoose (SocioCultural Research Consultants, Manhattan Beach, CA) to code the transcripts line-by-line, 


\section{CHAPTER 6}

organizing data into focused codes, conceptual categories, and major themes. Our team of investigators met regularly to discuss the codes and categories as well as the interactions between the themes that emerged from the data. We kept notes of our data collection decisions to create an audit trail and used the memoing function within Dedoose throughout the analytic process to keep track of our evolving understanding of the data. ${ }^{22}$ We found that our coding framework sufficiently represented our participants' stories and reflections after nine interviews. We subsequently completed 4 additional interviews, and in finding no counterexamples or novel insights from these narratives, deemed our sample to be sufficient for the study purpose. ${ }^{33}$

\section{Results}

We enrolled 13 participants (9 female) with a mix of early clinical experience (5 PGY1, 8 PGY2) from two emergency medicine training programs (4 from McMaster University, 9 from the University of Washington). Participants discussed a range of 2-6 clinical cases per interview, with total of 56 unique cases across the entire cohort. While analyzing these narratives, we came to interpret our participants' descriptions as a desire for 'supported independence,' where predictable and accessible supervisory structures enabled trainees to work semiautonomously through challenging situations. They offered examples of how supported independence was experienced as borrowed comfort during moments of uncertainty, described ways that they implicitly invoked (the right level of) support from their supervisors, and highlighted challenges they faced when they felt insufficiently supported.

\section{Borrowing comfort}

Within their experiences of uncertainty, our participants described several ways that supervisors reinforced the residents' sense of independence and safety. This began with a general sense that supervisors believed in their abilities, leading one participant to assume that "they trust me to do this. They wouldn't ask me to do this if they didn't think that I could" (Participant 4). Participants conceptualized supervision as a "safety net" (Participant 4) for workplace learning, particularly during evolving situations where errors or missteps remained 


\section{CHAPTER 6}

quite possible. One participant-in the context of caring for a patient she felt might be quite sick-commented on the validation that her supervisor provided:

"It helped me because I felt like I had backup. So, if something were to go awry, I felt like she was really there to support me. It wasn't like, 'Oh, I haven't seen my attending in an hour, and I'm worried about this guy, and what if something bad happens?' I felt like that gave a certain level of kind of reassurance. And also a kind of validation that she was also worried about him." (Participant 10)

Though they strived for independence during experiences of uncertainty, our participants seemed to generally acknowledge boundary conditions for when supervisory support was necessary. They lamented that asking for help sometimes meant that they would lose an opportunity to learn or try something new, but generally reflected that patient safety took precedent over their own experiential learning. One participant reflected:

"There's a point where, you know, the patient's interests always are going to outweigh mine...I will, to the extent that I feel comfortable, go as far as I can. But there is a point where I'm not going to like force it beyond, especially because there are people who know so much more than me... Why shouldn't I take advantage of that resource while I still can?" (Participant 11)

Yet even when help was readily available, trainees sometimes struggled in the moment to decipher whether or not they had reached a point when support was needed, as was illustrated by one participant's experience placing a central line:

"It was something I don't do very often, it's a little bit above my level of training, and I had some hiccups there along the way...I was just wondering if I'm going to get help, if I want help, and if I need help." (Participant 4)

In these circumstances, they relied on their supervisors to determine when and how much to step in. When trainees felt this timely and titrated supervisory support was available, it provided them with confidence that they could continue forward, reassured that their supervisors would provide strategic help when they got stuck. One participant reflected on how 


\section{CHAPTER 6}

a senior resident helped him to sequence a variety of treatment decisions during an evolving resuscitation:

"It was just the right amount out of my comfort zone...And I felt like the more next steps I know, the more comfortable I would feel...I felt comfortable enough that I knew what was going on and felt confident enough to say it, but still had [the senior resident] kind of like helping me along a bit to know the specifics of the order and whatnot. So, it felt good to be able to say [instructions to the team], but [I was] still out of my comfort zone enough that I wasn't like quite as confident as I would've liked to be." (Participant 12)

These types of experiences, in which they were able to successfully confront complexity with timely and titrated support, instilled trainees with a sense that they could work with greater independence during subsequent situations:

"Even...[when] things started to get away from me a little bit towards the end, I felt like I could hang on...like hanging on to a mechanical bull, each time you can hold on a little longer." (Participant 12)

Finally, trainees described how supervisors provided critical re-framing around whether discomfort they were experiencing with a given situation originated from deficiencies in their emerging knowledge and skills, or whether these were appropriate reactions to the case itself. Disentangling these influences of self versus situation seemed to be clearer in the minds of supervisors, who modelled how they handled cases at the borders (or beyond) their abilities. For example, in expressing hesitancy about how to make sense of a patient with vague neurologic symptoms, one trainee's supervisor highlighted that this case was outside the bounds of typical practice and proceeded to call a neurologist for help. The trainee reflected,

“Because [my supervisor] was so comfortable not knowing, it made me very comfortable. I'm like, okay, so maybe this is not something that should automatically be within the breath of my knowledge. Emergency Medicine is so vast and there's so much to know. Rosen's [the definitive textbook] is a very big book, and I'm sure maybe in one 
of the chapters somewhere it's there, but it's not one of the chapters my staff remembers and nor have I read, so it's okay." (Participant 7)

\section{Strategically invoking (the right level of) support}

Despite the expectation that their supervisors would intervene when necessary, participants also viewed the right level of support as something they had the ability (and responsibility) to actively negotiate. They negotiated the level of support strategically, invoking it when they felt themselves at the borders of their abilities while simultaneously aiming to maintain their roles as primary physician. To achieve this, our participants broadcasted their thinking or pantomimed their actions as deliberate efforts to strengthen their partnerships with their supervisors (as elaborated below). They adopted these approaches to proactively build trust and exert agency on their supervisory interactions in ways that enabled them to marshal support when it was needed most.

Broadcasting. Trainees in our study were strategic about how they shared their evolving understanding of a situation or their management approaches with their supervisors. Without prompting from their supervisors, they spontaneously verbalized their thoughts and feelings with the goal of making their current understanding of a situation and plans for next steps clear to their supervisors. These were strategic efforts to build supervisors' trust and to provide a structure whereby supervisors could provide timely corrections or targeted support. Trainees also used this strategy as a preemptive effort to convince supervisors that they were ready to do things that were at the borders of their abilities. One participant explained:

"[The supervisor] has to be extremely cautious with letting a first-year resident do something like this...I just tried my best to just talk to every single thing that was going through my head that I knew could be right in order to make sure that she felt confident in me, but also so that I felt confident as I was going through things. And in case she had any corrections as well." (Participant 4) 


\section{CHAPTER 6}

Additionally, participants broadcasted their discomfort and uncertainties as a means to strategically engage their supervisor's attention when they needed it most. One participant noticed that his supervisor seemed to perk up when he told him "you have to help me here because I don't want to miss something" (Participant 12) and described how he used similar phrases strategically to garner help when cases were troubling him. These broadcasting activities were also used strategically to assuage some supervisors who seemed to want or expect more information from trainees before allowing them to proceed. One participant reflected:

"I think there are certain attendings that like you expect to be a bit more anxious and then you manage those expectations by over-calling things out. Which is not a bad thing, especially when we're training, because y'all can't read our minds." (Participant 7)

Pantomiming. When acting as leaders of their teams, trainees used deliberate, exaggerated actions in view of their supervisors to check and validate their decision-making. Explicit, overstressed actions or statements made to the healthcare team within deliberate view of a supervisor during high stakes patient care moments allowed an indirect check-in to ensure a care plan was on track. This performative strategy was elaborated by one participant who projected confidence to a nurse regarding her decision to not activate a code stroke for a patient with transient neurologic symptoms, while simultaneously looking to her attending to verify that her decision-making was correct:

"I happened to be like standing right next to my attending and was like, 'I think that when [patients] get better we don't call it code stroke' [while] looking at my attending...It was me like explaining my reasoning why I didn't call a code stroke to the nurse, but also me simultaneously being like 'Right? Right? Right? Back me up on this one!' Like I don't think this is code stroke, but I'll check with somebody who just happens to be here." (Participant 11)

\section{Experiences of insufficient support}




\section{CHAPTER 6}

In contrast to the experiences and strategies above, participants described several instances where they found themselves needing to function independently without a sense of support. This was most salient to participants in instances where they directly asked for help and were, in their minds, denied support from their supervisors. This (unexplained) denial of support resulted in trainees having to interpret the supervisor's reasoning, and question whether the supervisor truly understood the resident's abilities in relation to the situation:

"I was like, okay, either [the supervisor] really thinks this is not an issue at all, and like I won't need help for this patient. Or she thinks that maybe I have more ability than I do." (Participant 6)

As a longer-term impact, these experiences left trainees with less confidence that the support would be there when they needed it in the future. This was evident in one trainee's efforts to get help with repairing a complex scalp laceration:

"It was extremely challenging. I had no idea where these edges went together...I was like, I have no idea what I'm going to do for this. So I just went to get my staff and I was like, 'Hey, I don't know what to do.' And she goes 'You should probably figure it out,' and like went the other way. And I was like... 'Oh sh\#t! Maybe I'm a little bit more on my own in residency than I thought I was.'” (Participant 4)

When such situations led to a sense that support was generally insecure, participants described feeling tentative about embarking into new experiences:

"I think I would have felt more independent if I felt like the help was more available and more accessible...but I felt like I couldn't really have [independence] because my help didn't feel secure." (Participant 6)

\section{Discussion}

These findings highlight interesting complexities in trainees' conceptualizations of supervision that were manifest during their experiences of uncertainty. Our participants relied on their supervisors as a safety net to work confidently at the edges of their comfort. They looked to 


\section{CHAPTER 6}

their supervisors to put borders around the scope of knowledge and practice that could be expected of them, counting on their supervisors to not put them in situations where they might cause irreparable harm. This confidence that supervisors would provide timely and titrated support enabled trainees to maintain ownership of these clinical cases even when they were feeling a bit over their heads. Trust was central to all of these supervisor-trainee interactions, and our participants described several ways that they themselves were agentic in shaping and reinforcing trust with their supervisors.

Viewing supervision through the eyes of trainees highlights the bidirectionality of trust in clinical training environments. ${ }^{34}$ Past work has focused on the ways that supervisors assess trainees' readiness for entrustment around a variety of professional activities, conceptualizing these real-time judgments as markers for when trainees are ready for

independence. ${ }^{10,12,14,17,18,35,36}$ Yet entrustment decisions fail to capture the formative processes by which trainees build confidence and independence around clinical tasks. Our results reinforce that trainees' trust in their supervisors was a necessary condition for them to feel safe, and therefore engage meaningfully with work that they perceived to be at the borders of their capabilities. These trust judgments spanned from general (e.g., Does this supervisor know what I can do? Will this supervisor be there when I need them?) to specific (e.g., Can this supervisor get me out of this situation?). Lacking trust in their supervisors, or trust in the reliability of their supervisors to step in when they get into trouble, trainees are likely to struggle to engage in safe and effective work within their zones of proximal development. ${ }^{19,20}$

Our participants' reflections on effective supervisory support offer insights that are distinct from traditional framings of supervision that focus on effective teaching and feedback in the workplace. ${ }^{1}$ While supervisors' guidance around management decisions or procedural skills could be viewed within prior constructions or supervised work in practice, trainees in our study additionally described a clear desire for supported independence. They were seeking a sweet spot where they perceived that they could safely struggle through problems and maintain ownership of a situation ${ }^{37}$ with the reassurance that help was available and accessible. These 


\section{CHAPTER 6}

results add an interesting wrinkle to our understanding of the zone of proximal development, ${ }^{19}$ which has historically been framed as a space where new problems could be solved through active collaboration with more capable supervisors. By gleaning implicit or explicit moral support from their supervisors (by borrowing comfort), our participants instead described a confidence to try things that they may not have otherwise tackled on their own. In this way, their zones of proximal development were extended not so much by direct help from their supervisors, but rather through the sense that they could confidently carry forward managing a situation through the comfort of their supervisors. Trainees may continue to struggle to recognize their own limitations, ${ }^{6,13}$ and to discern whether or not they need help. ${ }^{11}$ But our results would suggest that effective supervision can still help trainees to confidently engage with new and challenging problems through the reassurance that their supervisor will step in if things go off track.

From the perspective of supervisors, viewing their role as a safety net for clinicians-in-training who are attempting to practice with as much autonomy as possible shifts expectations towards identifying moments when their input could empower trainees to continue to own a problem and intervening when patient safety might be at risk. However, our findings also have resonance with the kinds of agentic actions that students used in past work to influence the entrustment decision-making of their supervisors ${ }^{37}$ in that our participants were actively trying to manage the level of support from supervisors. Thus, supervisors can also support learner agency by recognizing the ways that trainees attempt to strategically marshal attention when they need it most; in doing so, supervisors can provide timely support and advocacy, particularly when trainees perceive that they might be going "against the grain" of others in their work environment. ${ }^{39}$

Trainees' appraisals of discomfort in this study echo those described by experienced physicians in prior work, ${ }^{24,26}$ where discomfort signaled potential misalignments between their skills and the situation. Yet trainees in this study had a more tentative sense of what they should be able to do and struggled to distinguish the discomfort of learning (e.g., activities that would be safe 


\section{CHAPTER 6}

with sufficient supervisory support) from discomfort signaling that problems were beyond their abilities or scope of practice (e.g., instances when their supervisors would feel discomfort too). We would expect that authentic clinical work within one's zone of proximal development should generate discomfort, and supervisors can recognize this in their trainees as a signal that they are working within problem spaces where growth and learning is possible. Yet reflections from trainees in this study suggest that they are actively seeking to borrow the comfort or discomfort of their supervisors in these moments to gauge whether or not they were safe to proceed. Past descriptions of "back-stage"11(pg. 1083) or "hands off"13(pg. 1032) oversight, where trainees are not directly aware of the support they are receiving, may help to ensure patient safety, but might also generate distress or confusion about one's own capabilities, as evident in our trainees' reflections. These learning moments can thus be enriched when supervisors explicitly reinforce that a situation is within a trainee's capabilities (e.g., "There is nothing you can do here that I can't get you out of $\left.{ }^{\prime \prime(p g . ~}{ }^{84)}\right)$, signposting how support is enacted (e.g., Here's when I'll step in; or, Here's how to reach me if you need help), and intervening strategically to support their autonomy.

\section{Limitations}

These findings were shaped by our methodological decisions and should be interpreted in the context of several limitations. First, because our participants were prompted to reflect on the influences of supervision as they navigated experiences of uncertainty, these narratives may not fully capture the role of supervisors when trainees are feeling more comfortable or more certain. That said, in past work, trainees expressed substantial skepticism about their own capacity to accurately appraise their comfort when they were feeling uncertain, ${ }^{21}$ so we suspect that these insights about supervision can broadly reinforce trainees' abilities to self-regulate. Second, while our situated approach enabled our principal investigator to explore and probe the supervisory experiences of trainees in a practice environment well known to him, it is possible that his role as a supervisor at one of the sites limited participants' willingness to fully elaborate their experiences. Participants' reflections from the two sites echoed similar themes, so we suspect that this influence was minimal. Finally, these post-hoc reflections from trainees 


\section{CHAPTER 6}

without direct observation limit our interpretations about whether supervisory support was, or was not, appropriately enacted, and only reflect one side of these supervisor-trainee interactions.

\section{Conclusions}

Trainees exert agency in how they engage their supervisors' help during clinical experiences filled with uncertainty. By deliberately projecting their thinking to, and borrowing comfort from, their supervisors, trainees aimed to strike the appropriate balance between independence (for learning) and support (for safety). Supported independence thus offers a useful means to understand how supervisors might strategically help trainees who are tackling problems at the borders of their capabilities. 


\section{References}

1. Wiese A, Kilty C, Bennett D. Supervised workplace learning in postgraduate training: a realist synthesis. Med Educ. 2018;52(9):951-969.

2. Teunissen PW, Scheele F, Scherpbier AJ, et al. How residents learn: qualitative evidence for the pivotal role of clinical activities. Med Educ. 2007;41:763-770.

3. Klasen JM, Driessen E, Teunissen PW, Lingard LA. 'Whatever you cut, I can fix it': clinical supervisors' interview accounts of allowing trainee failure while guarding patient safety. BMJ Qual Saf. 2020;29:727-734.

4. Fischer MA, Mazor KM, Baril J, Alper E, DeMarco D, Pugnaire M. Learning from mistakes. Factors that influence how students and residents learn from medical errors. J Gen Intern Med. 2006;21:419-423.

5. Institute of Medicine. To Err Is Human: Building a Safer Health System. Washington, DC: The National Academies Press; 2000.

6. Moulton CA, Regehr G, Lingard L, Merritt C, Macrae H. Operating from the other side of the table: control dynamics and the surgeon educator. J Am Coll Surg. 2010;210:79-86.

7. Balmer DF, Giardino AP, Richards BF. The dance between attending physicians and senior residents as teachers and supervisors. Pediatrics. 2012;129:910-915.

8. Watling C, Driessen $E$, van der Vleuten CP, Lingard L. Learning from clinical work: the roles of learning cues and credibility judgements. Med Educ. 2012;46:192-200.

9. Balmer DF, Serwint JR, Ruzek SB, Giardino AP. Understanding paediatric residentcontinuity preceptor relationships through the lens of apprenticeship learning. Med Educ. 2008;42:923-929.

10. Dijksterhuis MG, Voorhuis M, Teunissen PW, et al. Assessment of competence and progressive independence in postgraduate clinical training. Med Educ. 2009;43:11561165.

11. Kennedy TJ, Lingard L, Baker GR, Kitchen L, Regehr G. Clinical oversight: conceptualizing the relationship between supervision and safety. J Gen Intern Med. 2007;22:1080-1085.

12. Ten Cate $\mathrm{O}$, Hart D, Ankel F, et al. Entrustment Decision Making in Clinical Training. Acad Med. 2016;91:191-198. 
13. Gingerich A, Daniels V, Farrell L, Olsen SR, Kennedy T, Hatala R. Beyond hands-on and hands-off: supervisory approaches and entrustment on the inpatient ward. Med Educ. 2018;52:1028-1040.

14. Ten Cate O, Chen HC. The ingredients of a rich entrustment decision. Med Teach. 2020;42:1413-1420.

15. Pimmer C, Pachler N, Genewein U. Contextual dynamics in clinical workplaces: learning from doctor-doctor consultations. Med Educ. 2013;47:463-475.

16. ten Cate O. Entrustability of professional activities and competency-based training. Med Educ. 2005;39:1176-1177.

17. Hauer KE, Oza SK, Kogan JR, et al. How clinical supervisors develop trust in their trainees: a qualitative study. Med Educ. 2015;49:783-795.

18. Kennedy TJ, Regehr G, Baker GR, Lingard L. Point-of-care assessment of medical trainee competence for independent clinical work. Acad Med. 2008;83:S89-92.

19. Vygotsky LS. Mind in Society: The Development of Higher Psychological Processes. Cambridge, MA: Harvard University Press; 1978.

20. Vermunt JD, Verloop N. Congruence and friction between learning and teaching. Learn Instr. 1999;9:257-280.

21. Ilgen JS, Regehr G, Teunissen PW, Sherbino J, de Bruin ABH. Skeptical self-regulation: Resident experiences of uncertainty about uncertainty. Med Educ. 2021;55:749-757.

22. Charmaz K. Constructing Grounded Theory: A practical guide through qualitative analysis. 2nd ed. London: Sage Publications; 2014.

23. Albert M, Mylopoulos M, Laberge S. Examining grounded theory through the lens of rationalist epistemology. Adv Health Sci Educ Theory Pract. 2018;24:827-837.

24. Ilgen JS, Bowen JL, de Bruin ABH, Regehr G, Teunissen P. "I Was Worried About the Patient, But I Wasn't Feeling Worried": How Physicians Judge Their Comfort in Settings of Uncertainty. Acad Med. 2020;95:S67-S72.

25. Ilgen JS, Eva KW, de Bruin A, Cook DA, Regehr G. Comfort with uncertainty: reframing our conceptions of how clinicians navigate complex clinical situations. Adv Health Sci Educ Theory Pract. 2019;24:797-809. 
26. Ilgen JS, Teunissen PW, de Bruin ABH, Bowen JL, Regehr G. Warning bells: How clinicians leverage their discomfort to manage moments of uncertainty. Med Educ. 2021;55:233241.

27. Glaser BG. Theoretical sensitivity : advances in the methodology of grounded theory. Mill Valley, CA: Sociology Press; 1978.

28. Bowen GA. Grounded Theory and Sensitizing Concepts. Int. J. Qual. Methods. 2006;5:1223.

29. Flanagan JC. The critical incident technique. Psychol Bull. 1954;51(4):327-358.

30. Cristancho S, Bidinosti S, Lingard L, Novick R, Ott M, Forbes T. Seeing in different ways: introducing "rich pictures" in the study of expert judgment. Qual Health Res. $2015 ; 25: 713-725$.

31. Cristancho SM, Helmich E. Rich pictures: a companion method for qualitative research in medical education. Med Educ. 2019;53:916-924.

32. Corbin J, Strauss AL. Basics of Qualitative Research: Techniques and Procedures for Developing Grounded Theory. 3rd ed. Los Angeles: Sage; 2008.

33. Malterud K, Siersma VD, Guassora AD. Sample Size in Qualitative Interview Studies: Guided by Information Power. Qual Health Res. 2015;26:1753-1760.

34. Damodaran A, Shulruf B, Jones P. Trust and risk: a model for medical education. Med Educ. 2017;51:892-902.

35. Hauer KE, Ten Cate O, Boscardin C, Irby DM, lobst W, O'Sullivan PS. Understanding trust as an essential element of trainee supervision and learning in the workplace. Adv Health Sci Educ Theory Pract. 2014;19:435-456.

36. Cianciolo AT, Kegg JA. Behavioral specification of the entrustment process. J Grad Med Educ. 2013;5:10-12.

37. Kiger ME, Meyer HS, Hammond C, et al. Whose Patient Is This? A Scoping Review of Patient Ownership. Acad Med. 2019;94:S95-S104.

38. Caro Monroig AM, Chen HC, Carraccio C, et al. Medical Students' Perspectives on Entrustment Decision-Making in an EPA Assessment Framework: A Secondary Data 
Analysis. Acad Med. 2020; doi: 10.1097/ACM.0000000000003858. Online ahead of print.

39. Watling C, Ginsburg S, LaDonna K, Lingard L, Field E. Going against the grain: An exploration of agency in medical learning. Med Educ. 2021;55:942-950 
CHAPTER 7

Discussion 


\section{CHAPTER 7}

\section{Background}

To comfortably engage in high stakes work while remaining uncertain is a paradox of expert clinical practice, and managing these moments is felt to be particularly challenging for trainees. This thesis addresses the overarching research question of what it means to be 'comfortable with uncertainty' with a collective body of work exploring the conceptual underpinnings of this phenomenon and the experiential aspects of how comfort manifests in clinical practice. I pursued this program of research by first seeking to understand how uncertainty and comfort manifest in the minds of experienced clinicians as they tackle ill-defined problems in practice. Doing so provided a foundation for understanding the metacognitive and situated ways that practicing clinicians notice, appraise, and act safely within these experiences. I then shifted my focus towards novice clinicians in training, seeking to understand how uncertainty manifests differently, and how their emerging sense of comfort might be importantly distinct from clinicians with more elaborated knowledge and experience. In seeking to understand these experiences in trainees, I was struck by how novice clinicians struggled with the dueling tensions of independence and support, and thus supplemented my analyses by exploring how novices strategically use their supervisors as resources to manage in-the-moment experiences of uncertainty. This discussion chapter describes the central findings of these studies and how these findings interrelate to form a cohesive program of research, concluding with strengths and limitations of this thesis as well as implications for educational practice and future research.

\section{Summary of Findings}

My critical review of the literature (Chapter 2) yielded several conceptual revelations that were central to my subsequent qualitative research studies. ${ }^{1}$ The first was disentangling the many conceptualizations of uncertainty that had been used in the health professions literature, ${ }^{2}$ with an aim of focusing this program of research on the situated, idiosyncratic, individualized experiences of uncertainty that manifest in the minds of clinicians in practice. As discussed in Chapter 1 , these negotiated aspects of uncertainty are importantly distinct from how clinical problems have been traditionally represented in the clinical reasoning literature, and I found 


\section{CHAPTER 7}

Kitchener's conceptualization of "ill-defined problems" to be a particularly helpful way of thinking about the types of situations that clinicians might be tackling in practice. ${ }^{3} \mathrm{By}$ hypothesizing that authentic clinical problems manifest with "conflicting assumptions, evidence, and opinion which may lead to different solutions," ${ }^{3(\mathrm{pg} 223)}$ I was able to move beyond the typical outcome-oriented, reductionistic constructions of uncertainty, instead focusing on the strategies that physicians use when noticing, attending to, and acting during experiences of uncertainty in the workplace.

The second important insight from my conceptual review was drawing the connection between the ways in which comfort seemed to be embodied in the health professions literature and Koriat's dual-based model of metacognitive judgments. Koriat originally advanced this model as a means to understand how individuals make in-the-moment judgements about their learning by combining "theory-based cues" drawn from their accrued past experiences and "experiencebased cues" that emerge from engaging with the unique problem itself. ${ }^{4,5}$ The model had strong resonance with the ways that I was thinking about comfort as an interplay between how clinicians made predications about how a situation might play out (e.g., forward planning) based on past experiences with similar problems, and how they concurrently monitored the problem in the moment. Koriat's model also helped me to think about the ways that comfort had parallels to past work regarding the cyclical nature of fluency, ${ }^{6,7}$ and I similarly hypothesized that comfort enables action and the ease with which one acts or makes ongoing predictions about how a problem might play out provides ongoing comfort.

I expected that clinicians' experiences with uncertainty would reflect the idiosyncratic ways that they interacted with dynamic problems in their workplace. To enable a flexible approach to understand these experiences, and because our focus on ill-defined problems differed substantially from past constructions of uncertainty, I used a constructivist grounded theory ${ }^{8}$ approach to iteratively explore and build theory from clinicians' accounts of these experiences. Based on past qualitative work exploring clinical reasoning in operative settings, ${ }^{9-15}$ I assumed that clinicians would be able to provide elaborated descriptions of the ways that uncertainty 


\section{CHAPTER 7}

manifested in their minds as they managed these experiences. I chose to sample amongst a cohort of emergency physicians for two reasons. First, these clinicians regularly care for patients with acute, complex, dynamic, and undifferentiated problems, and I expected that their approaches to tackling these types of problems would be negotiated, idiosyncratic, and constrained by the resources available in their work environment. These factors seemed wellaligned with the characteristics of ill-defined problems, and thus well-suited to study the types of experiences with uncertainty I was most interested in elaborating. Second, as an emergency physician myself, I felt well-acquainted with the problems that these clinicians tackle at work, as well as the ways these experiences are shaped by system influences and cultural norms. This, in combination with the fact that I interviewed colleagues from within my own clinical department, enabled me to probe the cognitive, emotional, and somatic manifestations of these experiences in a more nuanced way.

I gained several important insights from these studies of practicing emergency physicians' situated experiences with uncertainty. In Chapter 3, I describe the action-oriented ways that they made sense of uncertainty, conceptualizing their efforts around the questions of "what is going on?" and "what should I do?". In organizing their efforts to tackle uncertainty in these ways, they engaged in concurrent efforts to think through the root causes of patients' symptoms, how problems might progress, which actions were likely to be safe and effective, whether their unique skills seemed aligned with the problem(s) at hand, and whether their plans of care aligned with the perceived expectations of others. Comfort in these moments was manifest by these clinicians' sense that they could take the next step forward despite unresolved uncertainties, and this was shaped by interrelated and cyclical efforts at forward planning and monitoring. When forward planning, clinicians used mental simulations to consider things that might happen, and in thinking through the knowledge, skills, and resources that were potentially necessary to navigate a range of potential downstream situations, they also signposted "boundaries" as stopping points for when they needed to engage the help of others. Concurrent with forward planning, these clinicians described deliberate efforts to monitor their patients, themselves, and their environment. Interestingly, our participants 


\section{CHAPTER 7}

struggled to describe what comfort felt like, and generally described the sensation of dwelling in this state as an absence of worry or a lack of somatic manifestations such as a racing heart. These ongoing and interacting processes of forward planning and monitoring resulted in a fluid and continuously evolving state of comfort which enabled these clinicians to maintain a sense of control despite ongoing uncertainty, and uncertainty itself seemed to catalyze their ongoing appraisals of whether they remained on track.

Perhaps the most interesting finding in Chapter 3 was that comfort was neither dichotomous nor stable. In nearly all cases, participants described a balancing act between cues that generated comfort and others that generated discomfort, leading one participant to reflect that it was "almost a ratio of which is winning at that particular time." Rather than achieving an abstracted state of comfort that was generally applicable to experiences of uncertainty, they described how they iteratively negotiated their holistic appraisals around specific situations until they became sufficiently comfortable to act. This raised important questions about the competing tensions of discomfort, and how clinicians might use the counterbalancing effects of these appraisals in different ways.

Chapter 4 thus describes the shift in our analyses towards the ways in which experienced clinicians noticed and used discomfort when managing their uncertainty. In contrast to comfort, cues that generated appraisals of discomfort were particularly memorable for these participants, with substantially more palpable emotional and somatic manifestations. Participants were quick to recall their "heart speeding up" and wanting to "take some deep breaths," and further described vague cognitive and emotional signals such as "something doesn't feel $100 \%$ safe or $100 \%$ right here." These appraisals of discomfort seemed to trigger strategies aimed at gaining better control of a situation, from heightened monitoring, to considering the types of resources that might be needed, to engaging with problems in more deliberate or structured ways (e.g., using tried-and-tested clinical algorithms). Discomfort also triggered purposeful considerations of the aspects of a situation that clinicians felt they could manage on their own, when they needed help managing specific aspects of a problem, and 


\section{CHAPTER 7}

when they needed to hand over a problem to others. In these ways, discomfort seemed to be an important trigger for clinicians to think through the resources-both material and consultative-that they could call upon when working to maintain safety during experiences of uncertainty.

With this understanding of how a spectrum of comfort and discomfort manifests in the minds of experienced clinicians, I next sought to understand how these appraisals might be different in novice clinicians. Secondarily, I was looking for signals in the behaviors described by novices when experiencing uncertainty that might help to explain the frequent refrain from educators that trainees lack comfort and struggle to manage uncertainty. ${ }^{16-20}$ I again chose to explore these questions in the emergency medicine context, both to enable more direct comparisons with the data presented in Chapters 3 and 4, and because, I was quite familiar with the training structures germane to these clinicians' experiences in the emergency department.

I purposefully sampled amongst first- and second-year emergency medicine residents at two training programs, all of whom were in the first 15 months of their postgraduate experiences. Chapter 5 describes some interesting variations in these novice clinicians' experiences with uncertainty that distorted-relative to experienced clinicians-how they appraised their ongoing sense of comfort and discomfort. These distortions were driven largely by trainees' pervasive sense of skepticism in their abilities to accurately appraise a situation and their competency to manage it. Some of this skepticism was rooted in their difficulties distinguishing whether the discomfort generated by a particular experience was appropriately signaling that a situation was unsafe (e.g., that these feelings heralded dangerous territory that they could not get themselves out of, or worse, that they would create a situation where their supervisors would be unable to get them out of) versus whether their discomfort was a function of their insecurities about their own skills (e.g., that they were feeling over their head, but were-at least in the eyes of their supervisors - in fact competent to manage a situation). In both cases, a trainee's sense of discomfort may be appropriate self-regulation based on their sense of their own knowledge and skills, but in the second scenario, they are led to believe by supervisors 


\section{CHAPTER 7}

that their discomfort is something that they should functionally ignore because they are being overly sensitive (e.g., they are better than they think they are).

To combat this sense of skepticism and build comfort, trainees engaged in mental rehearsals to prepare for patient encounters, explicitly cross-checked their decisions with those around them, and implicitly observed the behaviors of their supervisors to get a sense of whether they were on track. I was particularly struck by trainees' efforts to maintain ownership of problems despite their ongoing sense of uncertainty and skepticism. This suggested interesting nuances in how trainees used supervisors to manage uncertainty, striving to remain engaged with problems that were the borders of their abilities even if they were not sure if they needed (or wanted) help. Chapter 6 describes how trainees used strategies to forge effective partnerships with their supervisors so that they were able to function semi-autonomously, invoking strategic support during moments where they felt like they were reaching the limits of their knowledge and skills in ways that mirrored the behaviors of experts observed in Chapters 3 and 4 . To foster these partnerships, trainees made deliberate efforts to engender trust, "broadcasting" how they were thinking through problems or by using deliberately performative actions so that their supervisors could provide corrective adjustments. This work raises questions of whether residents can accurately discern these sweet spots of "the right support at the right time," but these results may: a) shift supervisors' conceptualizations of the roles they can play to most effectively support trainees through experiences of uncertainty; and b) highlight some of the behavioral signals that trainees are giving during these moments that supervisors have misinterpreted as 'hesitancy' 21 or an 'intolerance' of uncertainty. ${ }^{22,23}$

Taken together, this body of research proposes:

1. Clinicians engage with workplace experiences of uncertainty using cognitive states that are dynamic, actively negotiated, and situationally embedded. Appraisals of comfort provide a useful means to explore clinicians' idiosyncratic processes of monitoring and forward planning as they engage with ill-defined problems in practice. 
2. Holistic appraisals of comfort exist on a dynamic spectrum, informed by cues that clinicians gather from themselves, their patients, and the environment. These appraisals inform when and how clinicians enact management approaches geared towards helping them maintain control despite experiencing uncertainty about 'what is going on' and 'what they should do.'

3. Novice clinicians are inherently skeptical of their abilities to generate accurate appraisals of comfort, leading to distortions in how they approach uncertainty relative to more experienced clinicians.

4. Supervisors can support novice clinicians' growth of comfort by strategically modeling how they forward plan and monitor within situations where they remain uncertain. This enables novices to remain safely engaged with, and learn from, authentic experiences with uncertainty.

\section{General Discussion}

The primary lesson from this program of research is that clinicians use holistic appraisals of comfort to negotiate their way through dynamic experiences of uncertainty in practice. This leads to important questions about how this fluid state of comfort relates to existing paradigms of self-regulation, how holistic appraisals of comfort influence clinicians' actions as they manage these situations in practice, and how supervisors can best support the growth of these skills in novice clinicians. This discussion will explore these questions by drawing linkages between prior literature and the findings from this program of research.

\section{Elaborating a fluid state of comfort}

Past conceptualizations of uncertainty that have framed clinicians' reactions to these experiences as generalizable traits..$^{23-28}$ For example, Gerrity and colleagues developed the "Physicians Reactions to Uncertainty" scales in the 1990s to measure physicians' affective reactions and coping behaviors in the context of both internal (cognitive and affective) and external (sociological and cultural) influences. ${ }^{24,26}$ These foundational scales drew from participants' responses to decontextualized statements such as "I am quite comfortable with 


\section{CHAPTER 7}

the uncertainty in patient care" or "I find the uncertainty involved in patient care disconcerting" ${ }^{26(p g .181)}$ as means to create archetypes of clinicians with different affective reactions to uncertainty, with the implication that these relatively stable dispositions would lead to differences in clinical decision-making. ${ }^{24} \mathrm{~A}$ range of tools have been developed by others in subsequent years to capture the cognitive, emotional, and behavioral influences that might shape clinicians' responses to uncertainty. ${ }^{29}$ By examining associations between scores from these tools and factors such as participant demographics and specialty, ${ }^{28}$ training experiences, ${ }^{22,23}$ Medicare claims, ${ }^{30}$ and scores from instruments measuring constructs such as burn-out, ${ }^{28}$ researchers have drawn hypotheses about the ways that physicians manage experiences of uncertainty in practice and considered the impacts of uncertainty on physician well-being. Geller and colleagues went as far as to propose that medical schools use scales such as these to screen for students who have the cognitive dispositions to effectively manage uncertainty in practice. ${ }^{31}$

Yet measuring approaches to uncertainty in these ways assumes that an individual's reactions to uncertainty are generalizable across situations. This runs counter to the extensive clinical reasoning literature highlighting the importance of context specificity in clinical reasoning. ${ }^{32-34}$ Clinical reasoning is shaped by contextual influences that are complex and multifaceted, ${ }^{35}$ such as the clinicians themselves (with their idiosyncrasies of training and past experiences ${ }^{32,36}$ ), the clinical problems they are tackling (including the idiosyncrasies of how disease manifests ${ }^{37,38}$ ), and the environment they are working in (with its idiosyncrasies of resources, both human and materia $\left.{ }^{39}\right)$. Taken together, the clinical reasoning literature suggested to me that physicians' cognitive states during experiences of uncertainty are likely shaped by these multiple interwoven influences, and that efforts to understand how clinicians manage these moments would require an approach that was distinct from the types of decontextualized scales advanced previously.

This led me to the conclusion that exploring the phenomena of uncertainty and comfort in the moment (a state) required a different approach than past work that treated individuals' 


\section{CHAPTER 7}

reactions as stable properties that could be applied broadly to disparate situations. As a result, I adopted a constructivist paradigm as a means to iteratively explore ill-defined problems in practice, drawing from my own experiences as a practicing clinician to help me unpack these experiences in ways that resonated with my own lived experiences. I was able to demonstrate how practicing emergency physicians' experiences with uncertainty were situationally embedded and dynamic, and that clinicians used their spectrum of comfort to appraise how they move through these thorny spaces. ${ }^{40,41}$ These results would suggest that appraisals of comfort evolve in the minds of clinicians as they sort through the cognitive, somatic, and emotional cues that are generated when managing complex problems in their unique work contexts. By balancing the competing influences of comfort and discomfort during these moments, clinicians were able to make holistic appraisals of their level of control, of how they might take action to better control these experiences, and of how they might most effectively monitor these situations. Because appraisals of comfort were ever-evolving and liminal, they informed clinicians' management approaches but remained sufficiently tentative that they could be adjusted as the clinician continued to engage with a problem.

In describing the cues that they were noticing during experiences of uncertainty, participants in these studies struggled to find the right language for these holistic appraisals of comfort. Comfort was particularly challenging to capture in words, and though there were undoubtedly cognitive aspects of this phenomenon, participants typically framed this as a "feeling" that a situation was under control. Discomfort was typically manifest through more palpable and cognitively available cues, though again these holistic appraisals were manifest with a sense that "something doesn't feel 100\% right." This has resonance with Leblanc's elaboration of eustress and distress, which have been described as cognitive states generated when individuals recognize alignment or misalignment, respectively, between their available resources and the needs of a situation. ${ }^{42}$ The spectrum of comfort that participants in my research studies described, however, seemed importantly distinct from eustress and distress. Instead, comfort appeared to exist as a quantum state where clinicians had heightened awareness that a problem was complex and had elements of unpredictability that might lead to 


\section{CHAPTER 7}

a situation that exceeded their capacity to manage it with control and confidence. But because this state was inherently liminal, it did not reach the dichotomous endpoints of eustress or distress where more definitive recognition of resource alignment or misalignment had been achieved (although clear distress was illustrated by data in Chapter 4 when experts "white knuckled" their way through problems they deemed to be beyond their typical capabilities but were unable to access help). Maintaining this sense of tentativeness inherent in appraisals of comfort seemed to further engage these clinicians in cyclical acts of monitoring and forward planning during experiences with uncertainty, which enabled them to work towards a state of sufficiency that allowed them to carry forward, change directions, or engage the help of others.

The ways that participants in these empirical studies described holistic appraisals of comfort also have resonance with, and provide language for, the kinds of in-the-moment self-regulatory behaviors that others have described previously. Moulton and colleagues, for example, have examined surgeons' shifts from routine to effortful modes of thinking as 'slowing down when you should, ${ }^{43}$ and these moments led these clinicians to engage in behaviors such as stopping a procedure or removing distractions in order to focus more intently on the task at hand. ${ }^{15}$ In doing so, these surgeons described acts of self-monitoring that seemed to mirror my participants' descriptions of experiencing emotional and somatic cues associated with discomfort, ${ }^{41}$ as they noted that their slowing down moments were manifest as "maybe I'm starting to sweat a little bit, I'm just not as happy as I was, I'm not enjoying it as much as I was." ${ }^{15(p g .1574)}$ By conceptualizing the ways that cognitive, somatic, and emotional cues inform a fluid state of comfort, the data in this program of research provides helpful specificity around how educators might use consciously-available cues to unpack why a slowing down moment has occurred (e.g., What am I noticing in myself, my patient, or my environment?). Unpacking the influences on clinicians' appraisals of comfort also appears to help them to determine if and when they can safely move forward in the moment (e.g., Am I sufficiently comfortable to take the next step? What things might happen? Do I need to change my approach or build in safeguards to make me feel better about this situation?). This differs from past work describing preemptive risk-mitigation strategies that surgeons consider prior to starting an operation, ${ }^{44}$ or 


\section{CHAPTER 7}

more general categorizations of problems as being within or outside one's comfort zone. ${ }^{45}$ Educators could instead focus more intentionally on probing learners' appraisals as they move through problems to model and reinforce the strategies that they use to handle experiences in their own evolving moments of uncertainty.

The fluid state of comfort also has interesting connections with past elaborations of how cue utilization frameworks might inform practices in health professions education. ${ }^{46}$ Participants in these studies were attending to a multitude of cues simultaneously, which illustrated interesting paradoxes and potential conflicting signals that they seemed to be managing in real time-such as the state of being worried (about the patient) while concurrently not feeling worried (about their abilities to manage the problem). ${ }^{40}$ Appraisals of comfort seemed to sit at the nexus of these competing cues, and reaching a sufficient threshold on either end of the spectrum of comfort to discomfort enabled clinicians to carry forward, engage in risk mitigation around particular cues that were troubling, or recognize moments when they needed others' help. Attending to one's own state of comfort thus provides a helpful trigger for learners and educators alike to unpack the variety of cues that might be shaping these appraisals and act on these influences in ways that they can move forward through experiences of uncertainty.

The state of comfort also seemed to place participants in a cyclical state of defining and redefining problems. This calls to mind principles of soft systems engineering, ${ }^{47}$ which emphasizes the importance of gathering different perspectives to define and understand a problem, ${ }^{48}$ and how one's engagement in these activities will change the situation itself. This 'learning cycle' 47 is similar to that which has been described in surgeons' intra-operative judgments, ${ }^{49}$ where weighing differing perspectives led to evolving definitions of the surgical problem at hand. These results provide nuance to how this paradigm applies to clinical reasoning by suggesting that these cyclical experiences of defining and redefining problems are shaped by more than simply the cognitively available aspects of a situation. Instead, it was clear that emotions and somatic reactions were both generated by-and shaped how participants reacted to-these experiences. As such, 'feeling your way through a problem' could be likened 


\section{CHAPTER 7}

to the cyclical ways that clinicians in these studies synthesized a multitude of cues into appraisals of comfort, using these ongoing feelings to gauge how a problem was progressing over time despite their ongoing uncertainties.

Acknowledging these somatic and emotional contributions to appraisals of comfort aligns well with past work describing appraisal theories of emotion..$^{50}$ These theories treat emotion as processes rather than states, and emotional processes are shaped by the interaction between individuals and the events around them. ${ }^{51}$ This interpretive aspect of appraisals emphasizes why two clinicians working in the same environment-such as the attending physicians and junior residents in these datasets-might have vastly different appraisals of the same clinical event. Some of these differences reflect the limits of human perception, because "human beings can only register a few elements of the blooming buzzing confusion that surrounds them." ${ }^{52(p g .126)}$ Yet the reflections from participants in these studies highlight how holistic appraisals are shaped by more than simply attending to the cues that are available to them in these moments. ${ }^{40,41,53,54}$ Instead, participants seemed to be weighing how these cues could be contextualized in conjunction with their own knowledge base, past experiences, social contexts, and environmental resources. It was these interactions that ultimately shaped how clinicians generated individualized and idiosyncratic appraisals of a given moment; this also likely explains why others around them may appraise the same situation in a different way.

\section{Translating Appraisals into Action}

Because this program of research is centered around the clinicians' management of ill-defined problems in practice, it is important to consider the linkages between appraisals and action. Comfort was more than simply a metacognitive state reflecting clinicians' understanding of a situation; rather, the clinicians in these studies seemed to be sorting and manipulating the confluence of cues from themselves, their patients, and the environment towards a state in which they could make actionable progress. This leads to questions about how management strategies and comfort dynamically interact, as well as what it means to be "sufficiently" comfortable to act. 
Past work in the field of appraisal theory has conceptualized emotional processes as "continuous and recursive," 51 (pg. 199) which resonates with the cyclical aspects of monitoring and forward planning that participants described when generating appraisals of comfort. Frijda has elaborated the concept of 'action readiness' as a linkage between experiences and behavior, using this framework to describe a "readiness to find and execute some action that can do something with or about the event and its affective value." ${ }^{15(\mathrm{pg} .614)}$ A state of action readiness can take the form of physical movements or preparation, and a given event can potentially generate multiple states of action readiness based upon how it is appraised. ${ }^{55}$ Within this framing, for example, an event such as a rapidly evolving clinical situation that is rife with uncertainty could be appraised as both a challenge and a threat-thereby generating multiple interacting states of action readiness. Frijda would suggest that it is the interactions between these multiple action readiness states that generates observable behaviors, such as the ways in which participants in these studies decided to wade into problems on their own in some situations, and triaged them to colleagues for help in others. ${ }^{55}$

The ways in which clinicians in these studies actively managed ill-defined problems despite their ongoing sense of uncertainty implies a belief that their ongoing engagement would enable them to successfully navigate these moments. These situationally bound experiences with uncertainty align with the concepts of self-efficacy, "driven by an interaction between selfconcept beliefs about one's skills or abilities and the specific context in which those skills or abilities will be applied for the attainment of the particular goal." ${ }^{16(\mathrm{pg} .}{ }^{548)}$ As discussed in Chapters 3 and 4, experienced clinicians seemed to be using their holistic appraisals of comfort to decide about next steps, and though they may have had tentative understandings of 'what is going on?' and 'what [they] should do,' they had a relatively strong sense of how they might reasonably move forward in ways that gave them the best chance at successfully managing these situations. Eva and Regehr have highlighted this reciprocal relationship between selfefficacy and success ${ }^{56}$-namely that success reinforces self-efficacy, and that a strong sense of self-efficacy leads to greater chances of being successful-and this was illustrated by the ways 


\section{CHAPTER 7}

that experienced participants in these studies used tried-and-tested approaches, algorithms, and boundary conditions to wade into ill-defined problems ${ }^{40}$ This aligns with Atkinson's assertion that experts develop a "faith and 'moral certainty' in the stability and predictability of the world-within-reach and of his or her perceptions of it. Such faith provides that sense of ' can do it again' which the practitioner relies on to get through the day's work." ${ }^{57(\mathrm{pg} .955)}$ In these ways, relative comfort or discomfort are not appraisals of whether clinicians can engage with situations generating uncertainty, but rather help clinicians to modulate how they approach and manage these situations in the moment.

In contrast, the experiences of trainees in Chapters 5 and 6 highlight the challenges that novice clinicians face when wading through experiences of uncertainty with more tentative constructions of their own comfort. This tentativeness seemed to be shaped by a relative lack of familiarity with the problems they faced, a general skepticism about their own abilities, and a lack of experience in seeing how these types of uncertainty experiences might progress. ${ }^{54} \mathrm{As}$ a result, trainees struggled to distinguish between the relative contributions of self (e.g., their sense of their own abilities) and situation (e.g., their sense of a problem's complexity, or why others in their environment seemed to be understanding a problem differently), leading to a pervasive sense of skepticism about their appraisals of comfort. Lacking confidence in these appraisals, these novice clinicians seemed to manifest a more tentative sense of self-efficacy to handle a situation without first gauging others' input. Activities such as mental rehearsals seemed to be these clinicians' manifestations of 'goal-oriented self-talk' ${ }^{58}$ that enabled them to focus and calm themselves ahead of new experiences. These self-reinforcing activities, coupled with efforts to check their impressions against those of more experienced colleagues helped to reinforce novice clinicians' emerging sense of self-efficacy. In particular, the partnerships forged between supervisors and trainees described in Chapter 6 provide some interesting ways in which novices can "hang on" to ownership of situations that are at the borders of the abilities. ${ }^{53}$ This enabled them to safely experience moments where their own self-efficacy and successful resolution of clinical problems were intertwined. In the words of Participant 12 , building self- 


\section{CHAPTER 7}

efficacy through authentic experiences in these ways was "like hanging on to a mechanical bull, each time you can hold on a little longer." 53

\section{Mechanisms to improve one's titration of comfort}

Appraisals of comfort appear to be central to how clinicians manage uncertainty, and the experiences of participants in these studies offer a glimpse into how these self-regulatory behaviors are learned and reinforced through authentic experiences in the workplace. Social interactions with peers, other health professionals, and-in the case of trainees-their supervisors influenced the ways these clinicians titrated their level of comfort, shaping how they enacted situationally-embedded management strategies in the face of their unresolved uncertainties. These findings align well with Zimmerman's social cognitive model of selfregulation, which emphasizes "triadic reciprocity" (pg.330) between individuals, their social context, and their environment. ${ }^{59}$ Thinking about self-regulation through this social cognition lens provides a useful way to frame the ways in which the experienced and novice participants' comfort was shaped by their interactions with those around them. Within the social cognition literature, these findings can be understood as examples of 'socially shared regulation of learning' (SSRL), where group members jointly regulate their shared activity, or 'co-regulation' where hierarchical relationships between group members lead one or more group members to regulate the activities of others. ${ }^{60,61}$

The findings from my program of research highlight how uncertainty places tension on the complex social and cognitive forces that clinicians navigate in the workplace. In struggling to interpret cues that they were receiving from themselves, their patients, and their environment, clinicians in these studies looked to others-both implicitly and explicitly-to get a sense of whether they were appropriately understanding and managing a situation. Experienced clinicians borrowed comfort from other health professionals within their emergency department environment, for example, during particularly challenging moments, even while remaining in the role as decision-maker. ${ }^{40}$ One participant, for example, used the affirming signals of a social worker and a bedside nurse to get a sense that she was managing a situation 


\section{CHAPTER 7}

appropriately when making the difficult decision to restrain a patient who was having a mental health crisis, reflecting: "I needed to hear from other people that this was okay...I wanted somebody to reassure [me]." ${ }^{\prime 1(\mathrm{pg} .}{ }^{237)}$ Trainees made similar efforts to align themselves with others around them, building comfort that they could safely carry forward with their management strategies even if they were feeling quite unsure of their own abilities. ${ }^{53,54}$ Misalignment with coworkers, in contrast, led trainees to question their knowledge (e.g., "I guess I'm wrong"54(pg. $\left.{ }^{752)}\right)$ or to struggle with the tension of advocating for their patients or aligning with others' disparate interpretations (e.g., "I want to give this guy something because I can tell he's really uncomfortable, but I don't want to make the nurses uncomfortable"54(pg. $\left.{ }^{753)}\right)$. These experiences of uncertainty suggest a relatively flat hierarchical structure between team members, and align with concepts germane to SSRL, ${ }^{62,63}$ where "interdependent or collectively shared regulatory processes, beliefs, and knowledge (e.g., strategies, monitoring, evaluation, goal setting, motivation, metacognitive decision making) [are] orchestrated in the service of a co-constructed or shared outcome." ${ }^{60(p g .191)}$

Co-regulation - a more hierarchical form of regulation between individuals - was also evident in participants' narratives as they strategically invoked the help of others whom they perceived to have more advanced or distinct skills. Trainees naturally looked to their supervisors to get a sense of whether they should be comfortable during moments of uncertainty, using their supervisors' affective reactions or an absence of redirection to gauge whether they were on track. ${ }^{54}$ Trainees further used the sense that they had backup from their supervisors to try things that they would not otherwise feel comfortable doing on their own, and used performative actions such as 'broadcasting' and 'pantomiming' to explicitly or implicitly check their actions during high stakes moments. ${ }^{53}$ Experienced clinicians used similar mechanisms to self-regulate in moments of uncertainty, 'handing over' parts of problems to specialists when they encountered issues that were beyond their knowledge or skills, and transitioning ownership of patients' problems to colleagues when they felt like different skills or resources were needed. ${ }^{41}$ Experienced clinicians similarly felt comfortable tackling challenging problems 


\section{CHAPTER 7}

at the borders of their skillset when they knew that they had colleagues available as backup, and this enabled them to signpost boundary conditions that signaled when they needed help. ${ }^{40}$

These instances of co-regulation between clinicians and those around them advance the traditional framing of the zone of proximal development (ZPD) which Vygotsky proposed as "the distance between the actual developmental level as determined by independent problem solving and the level of potential development as determined through problem solving [italics added]...in collaboration with more capable peers." ${ }^{64(\mathrm{pg} .86)}$ The findings of this program of research would suggest that the ZPD manifests differently with ill-defined problems, where solutions to problems are negotiated, idiosyncratic, and unknowable in the moment-even to experts. Effective learning experiences in these contexts instead manifest when individuals can safely try to manage problems with the knowledge that they can call upon others for support. Having backup-be it from supervisors or colleagues with different skills-enables trainees and experienced clinicians alike to have the sense that they can wade into problems where solutions remain nebulous, attempt skills that they may not use frequently, or tackle problems where a variety of management strategies might be tried. Whether achieving successful resolution of these problems or safely failing (e.g., requiring a more experienced or skilled colleague to intervene), ${ }^{65,66}$ these experiences not only advance clinical skills and knowledge, but also provide clinicians with vital cognitive, emotional, and environmental lessons that can help them to effectively self-regulate when facing similar problems in the future.

\section{Implications for Teaching and Learning}

One of the most important findings from Chapter 3 is that experienced clinicians balanced competing appraisals of comfort and discomfort while working through moments of uncertainty, and never achieved a state where they were simply 'comfortable with uncertainty. ${ }^{40}$ Instead, it was a holistic sense of sufficient comfort that enabled practicing clinicians to feel like they could continue carrying forward, ${ }^{40}$ and sufficient discomfort that triggered them to respond to moments with greater attention and intention. ${ }^{41}$ Trainees described similar experiences of sufficient comfort and discomfort pertaining to the patient 


\section{CHAPTER 7}

problems they faced, but their nagging sense of skepticism in these appraisals added discomfort to their overall sense of whether they could safely manage these complex situations. ${ }^{53,54}$ In thinking about how experienced clinicians might help trainees maximize their learning through these experiences, these findings would suggest that simple admonishments such as 'you need to be more comfortable with uncertainty' may lead to unintended consequences such as these trainees ignoring or pushing through the very signals of discomfort that these supervising clinicians themselves use to effectively manage their own uncertainty.

The findings from this program of research would instead suggest that effective instructional interactions between supervisors and trainees hinge on encouraging learners to leverage the discomfort generated from ill-defined problems as opportunities to approach these moments in different ways (e.g., perking up to attend to these moments deliberately; stepping back to monitor progress and ensure that necessary resources are in place; or borrowing comfort from others around them). ${ }^{40,41}$ Targeted statements by trainees such as "you have to help me here because I don't want to miss something" ${ }^{\prime 53}$ provide important cues for supervisors to both support trainees' learning and attend to ill-defined problems with greater vigilance. In these moments, supervisors can model these self-regulatory behaviors to their trainees, making explicit the ways that they identify and leverage their appraisals of comfort and discomfort as a more transparent form of expertise (rather than, as illustrated in Chapter 5, assuming that trainees will correctly interpret their appraisals based upon behaviors alone)..${ }^{54}$ And recognizing that trainees may perceive that sharing their own discomfort will result in a loss of learning opportunities (e.g., because supervisors have historically taken over and assumed greater control of these situations), ${ }^{14,21}$ supervisors must strive to promote psychologically safe learning environments ${ }^{67}$ where sharing discomfort is viewed as a means for trainees to leverage their supervisors' comfort so that they can safely work their way through these problems with enhanced support. ${ }^{68}$

By analyzing perspectives of both experienced and novice clinicians, this program of research also raises interesting questions about how differing appraisals of comfort and discomfort 


\section{CHAPTER 7}

manifest as supervisors and trainees work together with ill-defined problems in practice. As suggested by appraisal theories of emotion, ${ }^{51}$ there are likely to be many moments when uncertainty is experienced differently by two individuals in the same situation, and there are several examples in the HPE literature illustrating how discrepant appraisals might shape how supervisor-trainee dyads manage situations together. Moulton and colleagues have conceptualized 'out of sync' moments where-in the eyes of a surgeon supervising an operative procedure-trainees seemed to be slowing down too much or too little. ${ }^{14}$ In recognizing these moments, supervisors described struggling with the degree of control they should exert upon these situations, recognizing that their influence was shaping the balance between trainee learning and patient safety. Ott et al. further elaborated how trainee hesitation-a potential signal of discomfort-manifest in operative settings and how supervisors and residents alike interpreted these pauses as signs of incompetence. ${ }^{21}$ The surgical trainees in Ott's study seemed to make decisions about whether or not to disclose the underlying reasons for their hesitations based upon whether they should (in their minds) be able to perform a particular task, ${ }^{21}$ and this echoes past work by Kennedy and colleagues regarding the ways that trainees avoid help-seeking behaviors as a means to maintain control of learning experiences. ${ }^{69}$

The results from my program of research add to this conversation about autonomy and supervision by highlighting the struggles that trainees described when trying to discern whether their interpretations of cues were accurate, whether their appraisals of comfort or discomfort were appropriate, and when they should most effectively leverage support from their supervisors. ${ }^{53,54}$ These findings would suggest that supervisors could provide more impactful structures of support by deliberately probing the cues that trainees are experiencing in moments of uncertainty (e.g., the signals that trainees receive from themselves, from their patients, and their environment, just as they do so when tackling problems themselves), then exploring how the trainee makes decisions about how to proceed safely ahead. Such conversations are not meant to be normative-in fact, supervisors should expect that trainees will appropriately diverge in their appraisals of comfort and discomfort given their own unique knowledge and experiences. It is instead the act of discussing the cues that are influencing 


\section{CHAPTER 7}

these appraisals that enables supervisors to reinforce the kinds of self-regulation they themselves use to maintain safety during moments of uncertainty.

Divergent appraisals are likely to provide the most fodder for productive reflection. For example, when a trainee expresses discomfort within a situation where their supervisor is sufficiently comfortable, supervisors can focus their attention on providing scaffolding that helps trainees borrow their comfort most effectively while remaining engaged with an illdefined problem. Doing so might take the form of sharing why they consider the risks to be sufficiently attended to (either by the trainees themselves or by the assistance they can provide), making explicit the ways that they are collectively monitoring these moments, and helping trainees with particularly challenging steps of a problem so that they can maintain control. Buoyed by their own sense of ongoing comfort, supervisors can thus give trainees opportunities to build confidence engaging with ill-defined problems, enabling them to either succeed with support or fail safely. ${ }^{65,66,70}$ Regardless of the outcome, this type of supervisory support promotes experiences germane to trainees' growth of effective self-regulation.

Alternatively, it may be cues from behaviors of trainees themselves that push supervisors' holistic appraisals of a situation towards discomfort. This might occur when trainees' skills are misaligned with risks that are emerging from an evolving situation, if trainees appear to be missing important cues from these moments, if trainees' reflections highlight risks that a supervisor themselves had missed, or if a situation is progressing in ways that supervisors cannot fix without timely intervention. Akin to their own mechanisms for managing ill-defined clinical problems, ${ }^{40,41}$ these cues from trainees enable supervisors to more explicitly consider the risks of a given supervisory situation. In doing so, supervisors can more purposefully guide trainees' approaches and help them to understand why their apparent comfort might be misplaced (e.g., signposting cues that they missed or misinterpreted). Supervisors can further attend to risks (both patient- and trainee-related) in more intentional ways by monitoring for cues from a situation that build comfort or add to a growing sense of discomfort. 


\section{CHAPTER 7}

Helping trainees to forward plan and monitor in these contexts can thus shape supervisors' own holistic appraisals of comfort and can create border conditions for determining how long a supervisor lets a trainee manage a situation without direct intervention. And if supervisors' ongoing monitoring of a trainee's interaction with a situation provides cues that a situation is getting out of hand, they can leverage this sense of discomfort as trigger to step in and manage a situation more directly (ideally making this decision explicit to their trainees too). By incorporating cues from trainees into their holistic appraisals of comfort while managing illdefined problems in practice, supervisors can effectively straddle their dueling roles as educators (entrusted with enriching trainees' experiences) and leaders (entrusted with maintaining patient safety).

\section{Implications for Future Research}

While these findings provide important insights into the ways that clinicians use appraisals of comfort to manage experiences of uncertainty in practice, the epistemological and methodological decisions embedded in this program of research impact our findings and interpretations in important ways. Accordingly, there are several new directions that could be explored in subsequent work.

To start, my team's collective epistemological stance heavily influenced the literatures I drew upon when elaborating my initial understanding of how 'comfort with uncertainty' has been represented in the literature. ${ }^{1}$ Taking a cognitivist lens enabled me to draw upon a wealth of research pertaining to the ways that reasoning processes manifest in the minds of physicians, and this enabled me to incorporate work such as Koriat's 'dual-basis view of metacognitive judgments' ${ }^{4}$ and 'cue utilization' ${ }^{46}$ as foundational components of how appraisals of comfort were generated in the minds of clinicians. Yet the findings from my empirical studies also suggest strong sociocognitive influences on these appraisals of comfort, ${ }^{40,53,54}$ and this aligns with past work demonstrating the ways in which social forces influence clinicians' 


\section{CHAPTER 7}

interpretations and management of complex moments in practice. ${ }^{61,69,71-75}$ As such, future work could more intentionally consider these socially negotiated aspects of reasoning within clinical environments, using frameworks such as socially shared regulation of learning ${ }^{67}$ and coregulation ${ }^{76}$ to better understand how healthcare team members adjust their understanding of ill-defined problems through interactions with others in practice. ${ }^{61}$

Two methodological decisions also heavily shaped the kinds of conversations that I had with my participants. The first was that I chose to interview clinicians immediately following their shifts using a critical incident technique ${ }^{77}$ to unpack moments of uncertainty that had manifested during their preceding workday. Collecting narratives in this way enabled me to probe these reflections in deep ways without the concurrent time pressures and distractions inherent in authentic clinical settings. But this technique of post-facto data collection undoubtedly missed important conscious, subconscious, and environmental influences that shaped clinicians' experiences with uncertainty in the moment. ${ }^{34,78,79}$ Real-time observations, or methods that enable more deliberate consideration of these emergent influences ${ }^{80}$ could provide interesting nuance to the cues that clinicians are attending to as they make appraisals of comfort during moments of uncertainty.

The second methodological choice pertained to my focus on emergency medicine faculty and residents who worked in urban academic training centers. I chose this population of participants because emergency physicians regularly face complex, dynamic, and undifferentiated clinical problems in practice, and this seemed like an ideal setting to gather narratives around authentic experiences with uncertainty. It was further the setting that I was most familiar with as a practicing emergency physician myself, and embedding my work in this context enabled me to probe my participants' stories in more nuanced ways. Context, however, is seen to be central in how expert clinicians reason in practice, ${ }^{33,34,39,81,82}$ so exploring how appraisals of comfort are generated in contexts where material or personnel resources are limited (e.g., more austere environments), where engagement with patients occur in a more longitudinal fashion (e.g., primary care settings, or care on the hospital wards), or where clinical 


\section{CHAPTER 7}

work looks very different (e.g., the operating room or procedural suite) could provide important extensions to this program of research.

Finally, while my two rounds of data collection provided interesting contrasts in how uncertainty and appraisals of comfort manifest in experienced and novice emergency physicians' minds, I likely missed an opportunity to directly explore trainees' beliefs about expertise. Was their impression that their experiences of discomfort would eventually go away? Did they conceptualize discomfort as something that should be minimized as their clinical skills grew? It would be intriguing to know if novice clinicians viewed their sense of uncertainty as a transient aspect of their training or as an indelible part of their practice. Did they think that they would eventually be able to know most of the answers (e.g., they would learn to manage problems in ways that uncertainty was eliminated) or did they appreciate that the sense of uncertainty will always remain (e.g., they were hoping to gain confidence in their abilities to judge and manage instances of uncertainty in practice)? Questions such as these could help to elaborate the kinds of experts that these trainees are trying and expecting to become, and would provide nuance to past work concerning the growth of adaptive expertise. ${ }^{83}$

\section{Conclusions}

Appraisals of comfort are fundamental to how clinicians manage ill-defined problems in practice. My program of research advances the ways in which experiences of clinical uncertainty are understood and managed by clinicians in practice, and provides useful guidance for educators charged with supporting the growth of these essential self-regulatory skills in trainees. 


\section{References}

1. Ilgen JS, Eva KW, de Bruin A, Cook DA, Regehr G. Comfort with uncertainty: reframing our conceptions of how clinicians navigate complex clinical situations. Adv Health Sci Educ Theory Pract. 2019;24:797-809.

2. Djulbegovic B, Hozo I, Greenland S. Uncertainty in Clinical Medicine. In: Gifford F, Gabbay D, Thagard P, Woods J. Handbook of Philosophy of Science. Vol 16. Amsterdam, NL: North Holland Publishing Co.; 2011, 299-356.

3. Kitchener KS. Cognition, metacognition, and epistemic cognition: a three-level model of cognitive processing. Hum Dev. 1983;4:222-232.

4. Koriat A. Monitoring one's own knowledge during study: A cue-utilization approach to judgments of learning. J Exp Psychol Gen. 1997;126:349-370.

5. Koriat A, Bjork RA, Sheffer L, Bar SK. Predicting one's own forgetting: the role of experience-based and theory-based processes. J Exp Psychol Gen. 2005;133:643-656.

6. Begg I, Duft S, Lalonde P, Melnick R, Sanvito J. Memory predictions are based on ease of processing. J Mem Lang. 1989;28:610-632.

7. Rawson KA, Dunlosky J. Are performance predictions for text based on ease of processing? J Exp Psychol Learn Mem Cogn. 2002;28:69-80.

8. Charmaz K. Constructing Grounded Theory: A practical guide through qualitative analysis. 2nd ed. London: Sage Publications; 2014.

9. Cristancho SM, Apramian $\mathrm{T}$, Vanstone $\mathrm{M}$, et al. Thinking like an expert: surgical decision making as a cyclical process of being aware. Am J Surg. 2016;211:64-69.

10. Cristancho SM, Apramian T, Vanstone M, Lingard L, Ott M, Novick RJ. Understanding clinical uncertainty: what is going on when experienced surgeons are not sure what to do? Acad Med. 2013;88:1516-1521.

11. Cristancho SM, Bidinosti SJ, Lingard LA, Novick RJ, Ott MC, Forbes TL. What's behind the scenes? Exploring the unspoken dimensions of complex and challenging surgical situations. Acad Med. 2014;89:1540-1547. 
12. Cristancho $S M$, Vanstone $M$, Lingard $L$, LeBel ME, Ott $M$. When surgeons face intraoperative challenges: a naturalistic model of surgical decision making. Am J Surg. 2013;205:156-162.

13. Moulton CA, Regehr G, Lingard L, Merritt C, Macrae H. 'Slowing down when you should': initiators and influences of the transition from the routine to the effortful. J Gastrointest Surg. 2010;14:1019-1026.

14. Moulton CA, Regehr G, Lingard L, Merritt C, Macrae H. Operating from the other side of the table: control dynamics and the surgeon educator. J Am Coll Surg. 2010;210:79-86.

15. Moulton CA, Regehr G, Lingard L, Merritt C, MacRae H. Slowing down to stay out of trouble in the operating room: remaining attentive in automaticity. Acad Med. 2010;85:1571-1577.

16. Fargason CAJ, Evans HH, Ashworth CS, Capper SA. The importance of preparing medical students to manage different types of uncertainty. Acad Med. 1997;72:688-692.

17. Luther VP, Crandall SJ. Commentary: Ambiguity and Uncertainty: Neglected Elements of Medical Education Curricula? Acad Med. 2011;86:799-800.

18. White $\mathrm{G}$, Williams $\mathrm{S}$. The certainty of uncertainty: can we teach a constructive response? Med Educ. 2017;51:1200-1202.

19. Geller G, Faden RR, Levine DM. Tolerance for ambiguity among medical students: implications for their selection, training and practice. Soc Sci Med. 1990;31:619-624.

20. Simpkin AL, Schwartzstein RM. Tolerating Uncertainty - The Next Medical Revolution? N Engl J Med. 2016;375:1713-1715.

21. Ott M, Schwartz A, Goldszmidt M, Bordage G, Lingard L. Resident hesitation in the operating room: does uncertainty equal incompetence? Med Educ. 2018;52:851-860.

22. Cooke G, Tapley A, Holliday E, et al. Responses to clinical uncertainty in Australian general practice trainees: a cross-sectional analysis. Med Educ. 2017;51:1277-1288.

23. Han PK, Schupack D, Daggett S, Holt CT, Strout TD. Temporal changes in tolerance of uncertainty among medical students: insights from an exploratory study. Med Educ Online. 2015;20:28285. 
24. Gerrity MS, Devellis RF, Earp JA. Physicians Reactions to Uncertainty in Patient Care. A new measure and new insights. Med Care. 1990;28:724-736.

25. Gerrity MS, Earp JAL, Devellis RF, Light DW. Uncertainty and Professional Work Perceptions of Physicians in Clinical-Practice. Am J Sociol. 1992;97:1022-1051.

26. Gerrity MS, White KP, DeVellis RF, Dittus RS. Physicians' reactions to uncertainty: Refining the constructs and scales. Motiv Emot. 1995;19:175-191.

27. Han PKJ, Strout TD, Gutheil C, et al. How Physicians Manage Medical Uncertainty: A Qualitative Study and Conceptual Taxonomy. Med Decis Making. 2021;41:275-291.

28. Begin AS, Hidrue M, Lehrhoff S, Del Carmen MG, Armstrong K, Wasfy JH. Factors Associated with Physician Tolerance of Uncertainty: an Observational Study. J Gen Intern Med. 2021;26:1-7.

29. Hillen MA, Gutheil CM, Strout TD, Smets EMA, Han PKJ. Tolerance of uncertainty: Conceptual analysis, integrative model, and implications for healthcare. Soc Sci Med. 2017;180:62-75.

30. Allison JJ, Kiefe Cl, Cook EF, Gerrity MS, Orav EJ, Centor R. The association of physician attitudes about uncertainty and risk taking with resource use in a Medicare HMO. Med Decis Making. 1998;18:320-329.

31. Geller G. Tolerance for ambiguity: an ethics-based criterion for medical student selection. Acad Med. 2013;88:581-584.

32. Eva KW. What every teacher needs to know about clinical reasoning. Med Educ. 2005;39:98-106.

33. Durning $S$, Artino Jr AR, Pangaro L, van der Vleuten CP, Schuwirth L. Context and clinical reasoning: understanding the perspective of the expert's voice. Med Educ. 2011;45:927938.

34. Durning SJ, Artino AR, Boulet JR, Dorrance K, van der Vleuten C, Schuwirth L. The impact of selected contextual factors on experts' clinical reasoning performance (does context impact clinical reasoning performance in experts?). Adv Health Sci Educ Theory Pract. 2012;17:65-79. 


\section{CHAPTER 7}

35. Bates J, Ellaway RH. Mapping the dark matter of context: a conceptual scoping review. Med Educ. 2016;50:807-816.

36. Bowen JL. Educational strategies to promote clinical diagnostic reasoning. $\mathrm{N}$ Engl J Med. 2006;355:2217-2225.

37. Kleinman A, Eisenberg L, Good B. Culture, illness, and care: clinical lessons from anthropologic and cross-cultural research. Ann Intern Med. 1978;88:251-258.

38. Ilgen JS, Eva KW, Regehr G. What's in a Label? Is Diagnosis the Start or the End of Clinical Reasoning? J Gen Intern Med. 2016;31:435-437.

39. Durning SJ, Artino AR. Situativity theory: a perspective on how participants and the environment can interact: AMEE Guide no. 52. Med Teach. 2011;33:188-199.

40. Ilgen JS, Bowen JL, de Bruin ABH, Regehr G, Teunissen P. "I Was Worried About the Patient, But I Wasn't Feeling Worried": How Physicians Judge Their Comfort in Settings of Uncertainty. Acad Med. 2020;95:S67-S72.

41. Ilgen JS, Teunissen PW, de Bruin ABH, Bowen JL, Regehr G. Warning bells: How clinicians leverage their discomfort to manage moments of uncertainty. Med Educ. 2021;55:233241.

42. LeBlanc VR. The effects of acute stress on performance: implications for health professions education. Acad Med. 2009;84:S25-33.

43. Moulton CA, Regehr G, Mylopoulos M, MacRae HM. Slowing down when you should: a new model of expert judgment. Acad Med. 2007;82:S109-116.

44. Zilbert NR, St-Martin L, Regehr G, Gallinger S, Moulton CA. Planning to Avoid Trouble in the Operating Room: Experts' Formulation of the Preoperative Plan. J Surg Educ. 2015;72:271-277.

45. Zilbert NR, Murnaghan ML, Gallinger S, Regehr G, Moulton CA. Taking a Chance or Playing It Safe: Reframing Risk Assessment Within the Surgeon's Comfort Zone. Ann Surg. 2015;262:253-259.

46. de Bruin A, Dunlosky J, Cavalcanti R. Monitoring and Regulation of Learning in Medical Education: The Need for Predictive Cues. Med Educ. 2017;51:575-584. 
47. Checkland P. Soft systems methodology: a thirty year retrospective. Syst Res Behav Sci. 2000;17:S11-S58.

48. Cristancho S. What can we learn from a soft sister? A complementary lens to the systems engineering approach in medical education research. Med Educ. 2014;48:11391141.

49. Cristancho S, Lingard L, Forbes T, Ott M, Novick R. Putting the puzzle together: the role of 'problem definition' in complex clinical judgement. Med Educ. 2017;51:207-214.

50. Roseman IJ, Smith CA. Appraisal theory: Overview, assumptions, varieties, controversies. In: K. R. Scherer, A. Schorr, \& T. Johnstone (Eds.), Appraisal processes in emotion: Theory, methods, research. Oxford: Oxford University Press; 2001, 3-19.

51. Moors A, Ellsworth PC, Scherer KR, Frijda NH. Appraisal Theories of Emotion: State of the Art and Future Development. Emotion Review. 2013;5:119-124.

52. Ellsworth PC, Scherer KR. Appraisal processes in emotion. In: R. J. Davidson, K. R. Scherer, \& H. H. Goldsmith (Eds.), Handbook of affective sciences. Oxford: Oxford University Press; 2003, 572-595.

53. Ilgen JS, de Bruin ABH, Teunissen PW, Sherbino J, Regehr G. Supported Independence: The role of supervision to help trainees manage uncertainty. 2021;96:S81-S86.

54. Ilgen JS, Regehr G, Teunissen PW, Sherbino J, de Bruin ABH. Skeptical self-regulation: Resident experiences of uncertainty about uncertainty. Med Educ. 2021;55:749-757.

55. Frijda NH. The evolutionary emergence of what we call "emotions". Cogn Emot. 2016;30:609-620.

56. Eva KW, Regehr G. Self-assessment in the health professions: a reformulation and research agenda. Acad Med. 2005;80:S46-54.

57. Atkinson P. Training for certainty. Soc Sci Med. 1984;19:949-956.

58. Wolters CA. Regulation of motivation: Evaluating an underemphasized aspect of selfregulated learning. Educational psychologist. 2003;38:189-205.

59. Zimmerman BJ. A social cognitive view of self-regulated academic learning. J Educ Psychol. 1989;81:329. 


\section{CHAPTER 7}

60. Panadero $E$, Järvelä S. Socially shared regulation of learning: A review. European Psychologist. 2015;20:190-203.

61. Bransen D, Govaerts MJB, Panadero E, Sluijsmans DMA, Driessen EW. Putting selfregulated learning in context: Integrating self-, co-, and socially shared regulation of learning. Med Educ. 2021;doi: 10.1111/medu.14566. Online ahead of print.

62. Winne PH, Hadwin AF, Perry NE. Metacognition and computer-supported collaborative learning. International handbook of collaborative learning. In C. E. Hmelo-Silver, C. A. Chinn, C. K. K. Chan, \& A. O'Donnell (Eds.), The international handbook of collaborative learning. Abingdon: Routledge/Taylor \& Francis Group; 2013, 462-479.

63. Järvelä S, Hadwin AF. New frontiers: Regulating learning in CSCL. Educ Psychol. 2013;48:25-39.

64. Vygotsky LS. Mind in Society: The Development of Higher Psychological Processes. Cambridge, MA: Harvard University Press; 1978.

65. Klasen JM, Driessen E, Teunissen PW, Lingard LA. 'Whatever you cut, I can fix it': clinical supervisors' interview accounts of allowing trainee failure while guarding patient safety. BMJ Qual Saf. 2020;29:727-734.

66. Klasen JM, Lingard LA. Allowing failure for educational purposes in postgraduate clinical training: A narrative review. Med Teach. 2019;41:1263-1269.

67. Appelbaum NP, Dow A, Mazmanian PE, Jundt DK, Appelbaum EN. The effects of power, leadership and psychological safety on resident event reporting. Med Educ. 2016;50:343-350.

68. Tsuei SH, Lee D, Ho C, Regehr G, Nimmon L. Exploring the Construct of Psychological Safety in Medical Education. Acad Med. 2019;94:S28-S35.

69. Kennedy TJ, Regehr G, Baker GR, Lingard LA. 'It's a cultural expectation...' The pressure on medical trainees to work independently in clinical practice. Med Educ. 2009;43:645653.

70. Klasen JM. It Hurts Whether You Fail or Not. Acad Med. 2020;95:1207.

71. Jin CJ, Martimianakis MA, Kitto S, Moulton CA. Pressures to "measure up" in surgery: managing your image and managing your patient. Ann Surg. 2012;256:989-993. 
72. Kennedy TJ, Regehr G, Baker GR, Lingard L. Preserving professional credibility: grounded theory study of medical trainees' requests for clinical support. BMJ. 2009;338:b128.

73. Luu S, Patel P, St-Martin L, et al. Waking up the next morning: surgeons' emotional reactions to adverse events. Med Educ. 2012;46:1179-1188.

74. Novick RJ, Lingard L, Cristancho SM. The call, the save, and the threat: understanding expert help-seeking behavior during nonroutine operative scenarios. J Surg Educ. 2015;72:302-309.

75. Leung A, Luu S, Regehr G, Murnaghan ML, Gallinger S, Moulton CA. "First, do no harm": balancing competing priorities in surgical practice. Acad Med. 2012;87:1368-1374.

76. Vermunt JD, Verloop N. Congruence and friction between learning and teaching. Learn Instr. 1999;9:257-280.

77. Flanagan JC. The critical incident technique. Psychol Bull. 1954;51:327-358.

78. Norman G. Is the mouth the mirror of the mind? Adv Health Sci Educ Theory Pract. 2018;23:665-669.

79. van der Schaaf M, Bakker A, Ten Cate O. When I say...embodied cognition. Med Educ. 2019;53:219-220.

80. Pelaccia T, Tardif J, Triby E, et al. How and when do expert emergency physicians generate and evaluate diagnostic hypotheses? A qualitative study using head-mounted video cued-recall interviews. Ann Emerg Med. 2014;64:575-585.

81. Holmboe ES, Durning SJ. Understanding the social in diagnosis and error: a family of theories known as situativity to better inform diagnosis and error. Diagnosis. 2020;7:161-164.

82. van der Vleuten CP. When I say... context specificity. Med Educ. 2014;48:234-235.

83. Mylopoulos M, Regehr G. How student models of expertise and innovation impact the development of adaptive expertise in medicine. Med Educ. 2009;43:127-132. 

Summary 


\section{SUMMARY}

Uncertainty is central to authentic clinical practice in the health professions. There is a sense that novice clinicians struggle with uncertainty, lacking the comfort that experts seem to have when working through these difficult moments in practice. Yet how experts employ comfort to effectively manage experiences of uncertainty remains poorly understood. This thesis seeks to explore how comfort manifests in the minds of clinicians as they work through experiences of uncertainty and how these appraisals shape their strategies to manage these dynamic moments in practice.

Chapter 1 provides historical context around how uncertainty has been conceptualized in the health professions literature, and foregrounds how this program of research intends to shift focus towards in-the-moment experiences of uncertainty. A general take-home of this past work is that scholars have treated uncertainty as analogous to "something that is unknown," implying that diagnoses or management decisions could be known-or known with a greater degree of certainty - if clinicians used a variety of theoretical, statistical, or cognitive approaches to reduce uncertainty. I suggest that these abstractions of uncertainty centering around ways to reduce what is unknown towards reliable solutions may thus be importantly distinct from what it means to be uncertain in practice. This provides the foundation for this program of research, namely my efforts to better understand the seemingly paradoxical ways that clinicians are comfortable during in-the-moment experiences of uncertainty. This chapter introduces the studies within this thesis, and outlines several key research questions: (1) What types of circumstances in practicing clinicians' daily work generate the sense that they have an incomplete or insufficient understanding of a situation, and how is this sense of uncertainty experienced in these moments?; (2) How do practicing clinicians use judgments of comfort to appraise the extent to which their knowledge and skills are sufficiently aligned with a situation to deliver safe and effective care, and how do these appraisals shift their approaches to these situations?; (3) How do novice clinicians' appraisals of comfort differ from more experienced practicing clinicians, and how do novices think about potential responses given their sense of the challenges and affordances in the situation?; and, (4) How does supervision impact 


\section{SUMMARY}

trainees' experiences with uncertainty, and how do they perceive and balance the competing tensions of clinical independence, supervisory support, and patient safety?

Chapter 2 seeks to define and elaborate the notion of 'comfort with uncertainty' as a first step to thinking about and researching this phenomenon. Using a critical review methodology that draws from a broad range of literatures, this chapter begins by defining the types of uncertainty we were most interested in exploring, namely the lack of confidence that individuals feel in the moment when they have an incomplete mental representation of a problem. Comfort, in contrast, is described as one's confidence in their capabilities to act (or not act) in a safe and effective manner given the situation. This sense of comfort is hypothesized to result from the integration of a variety of perceptual, emotional, and situational cues. Several examples of how comfort with uncertainty is manifest in the literature are provided, drawing corollaries with Koriat's dual-basis view of metacognitive judgments with the hypothesis that comfort is enabled through ongoing efforts of self-monitoring and forward planning. This chapter concludes by discussing potential implications of using 'comfort with uncertainty' as a framework for educational and research programs.

Chapter 3 presents an exploratory study of practicing emergency physicians' experiences of uncertainty and seeks to better understand how comfort manifests in these moments. Using a constructivist grounded theory approach, I conducted semi-structured interviews with emergency medicine faculty using a critical incident technique, prompting them to reflect on experiences of uncertainty during a preceding clinical shift. Participants were asked to think about cases when they needed help from others (or not), and instances when they made decisions to discharge or admit patients with a lingering sense of uncertainty. I asked them to begin by hand-drawing visual representations of these experiences, then began the interviews with questions about how they experienced uncertainty and made real-time judgments regarding their comfort to manage a given problem. In analyzing these narratives, I found that participants wrestled with multiple forms of uncertainty, which broadly organized around their understanding of the problems they were facing and the potential actions they might take to 


\section{SUMMARY}

manage these situations. Participants described a fluid, actively negotiated state of comfort that was informed by their efforts to project forward and imagine how a problem might evolve, and these efforts were coupled with ongoing monitoring activities pertaining to patients, their own metacognitions, and their environment to gauge their progress through these experiences. Importantly, participants highlighted how holistic appraisals of comfort existed on a dynamic spectrum that included elements of both comfort and discomfort, and elaborated how seeking a state of 'sufficient comfort' enabled them to take diagnostic or management steps forward. These findings suggested that 'comfort with uncertainty' is more nuanced than a dichotomous sense of being comfortable or not. Instead, it seems to be an ever-evolving state that reflects and enables clinicians' predictions about how prepared they feel to manage the various ways in which problems might play out and determine how they should proactively monitor the progression of these problems under their care.

With the recognition that discomfort played an important role in the spectrum of comfort that was manifest in practicing clinicians, Chapter $\mathbf{4}$ probes deeper into our first dataset to explore the ways that discomfort influenced clinicians' experiences with uncertainty in practice. Using the constructivist grounded theory approach and the critical incident technique described in Chapter 3, my interview questions prompted participants to elaborate the cognitive, emotional, and somatic manifestations of discomfort, how they appraised and responded to these cues, and how they used available resources to act in these moments of uncertainty. I found elements of discomfort in all participants' case descriptions, and these appraisals were driven by a multitude of cues that alerted these clinicians that problems were evolving in unexpected ways or might require management skills that were outside of their abilities to handle safely and effectively. Discomfort thus served as a trigger for participants to monitor a situation with greater attention, to proceed more intentionally, and to think deliberately about the types of human and material resources they might call upon to strategically manage these uncertain situations. These results suggest that discomfort is more central to how experienced physicians manage uncertainty than past conceptualizations would imply, and that leveraging discomfort 


\section{SUMMARY}

provides an important impetus for clinicians to approach moments of uncertainty in strategic ways that help them to maintain control of complex, evolving situations.

In Chapter 5, I shift my focus towards the ways in which comfort manifests in the minds of more novice clinicians, anticipating that these clinicians might navigate experiences of uncertainty in ways that are distinct from what I had found in experienced clinicians. Informed by constructivist grounded theory methodology and enabled by a critical incident technique, these interviews prompted emergency medicine residents in the first- or second years of their post-graduate training programs to reflect on experiences of uncertainty during their preceding clinical shifts. I found that novice clinicians-in-training experienced uncertainty in ways that were similar to those I had heard from practicing clinicians in Chapters 3 and 4, forming appraisals of comfort as they struggled with uncertainties concerning the root causes of the patient problems and the potential management steps they might take. Yet novices expressed a pervasive sense of uncertainty about their own appraisals, and this in turn led them to struggle with efforts to select and interpret cues from patients, their environment, and themselves. Trainees described several strategies to combat this pervasive skepticism in the legitimacy of their appraisals, including rehearsing steps before a clinical encounter, checking their interpretations with others, and implicitly calibrating their appraisals to those of more experienced team members. These findings suggest that novice clinicians' experiences with uncertainty are shaped by their ongoing skepticism in their own abilities. To help novices to self-regulate more effectively, I suggest that supervisors and other healthcare team members can more deliberately elaborate the strategies that they themselves use to approach ill-defined problems in practice, coupling this with real-time validation and calibration of the clinical judgments that novices make as they engage in experiences of uncertainty.

Chapter 6 examines how trainees leverage the support of their supervisors to help them manage workplace experiences of uncertainty. These emergent findings from the dataset described in Chapter 5 elaborate how novice emergency medicine trainees conceptualized the role of their supervisors as they struggled to maintain control of situations that generated 


\section{SUMMARY}

uncertainty. Participants described a strong desire for 'supported independence,' where predictable and accessible supervisory structures enable them to work semi-autonomously through challenging clinical situations and also highlighted challenges they faced when feeling insufficiently supported. Trainees described strategies to borrow supervisors' comfort during moments of uncertainty as a means to invoke (the right level of) support and explained how they broadcasted their thinking out loud or performed exaggerated actions in view of their supervisors as mechanisms to check and validate their decision-making. I suggest that educators can better support trainees in their growth towards self-regulation by recognizing these behaviors as overtures for support. In doing so, supervisors can help trainees strike the balance between independence for the purposes of learning and support that ensures patient safety.

Chapter 7 synthesizes the empirical findings from this program of research, elaborates connections to the health professions and social cognition literatures, and suggests several directions for future research. I begin by considering the central finding that situationally embedded appraisals of comfort exist on a dynamic spectrum and explore how appraisal theories of emotion help to explain why individuals can experience the same situation quite differently. I discuss how differences in appraisals impact individuals' readiness to act, and how self-regulatory behaviors are learned and reinforced through clinicians' authentic experiences in the workplace. This raises interesting questions about how constructs from the social cognition literature such as socially shared regulation of learning and co-regulation might be better reinforced in educational programs, in particular how effective supervision can enable trainees to safely try to manage problems within their zones of proximal development. I suggest that supervisors may, in fact, be most useful to trainees when their appraisals differsharing their comfort to help trainees carry forward (e.g., helping trainees to effectively manage their discomfort) and stepping in to maintain safety when trainee comfort appears misaligned with the emerging risks of a situation. I conclude with several suggestions for future research, exploring how questions around comfort with uncertainty might be probed through different epistemological lenses, data collection techniques, and contexts. 
Samenvatting 


\section{SAMENVATTING}

Onzekerheid staat centraal in de dagelijkse klinische zorgpraktijk. We zijn ons ervan bewust dat beginnende clinici worstelen met onzekerheid, omdat zij, in tegenstelling tot specialisten, zich niet comfortabel voelen wanneer zij zich door moeilijke momenten in de praktijk heen werken. Hoe specialisten zich comfortabel voelen om effectief met hun onzekerheid om te gaan, blijft echter onduidelijk. Dit proefschrift poogt te onderzoeken hoe comfortabel voelen zich bij clinici manifesteert terwijl zij zich door deze onzekerheidsbeleving heen werken en hoe hun afwegingen van invloed zijn op de wijze waarop zij met deze dynamische momenten in de praktijk omgaan.

Hoofdstuk 1 geeft een historische context bij de vraag hoe onzekerheid in de literatuur over zorgberoepen is geconceptualiseerd en belicht hoe het onderhavige onderzoeksprogramma de focus beoogt te verleggen naar onzekerheidsbeleving "in het moment". Een algemene lering die we uit dit eerdere werk kunnen trekken, is dat wetenschappers onzekerheid hebben behandeld als "iets dat onbekend is", wat suggereert dat diagnoses of beleidsplannen bekend zouden kunnen zijn, of met grotere zekerheid zouden kunnen worden (vast)gesteld, wanneer clinici een mix van theoretische, statistische of cognitieve werkwijzen zouden hanteren om onzekerheid te verminderen. Ik stel voor dat deze abstracte invullingen van onzekerheid, waarin manieren om wat onbekend is terug te brengen tot betrouwbare oplossingen centraal staan, daarom in belangrijke mate verschillen van wat het betekent om in de praktijk onzeker te zijn. Dit vormt de basis voor het onderhavige onderzoeksprogramma, namelijk mijn poging om inzicht te bieden in de paradoxale manier waarop clinici zich op comfortabel voelen tijdens momentane ervaringen van onzekerheid. Dit hoofdstuk introduceert de onderzoeksstudies binnen dit proefschrift en zet een aantal belangrijke onderzoeksvragen op een rij: 1) Wat voor soorten omstandigheden geven praktiserend clinici in hun dagelijks werk het gevoel dat ze een situatie niet volledig of onvoldoende begrijpen en hoe wordt dit gevoel van onzekerheid op deze momenten ervaren?; 2) Hoe gebruiken praktiserend clinici inschattingen van comfortabel voelen om te bepalen in welke mate hun kennis en vaardigheden voldoende op een situatie zijn afgestemd om veilige en doelmatige zorg te kunnen verlenen en hoe zijn deze afwegingen van invloed op de manier waarop zij met deze situaties omgaan?; 3) Hoe verschillen de 


\section{SAMENVATTING}

inschattingen van comfortabel voelen door beginnende clinici van die van meer ervaren praktiserend clinici en wat zien beginners als mogelijke responsen gezien de moeilijkheden en mogelijkheden die de situatie volgens hen biedt?; en 4) Hoe beïnvloedt supervisie de ervaring die artsen in opleiding hebben met onzekerheid en hoe zien en balanceren zij de tegenstrijdige spanningen tussen klinische onafhankelijkheid, begeleiding en patiëntveiligheid?

Hoofdstuk 2 tracht het begrip "comfortabel met onzekerheid" te definiëren en te specificeren als eerste stap in het nadenken over en onderzoeken van dit fenomeen. Aan de hand van een kritische review van literatuur, begint dit hoofdstuk met het definiëren van de soorten onzekerheid die we bij voorkeur wilden onderzoeken, namelijk het gebrek aan vertrouwen dat individuen voelen op het moment dat ze een niet complete mentale voorstelling hebben van een probleem. Comfortabel wordt daarentegen omschreven als het vertrouwen dat men heeft in het eigen vermogen om op een veilige en effectieve manier te handelen (of niet te handelen) gezien de situatie. Er wordt verondersteld dat dit comfortabele gevoel zich voordoet wanneer verschillende perceptuele, emotionele en situationele signalen worden geïntegreerd. Er worden verschillende voorbeelden gegeven van hoe "comfortabel met onzekerheid" tot uitdrukking komt in de literatuur, waarbij een vergelijking wordt getrokken tussen Koriats tweeledige visie op metacognitieve oordelen en de veronderstelling dat een comfortabel gevoel wordt aangewakkerd door voortdurende zelfcontrole en vooruit planning. Het hoofdstuk wordt afgesloten met een bespreking van de potentiële gevolgen van het gebruik van het concept "comfortabel met onzekerheid" als kader voor onderwijs- en onderzoeksprogramma's.

Hoofdstuk 3 presenteert een exploratief onderzoek naar de onzekerheidsbeleving van praktiserend SEH-artsen en tracht beter te begrijpen hoe het comfortabel zijn zich op deze momenten manifesteert. Geleid door een constructivist grounded theory benadering heb ik semigestructureerde interviews afgenomen bij SEH-staf, waarbij ik hun aan de hand van een kritische incidententechniek vroeg te reflecteren op momenten van onzekerheid tijdens een voorgaande klinische dienst. De deelnemers werd gevraagd om na te denken over gevallen 


\section{SAMENVATTING}

waarin zij hulp van anderen nodig hadden (of juist niet), en over gevallen waarin zij het besluit namen om patiënten te ontslaan of op te nemen met een aanhoudend gevoel van onzekerheid. Eerst vroeg ik hun om met de hand een visuele voorstelling van deze ervaringen te tekenen, alvorens het interview te beginnen met vragen over hoe zij hun onzekerheid hadden ervaren en ter plekke een inschatting maakten van hoe prettig zij zich voelden bij het aanpakken van een bepaald probleem. Bij het analyseren van deze verhalen constateerde ik dat de deelnemers met meerdere vormen van onzekerheid worstelden en dat deze in grote lijnen te maken hadden met hun begrip van de problemen waarmee ze geconfronteerd werden en met de mogelijk te ondernemen acties om deze situaties het hoofd te bieden. De deelnemers beschreven een actief onderhandelde staat van comfort die zij tot stand brachten door vooruit te kijken en zich voor te stellen hoe een probleem zich zou kunnen ontwikkelen, waarbij zij voortdurend hun patiënten, hun eigen metacognitie, alsook hun omgeving bleven monitoren om hun voortgang door deze ervaringen heen in te schatten. Opmerkelijk genoeg benadrukten de deelnemers dat holistische inschattingen van de mate waarin zij zich prettig voelden zich op een dynamisch continuüm bevonden dat zowel het element "prettig voelen" als "niet comfortabel voelen" omvatte, en specificeerden zij hoe het zoeken naar een staat van het zich "voldoende prettig voelen" hen in staat stelde om stappen te zetten ten aanzien van diagnose en beleid. Deze bevindingen maken aannemelijk dat het begrip "comfortabel met onzekerheid" genuanceerder is dan een simpele dichotomie van het zich prettig vs. niet prettig voelen. In plaats daarvan lijkt het een voortdurend evoluerende staat te zijn die de voorspellingen van clinici over hoe voorbereid zij zich voelen om de diverse manieren waarop de problemen zich zouden kunnen afwikkelen aan te pakken en te bepalen hoe zij de voortgang van deze problemen onder hun hoede proactief zouden moeten monitoren, weerspiegelt en mogelijk maakt.

Toen de belangrijke rol van niet comfortabel voelen in het zich-prettig-voelen-continuüm dat zich bij praktiserend clinici manifesteerde eenmaal was erkend, ging Hoofdstuk 4 dieper in op onze eerste dataset om erachter te komen op welke manier zich niet comfortabel voelen de onzekerheidsbeleving door clinici in de praktijk beïnvloedde. Opnieuw maakte ik gebruik van de in Hoofdstuk 3 beschreven contstructivist grounded theory benadering alsmede de kritische 


\section{SAMENVATTING}

incidenten techniek. Mijn interviewvragen spoorden de deelnemers aan om de cognitieve, emotionele en somatische uitingen van zich niet comfortabel voelen te specificeren, alsook hoe zij deze signalen beoordeelden en erop reageerden, en hoe zij beschikbare middelen aanwendden om in deze momenten van onzekerheid te handelen. Ik ontdekte elementen van niet comfortabel voelen in de voorbeeldbeschrijvingen van alle deelnemers en deze beoordelingen waren ingegeven door een veelvoud aan signalen die deze clinici waarschuwden dat problemen zich anders dan verwacht aan het ontwikkelen waren of vaardigheden vereisten die niet binnen hun vermogen lagen om ze veilig en effectief af te handelen. Niet comfortabel voelen vormde dus een aanleiding voor de deelnemers om een situatie nauwlettender in de gaten te houden, om doelbewuster te werk te gaan en om bewust na te denken over de menselijke en materiële middelen die ze zouden kunnen aanboren om deze onzekere situaties strategisch aan te pakken. Deze resultaten geven aan dat zich niet comfortabel voelen een belangrijkere rol speelt in de manier waarop ervaren artsen met onzekerheid omgaan dan eerdere conceptualiseringen suggereren en dat wanneer clinici het niet comfortabel voelen dat zij ervaren benutten dit een belangrijke stimulans voor hen kan zijn om momenten van onzekerheid op een strategische manier tegemoet te treden die hen helpt om complexe, veranderlijke situaties onder controle te houden.

In Hoofdstuk 5 verleg ik mijn focus naar de manier waarop comfortabel voelen zich manifesteert bij meer junior clinici, in de verwachting dat deze clinici wellicht op een andere manier met gevoelens van onzekerheid omgaan dan zoals ik dat bij ervaren clinici had geconstateerd. Gekenmerkt door een constructivist grounded theory benadering en vormgegeven met behulp van een kritische incidenten techniek, spoorden deze interviews artsen uit het eerste of tweede jaar van hun SEH-vervolgopleiding aan om te reflecteren op momenten van onzekerheid tijdens hun voorgaande klinische diensten. Ik ontdekte dat junior clinici in opleiding onzekerheid beleefden op een manier die vergelijkbaar was met wat ik in Hoofdstuk 3 en 4 van de praktiserend clinici had vernomen, namelijk dat zij al worstelend met onzekerheden over de onderliggende oorzaak van de patiëntklachten en de mogelijk te nemen beleidsstappen een inschatting maakten van de mate waarin zij zich prettig voelden. Bij de 


\section{SAMENVATTING}

junior clinici was er echter sprake van een overheersende onzekerheid over hun eigen inschattingen, en dit zorgde er weer voor dat zij moeite hadden met het selecteren en interpreteren van signalen van patiënten, hun omgeving en van henzelf. De artsen in opleiding beschreven diverse strategieën waarmee zij hun overheersend sceptische houding ten aanzien van de juistheid van hun inschattingen probeerden tegen te gaan, zoals het oefenen van bepaalde stappen vóór het klinisch consult, het checken van hun interpretatie bij anderen en het impliciet toetsen van hun inschattingen aan die van meer ervaren teamleden. Deze bevindingen geven aan dat de manier waarop junior clinici onzekerheid beleven wordt bepaald door hun aanhoudend sceptische houding ten aanzien van hun eigen capaciteiten. Om beginners te begeleiden bij een effectievere zelfregulatie, stel ik voor dat supervisoren en andere leden van het zorgteam doelbewuster ingaan op de strategieën die zij zelf gebruiken om moeilijk te vangen problemen in de praktijk het hoofd te bieden, en dit te koppelen aan directe validatie en aanpassing van de klinische inschattingen die beginners maken wanneer zij te maken krijgen met momenten van onzekerheid.

Hoofdstuk 6 onderzoekt hoe artsen in opleiding de steun van hun supervisoren gebruiken om hen te helpen hun onzekerheidsbeleving op de werkplek in goede banen te leiden. Deze bevindingen die voortkwamen uit de in Hoofdstuk 5 beschreven dataset geven weer welke rol junior artsen in opleiding SEH aan hun supervisoren toekenden wanneer zij voor situaties stonden die voor onzekerheid zorgden en deze onder controle probeerden te houden. De participanten beschreven een sterke behoefte aan "begeleide onafhankelijkheid", waarbij een voorspelbare en toegankelijke supervisie-opzet hen in staat stelde om zich half zelfstandig door lastige klinische situaties heen te werken. Ook wezen zij op de moeilijkheden die zich voordeden wanneer zij het gevoel hadden dat deze begeleiding tekortschoot. Voorts beschreven de artsen in opleiding strategieën waarmee ze het comfortabel voelen van hun supervisoren leenden op momenten van onzekerheid met het doel de juiste mate van begeleiding te ontvangen. Ook lichtten ze toe dat ze hardop gingen nadenken of handelingen overdreven verrichtten in het bijzijn van hun supervisors als tactiek om hun besluitvorming te controleren en te bevestigen. Ik veronderstel dat opleiders artsen in opleiding beter zullen 


\section{SAMENVATTING}

kunnen ondersteunen in hun groei naar zelfregulatie wanneer zij dit gedrag herkennen als een roep om begeleiding. Op die manier zullen supervisoren artsen in opleiding kunnen helpen een evenwicht te vinden tussen onafhankelijkheid ter bevordering van het leren en begeleiding ter garantie van de patiëntveiligheid.

Hoofdstuk 7 vat de empirische bevindingen van dit onderzoeksprogramma samen, legt verbanden met de literatuur over zorgberoepen en sociale cognitie en zet diverse lijnen uit voor toekomstig onderzoek. Eerst sta ik stil bij de voornaamste bevinding dat situationeel ingebedde inschattingen van het zich al of niet comfortabel voelen zich op een dynamisch continuüm bevinden en verdiep ik me vervolgens in de vraag hoe theorieën over het inschatten van emoties kunnen helpen verklaren waarom individuen dezelfde situatie heel verschillend kunnen ervaren. Ik bespreek hoe inschattingsverschillen iemands bereidheid tot handelen beïnvloeden en hoe zelfregulerend gedrag wordt aangeleerd en versterkt door ervaringen die clinici in het echt doormaken op de werkplek. Dit roept interessante vragen op over hoe constructen uit de socialecognitieliteratuur, zoals sociaal gedeelde regulatie van leren en coregulatie, beter tot uitdrukking zouden kunnen komen in onderwijsprogramma's, in het bijzonder hoe effectieve supervisie ervoor kan zorgen dat artsen in opleiding binnen hun zone van naaste ontwikkeling op een veilige manier kunnen proberen om problemen het hoofd te bieden. Ik veronderstel dat supervisoren juist het meest voor artsen in opleiding kunnen betekenen wanneer hun inschattingen afwijken van die van de arts in opleiding, zodat zij het comfortabel voelen kunnen delen en daarmee de arts in opleiding vooruithelpen (d.w.z. dat zij de arts in opleiding helpen om effectief met het zich niet comfortabel voelen leren om te gaan) en veiligheidshalve kunnen ingrijpen wanneer de mate van kalmte die de arts in opleiding voelt niet overeen lijkt te stemmen met de risico's die zich voordoen in een situatie. Ten slotte besluit ik met het doen van diverse aanbevelingen voor toekomstig onderzoek, waarbij ik nader verken hoe vragen rondom het zich comfortabel voelen met onzekerheid vanuit diverse epistemologische invalshoeken, dataverzamelingstechnieken en contexten onderzocht kunnen worden. 
Scientific Impact 


\section{SCIENTIFIC IMPACT}

This section briefly describes the rationale and objectives of this thesis, discusses key results and conclusions, and elaborates several potential implications of these findings to the scientific community, society, and health professions educators.

\section{Project Rationale, Objectives, and Findings}

Uncertainty is fundamental to the practice of medicine, and clinicians' abilities to effectively manage these experiences is viewed as a marker of expertise. Clinicians can respond constructively to experiences of uncertainty in many ways, from strategies to elaborate the root causes of a patient's symptoms, to signposting risks that may surface as a clinical problem evolves, to considering the resources they may need to safely manage a problem. This thesis sought to understand clinicians' in-the-moment experiences with uncertainty, elaborating the notion of 'comfort' as means to better understand how they notice, make sense of, and respond to complex situations in practice.

In the initial qualitative study of practicing emergency physicians, experiences of comfort were described as a dynamic spectrum of in-the-moment appraisals. On one end of this spectrum, clinicians felt sufficiently comfortable to continue managing problems when they were able to project forward and imagine how situations might evolve, concurrently identifying boundary conditions to signal when they were reaching the borders of their expertise. Comfort was reinforced when-in the process of monitoring their patients, their own metacognitions, and their environment-they felt that a problem was proceeding as expected. On the other end of this spectrum, clinicians described discomfort when cues alerted them to problems that were evolving in unexpected ways or when they identified aspects of problems that were beyond their abilities. This discomfort served as a trigger for clinicians to monitor a situation with greater attention, proceed more intentionally, and think deliberately about the types of human and material resources they might call upon strategically to manage these situations. Taken together, the real-time balancing act between appraisals of comfort and discomfort gave clinicians the sense for how they could proceed safely through evolving experiences of uncertainty in their workplace. 


\section{SCIENTIFIC IMPACT}

An ensuing qualitative study of emergency medicine clinicians-in-training demonstrated similar manifestations of this spectrum of comfort with uncertainty, yet these novice clinicians' experiences were substantially colored by their own skepticism in their abilities to accurately appraise these situations. To cope with this uncertainty about themselves, trainees set themselves up for success by rehearsing the steps they intended to cover with their patients, then checked their interpretations of these experiences explicitly or implicitly against the appraisals of other members of their healthcare team. In discussing their unique experiences of uncertainty, trainees also elaborated several means that they used to forge effective partnerships with their supervisors, such as broadcasting their thinking or engaging in deliberately performative actions to garner their supervisors' attention. These studies suggest important lessons for how trainees learn to manage uncertainty in practice and suggest ways that supervisors can simultaneously support this growth and maintain patient safety.

\section{Impact on Science and Healthcare}

These findings have broad potential implications to science and healthcare. A wide variety of fields such as philosophy, mathematics, psychology, and engineering have explored ways to conceptualize, understand, and address uncertainty. While contextually, methodologically, and conceptually diverse, most of these approaches are oriented towards a reductionistic construction to uncertainty, aiming to name and sort factors that contribute the uncertainties of a prototypical problem. These factors are then used to generate statistical or probabilistic predictions about how a problem is likely to play out or how individuals are likely to act when confronted with a similar situation. This type of work provides helpful background for the ways in which individuals' knowledge, past experiences, and personality traits might interact with a wide variety of influences in an environment to shape their uncertainty. Yet such work has several important assumptions, all of which begin with a fairly positivist and reductionistic orientation to uncertainty: 1) that individuals will identify and interpret contextual factors or cues in the same ways; 2 ) that the probabilistic influences of these cues or data can be assigned and used in real time by individuals; and 3) that problems have mutually agreed-upon and 


\section{SCIENTIFIC IMPACT}

verifiable solutions. Lacking these conditions in a given moment of uncertainty, however, it is likely that the conceptual, statistical, and philosophical approaches that have been used historically to understand uncertainty are quite different from what individuals experience and do when they are uncertain.

This program of research begins with a much more constructivist and contextually-embedded notion of uncertainty. In contrast to fields such as mathematics or psychology where welldefined solutions can be identified and measured with relative precision, health professionals tackle problems that are vastly more ambiguous, negotiated, and idiosyncratic. For example, patients manifest a wide variety of symptoms and exam findings for a given disease, respond to treatments differently, and have disease states that are in constant evolution. In making sense of what might be going on with their patients and what they might do to help them, clinicians draw from their own idiosyncratic training and past experiences to gather information from their patients, diagnostic tests, and others in their work environment while concurrently enacting management strategies that harness the resources they have at their disposal. The ways that health professionals tackle uncertainty in their unique work contexts thus aligns well with the construct of 'ill-defined problems' where, as defined by Karen Kitchener elaborates, "there are conflicting assumptions, evidence, and opinion that may lead to different solutions." The findings from this program of research-namely the ways that clinicians make holistic predictions about how a problem might play out, how they intentionally monitor themselves and a situation, and how they use appraisals of comfort to be agentic in managing these experiences-may thus prove useful to other fields seeking to understand how individuals grapple with ill-defined problems in other contexts.

The constructions of 'comfort with uncertainty' elaborated by these research findings also offer several important implications for healthcare institutions. First and foremost, these results emphasize the dynamic and idiosyncratic ways that experienced clinicians make sense of the problems they are negotiating within their unique work contexts. This calls into question the notion that there is a stable construct of what it means to be an expert. Instead, expertise 


\section{SCIENTIFIC IMPACT}

seems to manifest through clinicians' abilities to effectively self-regulate when they feel uncertain, recognizing the emergent risks and the limits of their abilities, reflecting upon the alignment between their skills and the problem at hand, monitoring their patients and other team members intentionally, and drawing upon the resources that are available to them. This highlights the complex fabric of healthcare work environments, the ways in which clinicians rely on other health professionals (e.g., 'borrow comfort') to help bridge the gaps between their abilities and the demands of a problem, and the ways in which systems can effectively support collaborative ways of delivering care. This program of research has not elaborated the other side of these conversations-namely the vantage points of colleagues who have been called upon for help-and these perspectives are needed in future work to gain a deeper understanding of how systems can support these collaborations when they are needed most. That said, the implication from this research is that managing uncertainty is often a shared endeavor between health professionals, best fostered within systems where expressing vulnerability, asking others for help, and collaborative work are expected attributes of highfunctioning interprofessional and interdisciplinary teams.

\section{Impact on Society}

From a societal perspective, these findings provide nuance around the ways that patients understand the work of clinicians caring for them. Expertise in medicine is typically characterized in the lay media as tantamount to 'solving a case,' akin to detectives sleuthing for answers to unsolved problems. The American television drama "House" encapsulated this construction of medical expertise, chronicling the fictional character Dr. Gregory House as he pieced together pieces of clinical puzzles to arrive at diagnoses that had befuddled those before him. This inevitably led to statements such as "I solved the case, my work is done" (pilot episode), reinforcing the presumption that effective medical management is conditional upon diagnostic precision, and that expert clinicians guide their care teams by arriving at these diagnostic epiphanies in isolation. Yet this construction of medical expertise diverges greatly from the narratives shared by participants in these studies. Clinicians instead described tentative, negotiated, and dynamic constructions of problem-solving in moments of 


\section{SCIENTIFIC IMPACT}

uncertainty. To work through these experiences, they used cues from their patients, themselves, and their environment to 'feel' their way towards the next management steps even though they were not entirely sure what was going on or what types of interventions might help.

There thus seems to be a disconnect between how patients conceptualize the work of clinicians and the actual ways that clinicians work through problems in practice. Providing patients with a better understanding of how these processes play out in real time may, for example, may help them to understand why one clinician manages their problem(s) differently than another, why second opinions often result in different constructions of diagnostic and treatment plans, and why care feels so different in different contexts (e.g., the clinic, the emergency department, or the hospital wards).

This implies that greater effort is needed to reach patient audiences to animate the ways that clinicians manage uncertainty in practice. This discourse could be stimulated by capturing clinicians' narrative descriptions of how they experienced and managed dynamic scenarios that were rife with uncertainty, including the ways that they communicated these experiences to their patients. Podcasts, radio or television interviews, or live case-based discussions would all offer new ways for clinicians to elaborate these experiences with vulnerability and nuance. Multi-disciplinary and interprofessional conferences where clinicians, patients, policy makers, and patient advocates interact are also a ripe venue to engage in discussions about how best to support both patients and clinicians as they negotiate these experiences. The American and European 'Diagnostic Errors in Medicine' conferences offered by the Society to Improve Diagnosis in Medicine, for example, are venues where the patient-, provider-, and systembased influences on these uncertainty experiences could be unpacked from a variety of perspectives.

I had intended to discuss these issues concerning uncertainty as an invited keynote speaker at the 2020 European Diagnostic Errors in Medicine (EuroDEM) conference which was 


\section{SCIENTIFIC IMPACT}

unfortunately delayed due to the COVID-19 pandemic. I am hopeful that I can travel to Europe as a keynote speaker for the 2022 EuroDEM conference and additionally hope to translate these lessons into other media (e.g., podcasts, blog posts, magazine articles) that have a wider patient audience. Ideally, I can partner with non-clinicians in these efforts to generate lessons that are clear and pragmatic to the lay public. One goal could be to change the discourse around 'shared decision making' towards conversations that acknowledge the variety of ways that clinicians and patients form partnerships and communicate effectively when navigating uncertainty together.

\section{Impact on Health Professions Educators}

These research findings have the most direct impact on researchers and educators in the health professions. Since its publication in 2019, my conceptual manuscript on 'comfort with uncertainty' elaborated in Chapter 2 has been accessed over 1000 times on ResearchGate and cited 32 times by articles discussing topics such as clinical reasoning, diagnostic calibration, epistemologies in simulation, and the role of self-confidence. It was additionally referenced by Dr. Ray Land in his opening plenary "Threshold Concepts and Troublesome Knowledge" for the 2019 Association for Medical Educators in Europe (AMEE) annual meeting in Vienna, Austria.

I have shared these findings at local, regional, and national conferences in an effort to help others reimagine how clinical reasoning can be conceptualized and reinforced in our teaching practices. Locally, I presented these findings to the University of Washington Graduate Medical Education community on two occasions, with a total of over 180 residency leaders in attendance. These sessions emphasized the importance of attending to learners' signals for when they were experiencing discomfort, as well as strategies for effective modeling by supervisors. Regionally, I presented findings from Chapter 5 as an oral abstract at the 2021 AAMC Group on Educational Affairs regional meeting. And nationally, the findings elaborated in Chapters 3 and 6 were accepted as papers in Academic Medicine's competitive "Research in Medical Education" (RIME) supplement in 2020 and 2021, respectively. The findings from Chapter 6 will be presented as an oral abstract at the 2021 AAMC “Learn, Serve, Lead" virtual 


\section{SCIENTIFIC IMPACT}

conference, and I discussed the findings from Chapter 3 in a dedicated AAMC podcast led by RIME program leaders after the 2020 AAMC conference was shifted to a virtual format. The central implications for health professions educators that have been shared in these various speaking engagements are elaborated below.

For clinician educators who directly supervise trainees, it is essential to recognize that novice clinicians are inherently skeptical of their abilities to self-regulate effectively during experiences of uncertainty. This sets the stage for educators to monitor trainees more intentionally for instances when they are seeking support, manifest when trainees 'broadcast' their thinking about a problem, make efforts to cross-check their thinking with others, or express worry or concern about an evolving situation. It is equally important for clinician educators to realize that trainees often use supervisors' guidance in implicit ways, taking the absence of redirection as permission to proceed ahead or making assumptions about a supervisor's guidance based upon their body language or affect. This would suggest that supervisors can better support trainees by more deliberately broadcasting their own thought processes about the risks they are considering as a problem evolves, vulnerably sharing their emotional and somatic reactions to a situation as a marker of their own internal appraisals, and explicitly discussing how these appraisals are shifting their approaches to a given situation. Modeling of these behaviors provides real-time lessons to trainees regarding how experts self-regulate when uncertain. These lessons for supervisors could be reinforced, for example, in faculty development workshops on feedback or bedside teaching, or within courses emphasizing how to effectively debrief simulation scenarios.

These findings also have several implications for curriculum designers charged with building experiences that mimic the types of work that trainees engage with in authentic clinical practice. Traditional medical curricula are frequently oriented towards the diagnosis and treatment of specific medical conditions, thereby deemphasizing the processes by which information is gathered, interpreted, and acted upon in real time when patients present with new or undifferentiated problems. The results from this research program would suggest that 


\section{SCIENTIFIC IMPACT}

curriculum designers should build novel curricula that more purposefully address clinicians' experiences with uncertainty, prompting trainees to tackle clinical problems that are ambiguous, dynamic and negotiated and elaborating the risks they believe are at play in a given clinical moment. Training exercises such as theses should prompt trainees to think through the kinds of help they might need from others in order to address the problem at hand, and this would provide a novel means to emphasize the value of interprofessional collaborations. Designing curricula in these ways would help trainees to practice the self-regulatory behaviors that experienced clinicians use when encountering uncertainty, help them recognize the interdependence between different health care professionals, and more deliberately signpost the system forces that influence their care of patients with ill-defined problems. 


\section{CURRICULUM Vitae}

Jonathan Ilgen was born on December 11, 1976 in Princeton, New Jersey. After obtaining his bachelor's degree from Williams College in Williamstown, Massachusetts in 1999, he spent a year working at the National Institutes of Health in Bethesda, Maryland before matriculating as a student at the University of Southern California Keck School of Medicine. Upon graduating medical school in 2004, he began his Emergency Medicine training at the Harvard Affiliated Emergency Medicine Residency program, with clinical training at Massachusetts General Hospital, Brigham \& Women's Hospital, and Boston Children's Hospital. He completed his Emergency Medicine training in 2008, serving as a chief resident during his final year, then began a two-year Medical Education Research Fellowship program at Oregon Health \& Science University before joining the University of Washington (UW) faculty in 2010. Dr. Ilgen's interest in clinical reasoning began during his fellowship under the mentorship of Dr. Judith Bowen, and he has been incredibly fortunate to explore this interest through collaborations with scholars at the University of British Columbia and McMaster University over the past decade. This work has been buoyed by his ongoing clinical and teaching experiences with students and trainees at the University of Washington, where he serves as a longitudinal mentor within the School of Medicine's Colleges system and a practicing clinician at Harborview Medical Center. Dr. Ilgen directs the Medical Education Research Fellowship within the UW Department of Emergency Medicine and concurrently serves as the Vice Chair for Faculty Development \& Education. He is an author on 60 peer-reviewed manuscripts, 18 as first author and 14 as senior author, and currently serves as an Associate Editor for the Journal of Graduate Medical Education. 


\section{ACKNOWLEDGEMENTS}

This PhD experience has reinforced how lucky and privileged I am to be surrounded by such a generous, kind, and supportive community.

To Anique, Pim, and Glenn, it is impossible to capture the gratitude I have for your support as my PhD team. One never entirely knows what they are going to learn when they embark on a $\mathrm{PhD}$, and while it would take an entire chapter of this dissertation to enumerate the ways that my scholarship has grown by working alongside you, the most enduring legacy of this experience will be your mentorship. I truly experienced 'supported independence' as I worked through each piece of this dissertation, struggling and trying new things in my zone of proximal development with the reassurance that you were there to pick me up when I (frequently) got stuck. I cannot thank you enough, and will take these lessons of beneficent support with me as I aim to help others with their scholarship in the years ahead.

I have been incredibly fortunate to have an army of mentors and collaborators that have supported my interests in health professions scholarship. Kimo Takayesu, Lainie Yarris, and Judith Bowen were the original catalysts of this journey, and I have been so lucky to find friends such as Kevin Eva, Geoff Norman, Jonathan Sherbino, Sandra Monteiro, Andrea Gingerich, Gurpreet Dhaliwal, and David Cook, among many others, who have pushed me to think about my scholarship with rigor and nuance. This crazy idea to pursue a mid-career PhD would have never materialized had I not had such positive experiences working within a wonderful community of health professions scholars.

To my community of students, residents, and colleagues at the University of Washington, I will be forever grateful for the many conversations and patient care experiences I have had with you over the past decade or so. These experiences have helped me to understand the many ways that uncertainty plays out in our work, how we learn to manage these moments, and the ways that we can work together most effectively to care for our patients. I am particularly indebted to all that I have learned from faculty community around the UW Department of 
Emergency Medicine's Medical Education Research Fellowship, including Joshua Jauregui, Annie Chipman, Alisha Brown, Jeff Riddell, Laura Welsh, Bjorn Watsjold, Ashley Amick, and Caitlin Schrepel. I am also indebted to the ongoing support from our department chair, Susan Stern.

Finally, and most importantly, I dedicate this PhD to my family. To my parents and my brother Colin, there is no doubt that that our family adventures, childhood experiences, and mealtime conversations have impacted my path and curiosity as a clinician-educator. To my daughters Hannah and Grace, thank you for letting me burrow myself away periodically to meet some of the deadlines for this thesis. I hope that this dissertation shows that even old guys with embarrassing dad jokes can accomplish big things when they set goals and work hard. And to my wife Ann, I cannot thank you enough for unequivocally supporting me throughout this PhD journey. You have been the foundation that enabled me to do this work, and there was absolutely no way that I could have done this without you. 


\section{SHE DisserTATION SERIES}

The SHE Dissertation Series publishes dissertations of PhD candidates from the School of Health Professions Education (SHE) who defended their PhD theses at Maastricht University. The most recent ones are listed below. For more information go to:

https://she.mumc.maastrichtuniversity.nl

Lestari, E. (05-10-2021) INTERPROFESSIONAL EDUCATION Lessons from Indonesia

Atherley, A. (27-09-2021) Beyond the struggles: Using social-developmental lenses on the transition to clinical training

Schillings, M. (06-07-2021) Talking about feedback: Face-to-face peer dialogue about written feedback

Wilbur, K. (05-07-2021) NO WHERE / NOW HERE: Context and Competency Expectations in Workplace-Based Training

Bendermacher, G. (02-07-2021) Navigating from Quality Management to Quality Culture

Ahmed Khan, R. (29-06-2021) Assessing curriculum viability in Undergraduate Medical Education

Chim, H.Q. (30-03-2021) Physical Activity Behavior and Learning in Higher Education

Dominguez, L.C. (23-02-2021) Persistence in surgical training: The role of job crafting and leadership

Bindels, E. (22-02-2021) DOING WELL, GETTING BETTER; Facilitating physicians' reflection on their professional performance

Iqbal, Z. (15-12-2020) All stakeholders matter in faculty development: Designing entrustable professional activities for small group facilitation

Tran, QT. (09-12-2020) Nationwide implementation of medical skills training laboratories in a developing country: studies from Vietnam

Pacifico, J. (30-11-2020) Making the Implicit Explicit: Uncovering the Role of the Conceptions of Teaching and Learning and the Perceptions of the Learning Climate in Postgraduate Medical Training. 
Nishigori, H. (17-11-2020) Why do doctors work for patients? Medical professionalism in the era of neoliberalism

Oudkerk Pool, A. (06-11-2020) Competency-based portfolio assessment-Unraveling stakeholder perspectives and assessment practices

Geel van, K. (05-11-2020) Lifelong learning in radiology: all eyes on visual expertise Stammen, L. (16-10-2020) Pursuing - High-Value, Cost-Conscious Care - The Role of Medical Education

Meulen van der, M. (15-10-2020) Assessment of physicians' professional performance using questionnaire-based tools

Matsuyama, Y. (05-10-2020) Contextual attributes fostering self-regulated learning in a teachercentered culture: learner's professional identity formation is a trigger

Rovers, S. (16-09-2020) Growing knowledge, supporting students' self-regulation in problembased learning

Bourgeois-Law, G. (03-09-2020) Conceptualizations of remediation for practicing physicians

Giuliani, M. (19-05-2020) A Critical Review of Global Curriculum Development, Content and Implementation in Oncology

Schreurs, S. (20-03-2020) Selection for medical school; the quest for validity

Schumacher, D. (19-03-2020) Resident Sensitive Quality Measures: Defining the Future of Patient-Focused Assessment

Sehlbach, C. (21-02-2020) To be continued.... Supporting physicians' lifelong learning

Kikukawa, M. (17-12-2019) The situated nature of validity: Exploring the cultural dependency of evaluating clinical teachers in Japan

Kelly, M. (10-12-2019) Body of knowledge. An interpretive inquiry into touch in medical education

Klein, D. (06-11-2019) The performance of medical record review as an instrument for measuring and improving patient safety

Bollen, J. (01-11-2019) Organ donation after euthanasia: medical, legal and ethical considerations 
Wagner-Menghin, M. (25-09-2019) Self-regulated learning of history-taking: looking for predictive cues

Wilby, K. (02-07-2019) When numbers become words: Assessors' processing of performance data within OSCES

Szulewski, A. (20-06-2019) Through the eyes of the physician: Expertise development in resuscitation medicine

McGill, D. (29-05-2019) Supervisor competence as an assessor of medical trainees; Evaluating the validity and quality of supervisor assessments

Van Rossum, T. (28-02-2019) Walking the tightrope of training and clinical service; The implementation of time variable medical training 
